\title{
F VF
}

FORUM VORMÄRZ FORSCHUNG

\author{
Jahrbuch 2018
}

\section{Menschenrechte}

im Vormärz 
Kuratorium:

Michael Ansel (Wuppertal), Olaf Briese (Berlin), Birgit Bublies-Godau (Dortmund), Norbert Otto Eke (Paderborn), Philipp Erbentraut (Frankfurt a. M.), Jürgen Fohrmann (Bonn), Bernd Füllner (Düsseldorf), Katharina Gather (Paderborn), Katharina Grabbe (Münster), Detlev Kopp (Bielefeld), Hans-Martin Kruckis (Bielefeld), Sandra Markewitz (Vechta), Anne-Rose Meyer (Wuppertal), Maria Porrmann (Köln), Florian Vaßen (Hannover) 


\section{$\mathrm{FVF}$ \\ FORUM VORMÄRZ FORSCHUNG \\ Jahrbuch 2018 \\ 24. Jahrgang \\ Menschenrechte im Vormärz}

herausgegeben

von

Sandra Markewitz und Jean-Christophe Merle 
Das FVF im Internet: www.vormaerz.de

Bibliografische Information der Deutschen Nationalbibliothek

Die Deutsche Nationalbibliothek verzeichnet diese Publikation in der Deutschen Nationalbibliografie; detaillierte bibliografische Daten sind im Internet über http://dnb.d-nb.de abrufbar.

Das FVF ist vom Finanzamt Bielefeld nach $\$ 5$ Abs. 1 mit Steuer-Nr. 305/0071/1500 als gemeinnützig anerkannt. Spenden sind steuerlich absetzbar.

Namentlich gekennzeichnete Beiträge müssen nicht mit der Meinung der Redaktion übereinstimmen.

Redaktion: Detlev Kopp

Publiziert von

Aisthesis Verlag Bielefeld 2021

Postfach 1004 27, D-33504 Bielefeld

Satz: Germano Wallmann, geisterwort.de

Open Access ISBN 978-3-8498-1644-5

Print ISBN 978-3-8498-1376-5

E-Book ISBN 978-3-8498-1377-2

www.aisthesis.de

\section{(2) (1) ( )}

Dieses Werk ist lizenziert unter einer Creative Commons Namensnennung Weitergabe unter gleichen Bedingungen 4.0 International Lizenz. 


\section{Wolfgang Schild (Bielefeld)}

\section{Das Recht des Menschen bei Richard Wagner}

„Erkennt das Recht, das von Gott verliehene Menschenrecht“, denn „wir sind in die Rechte freier Menschenwürde vollständig eingetreten“" „Des Menschen Recht ist, durch immer höhere Vervollkommnung seiner geistigen, sittlichen und körperlichen Fähigkeiten zum Genusse eines stets wachsenden, reineren Glückes zu gelangen. [---] Bestimmung und Recht sind eins, und das Recht des Menschen ist einfach: seine Bestimmung zu erreichen“"2. „Nur die Not, welche zum Äußersten treibt, ist die wahre Not; nur diese Not ist aber die Kraft des wahren Bedürfnisses; nur ein gemeinsames Bedürfnis ist aber das wahre Bedürfnis; nur wer ein wahres Bedürfnis empfindet, hat aber ein Recht auf Befriedigung desselben." ${ }^{\text {"3 }}$

Das erste Zitat stammt aus dem Manuskript eines Vortrages, den Richard Wagner am 14. Juni 1848 abends in der Hauptversammlung des Sächsischen Vaterlandsvereins (Tagesordnungspunkt: „Fortsetzung der Vorträge und Besprechung über das Wesen der const.-monarchischen und der republikanischen Staatsverfassung ") vor 3000 Menschen im Garten des polnischen Brauhauses hielt und den er am 15. Juni 1848 als Extra-Beilage (zu Nr. 191) des Dresdner Anzeigers und Tageblatts veröffentlichte, zwar anonym, aber für jeden in Dresden - wo er seit dem 2. Februar 1843 als königlich-Sächsischer Hofkapellmeister tätig war - erkennbar aus seiner Feder (weshalb seine Autorschaft unbezweifelbar ist); also zu der damals (noch) heiß diskutierten Frage (daher der Titel): „Wie verhalten sich republikanische Bestrebungen

1 Richard Wagner. Wie verhalten sich republikanische Bestrebungen dem Königtum gegenüber? In: ders., Dichtungen und Schriften. Jubiläumsausgabe in zehn Bänden. Hg. Dieter Borchmeyer. Frankfurt a. M. Insel 1983, V, S. 211-221, 215. - Die im Folgenden zitierten Briefe Wagners finden sich (leicht auffindbar und deshalb nicht gesondert ausgewiesen) in der zeitlich geordneten Gesamtausgabe: Richard Wagner. Sämtliche Briefe in 35 Bänden, anfangs herausgegeben von Gertrud Strobel und Werner Wolf, ab dem Bd. 10 in einer Neukonzeption von Werner Breig.

2 Richard Wagner. Der Mensch und die bestehende Gesellschaft. In: ders., Dichtungen (wie Anm. 1), V, S. 229-233, 230f.

3 Richard Wagner. Das Kunstwerk der Zukunft. In: ders., Dichtungen (wie Anm. 1), VI, S. 9-157, 15. 
dem Königthum gegenüber?" ${ }^{4}$ Das zweite Zitat findet sich in einem Beitrag in der Nummer 6 der von August Röckel seit dem 26. August 1848 herausgegebenen „Volksblätter“ vom 10. Februar 1849 mit dem Titel „Der Mensch und die bestehende Gesellschaft", anonym erschienen, aber heute überwiegend Richard Wagner zugeschrieben (worauf noch einzugehen sein wird). Diese beiden Zitate ${ }^{5}$ werden also Arbeiten zugeordnet, die als seine „Revolutionsschriften“ bezeichnet werden. Das dritte Zitat stammt aus der von Wagner 1849 unter seinem Namen veröffentlichten Schrift „Das Kunstwerk der Zukunft“, die herkömmlich zu den „Reformschriften“ (1849 bis 1852) gezählt werden. Im Hauptteil (unter II.) werden diese drei Schriften im Rahmen aller „Revolutions-“ und „Reformschriften“ vorgestellt; dabei wird auch die Frage der Autorenschaft der anonymen Beiträge in den „Volksblättern“ angesprochen. Überdies wird damit das Verhältnis der „Revolutionsschriften“ zu den „Reformschriften“ kurz angesprochen. Unter I. ist mit einer kurzen Darstellung der historischen Situation in Sachsen zu dieser Zeit zu beginnen. Als Ausblick unter III. wird kurz schließlich der weitere Bogen zu dem eigentlichen Thema der „Reformschriften“ gezogen.

\section{Die revolutionäre Zeit in Sachsen}

$\mathrm{Zu}$ erinnern ist, dass es schon in der Revolutionswelle - die im Juli 1830 in Frankreich zur Absetzung von Karl X. und zur Einsetzung des „Bürgerkönigs" Louis Philippe von Orleans geführt, darüber hinaus auch Unruhen

4 Die Einladung zu dieser Hauptversammlung und die erste Seite dieser Extra-Beilage sind abgebildet in: Eckart Kröplin. Richard Wagner. Theatralisches Leben und lebendiges Theater. Leipzig. Deutscher Verlag für Musik 1989, Abbildung 6 und 7. Von daher ist die These, dass Wagner zuerst das Manuskript anonym veröffentlicht und es dann in der späteren Versammlung auf Bitten von August Röckel vorgetragen hat, eindeutig widerlegt. Zu dieser Arbeit von Wagner Vgl. Friedrich Dieckmann. Ein Komponist im Aufstand. Richard Wagner und die deutsche Revolution. In: Zukunftsbilder. Richard Wagners Revolution und ihre Folgen in Kunst und Politik. Hg. Hermann Danuser/Herfried Münkler. Schliengen. Edition Argus 2002, S. 19-46, 28; Eckart Kröplin. Richard Wagner und der Kommunismus. Würzburg. Königshausen \& Neumann 2013, S. $53 \mathrm{ff}$.

5 Selbstverständlich finden sich auch in anderen Schriften Wagners manche Erwähnung eines „Rechtes“, deren Interpretation aber nichts Bemerkenswertes herausbringen kann. 
in Italien, Polen, den Niederlanden und einigen deutschen Staaten (darunter auch Sachsen) provoziert hatte - zu umfassenden gesellschaftlichen und vorsichtigen politischen Reformen im Königreich Sachsen gekommen war. Am 4. September 1831 wurde die erste sächsische Verfassung erlassen, Sachsen somit eine konstitutionelle Monarchie. Es war eine Aufbruchsstimmung entstanden - im Übrigen auch für den 17jährigen Richard Wagner, damals Student in Leipzig -, insbesondere wegen der neuen Allgemeinen Städteordnung und der Landgemeindeordnung unter der bürgerlichen Bevölkerung. Ein neues stadtbürgerliches Selbstbewusstsein kam etwa in den Kommunalgarden (also den städtischen Bürgerwehren) zum Ausdruck. In Sachsen ${ }^{6}$ wurden die überkommenen Feudalverhältnisse größtenteils aufgelöst. Weitere Reformschritte erfolgten durch Beratung und Verabschiedung von Gesetzen in den konstitutionellen Landtagen. Doch gelang es nicht, die unterschiedlichen Interessen der Stände wirklich auszugleichen.

Weitere politische Reformen wurden vor allem im Bildungsbürgertum befürwortet. Ein reger Gedankenaustausch fand in den 1830er und 40er Jahren in einer Öffentlichkeit statt, die durch Bücher, Zeitungen, Zeitschriften, eine Vielzahl von Vereinen und überlokale Festivitäten bald auch über die Einzelstaaten hinauswirkte, zugleich aber von den staatlichen Polizeiund Zensurbehörden unterdrückt wurde. Dabei waren Liberalismus und Nationalbewegung (auch in Sachsen) zwei Seiten derselben (oppositionellen) Medaille. Die Quintessenz im liberalen Weltbild der Gebildeten lautete: ,politischer Fortschritt [ist] dringend notwendig, um die Probleme der Gegenwart zu lösen. Die ständischen Wurzeln der Gesellschaft hatten ihre bindende Kraft verloren, daher [ist] für die dynamischen Kräfte in Stadt und Land ein neuer politischer Rahmen zu schaffen, der nicht mehr auf patriarchalisch-obrigkeitlicher Fürsorge und Bevormundung aufbaute, sondern auf staatsrechtlicher Gleichheit, gesellschaftlicher Selbstverwaltung und politischer Mitbestimmung basierte" (16). Doch gab es keinen einheitlichen Plan, erst recht keinen, der eine Revolution einkalkulierte oder sie gar vorbereitete; die Vorstellungen gingen selbst unter den Anhängern der liberalen Opposition auseinander.

6 Die folgenden Ausführungen stützen sich in vielem mit wörtlichen Zitaten auf: Jörg Ludwig/Andreas Neumann. Revolution in Sachsen 1848/49. Darstellung und Dokumente. Sächsische Landeszentrale für politische Bildung und sächsisches Hauptstaatsarchiv Dresden. Eigenverlag Dresden 1999. Die Seitenzahlen im Text beziehen sich auf diese Schrift. 
Dies zeigte sich in Sachsen bei einer der größten vormärzlichen Unruhen, der Demonstration gegen den Prinzen Johann, den Bruder des Königs Friedrich August, am 12. August 1845 in Leipzig. Johann galt als Exponent papsttreuer katholischer Frömmelei - die Königsfamilie war katholisch (während die Bevölkerung überwiegend protestantisch war) -, was der neuen Bewegung der „Deutschkatholiken“ ein Dorn im Auge war. ${ }^{7}$ In Leipzig jedenfalls kam es damals zu Demonstrationen gegen den Prinzen, weshalb Militär herbeigerufen wurde, das dann wahllos in die Menge schoss, wodurch wegen der zahlreichen Todesopfer ein echter Tumult entstand. Die sächsische Regierung vermied es, die verlangte Untersuchung dieser Vorgänge durchzuführen. 1846 wurde wenigstens eine gemäßigte neue Regierung eingesetzt. Doch entstand, auch durch Missernten und eine Wirtschaftskrise in Sachsen, die die materielle Lage der Bevölkerung sehr verschlechterte, eine große Unzufriedenheit unter der Bevölkerung.

Im März $1848 \mathrm{kam}$ es - initiiert von einem Aufstand im Januar in Palermo und dann der französischen Februarrevolution, die zur Einführung der zweiten Republik führte - in vielen deutschen Einzelstaaten zu den sog. „Märzforderungen“: nach Verfassungseid des Heeres, Presse-, Vereins- und Versammlungsfreiheit, Reform des Wahlrechts, Abbau verbliebener Feudallasten, Volksvertretung beim Deutschen Bund, Geschworenengerichten nach englischem Vorbild. Manche waren erfolgreich. Angesichts des Autoritätsschwundes seiner Regierung und unter dem Eindruck der erfolgreichen Wiener Revolution (13. März 1848) - die im Übrigen Richard Wagner zu seinem unter II. angesprochenen Gedicht „Gruß aus Sachsen an die Wiener“, das mit Namensnennung am 1. Juni in der Allgemeinen Österreichischen Zeitung erschien ${ }^{8}$, inspirierte - entließ Sachsens König sämtliche Minister und berief ein liberales Kabinett ein, das am 16. März 1848 die Arbeit aufnahm. Die Minister verstanden sich als rechtmäßige königlichsächsische Regierung, leiteten Maßnahmen ein und begannen, Reformen durchzusetzen. Doch war dies der zunehmend unzufriedenen Bevölkerung

7 Es darf angemerkt werden, dass in diesen religiösen Spannungen Wagners „Tannhäuser" viel Unruhe erzeugen musste. Vgl. James Garratt. Music, Culture and Social Reform in the Age of Wagner. Cambridge University Press 2010, S. 44ff.; Helmut Kirchmeyer. Situationsgeschichte der Musikkritik und des musikalischen Pressewesens in Deutschland. Das zeitgenössische Wagner-Bild. Bd. I. Regensburg. Gustav Bosse 1972, S. 333ff.

8 Vgl. Richard Kröplin. Richard Wagner-Chronik. Stuttgart. Metzler 2016, S. 140. 
zu wenig, der es vor allem um Besserung ihrer materiellen und sozialen Lage ging („soziale Frage“), welches Anliegen sie mit einem kämpferischen, gegen das Privateigentum der Besitzenden gewaltbereiten Antikapitalismus und der Forderung nach einem „gerechten Auskommen“ verband. Ende März stürmten Handwerker im erzgebirgischen Elterlein und Mittweida zwei Nagelfabriken, die sie zerstörten; am 5. April 1848 kam es in Waldenburg zu einem Aufstand, in dem das Schloss des dortigen Fürsten in Brand gesteckt wurde. Zudem hatten sich nach dem März 1848 und der Einführung der Vereins- und Versammlungsfreiheit politische Vereine (mit eigenen Presseorganen) gebildet, in Sachsen die liberalen „Deutschen Vereine“ (mit dem Schwerpunkt in Leipzig) und die demokratischen „Vaterlandsvereine“, die sich (vor allem von der Popularität des Robert Blum profitierend) zur mitgliederstärksten politischen Organisation in Sachsen entwickelten (denen sich - unter dem Einfluss von August Röckel, auf den noch einzugehen ist auch Richard Wagner anschloss). Im Mai 1848 kam es zur Gründung auch des Arbeitervereins (in Leipzig). Inhaltlich unterschieden sie sich anfangs nicht in den politischen Forderungen (auch nach der Einheit Deutschlands), auch nicht in der Anerkennung der notwendigen Lösung der sozialen Frage, sondern nur in den unterschiedlichen Vorstellungen, wie die betroffenen (armen) Bevölkerungskreise an dem politischen Veränderungsprozess zu beteiligen waren. Diese Differenz zeigte sich im April 1848 bereits bei den Wahlen zur deutschen Nationalversammlung, die eine Verfassung für den zu gründenden deutschen Nationalstaat ausarbeiten sollte. Die liberale sächsische Regierung schloss „Unselbständige“ vom Wahlrecht aus, offensichtlich auch, weil sie in den unteren Bevölkerungsschichten die Anhänger der Demokraten vermuteten. Erstaunt musste sie zur Kenntnis nehmen, dass aus den Wahlen dennoch knapp 70 Prozent demokratische Abgeordnete hervorgingen. Dies musste zu einer intensiven Auseinandersetzung um die demokratische Ausgestaltung des politischen Systems führen, die auch ein Kampf verschiedener Zukunftsvisionen war, der bisweilen den Charakter eines (durchaus wörtlich zu verstehenden) Glaubenskrieges annahm. Hinzu kam eine Distanz in Lebenswelt und Alltag. Liberalismus und Demokratie in Sachsen hatten verschiedene soziale Einzugsbereiche und unterschiedliche politische Stile; vor allem verfügten die demokratischen Führer über rednerisches Talent und die Gabe bzw. Bereitschaft, für ihre Ziele öffentlich zu werben und die „Volksleidenschaft“ zu erwecken.

Die politischen Lager drifteten im Sommer und Frühherbst 1848 immer weiter auseinander, wozu auch die Entwicklung in der Nationalversammlung 
in der Frankfurter Paulskirche das Ihrige beitrug. Zwar schuf die Versammlung mit der provisorischen Zentralgewalt und dem Reichsverweser eine Regierung, doch diese hatte kaum Einfluss auf die Einzelstaaten, in denen sich immer noch die politische Macht konzentrierte. Als der König von Preußen im Krieg gegen Dänemark (wegen Schleswig-Holstein) einen Waffenstillstand ohne Informierung der Nationalversammlung oder des Reichsverwesers schloss, kam es in Frankfurt und einigen anderen Städten zu den "Septemberunruhen“, also Demonstrationen, die teils in Barrikadenkämpfe mündeten. Die Demokraten fürchteten nun eine sich verstärkende Reaktion; Robert Blum zog im Oktober 1848 mit einer Abordnung nach Wien, wo ein neuer Barrikadenkampf ausgebrochen war, um den Kämpfern die Unterstützung der linken Fraktionen der Nationalversammlung zu überbringen. Der Aufstand wurde niedergeschlagen, Blum am 9. November 1848 standrechtlich erschossen. Auch in Preußen etablierte Friedrich Wilhelm IV. seine Macht, ließ wieder Truppen in Berlin einrücken und schränkte per Notverordnung Vereins- und Pressefreiheit ein.

In Sachsen entbrannte im Dezember 1848 wegen der Wahl für einen neuen Landtag der erste moderne Wahlkampf in der sächsischen Geschichte. Die Vaterlandsvereine, die sich bereits in einen republikanischen und einen konstitutionellen (also auch eine konstitutionelle Monarchie anerkennenden) Flügel gespalten hatten, schlossen sich unter dem Motto „Durch Freiheit zur Einheit“ zusammen; die Märzregierung ergriff Partei für die liberalen Deutschen Vereine, die für die Bewahrung der monarchischen Rechte eintraten. Die Wahl brachte einen Erdrutschsieg der Demokraten. So setzte der im Januar 1849 eröffnete Landtag die Regierung durch politische Forderung zunehmend unter Druck, auch wenn im politischen Alltag durchaus Kompromisse gelangen. Doch kam es im Februar 1849 zu einer Vermengung der sächsischen und der nationalen Verfassungsfrage. Die Nationalversammlung hatte als ersten Teil des von ihr in Angriff genommenen Verfassungswerkes die „Grundrechte des deutschen Volkes“ verabschiedet. Nach längerer Diskussion um deren Umsetzung in Sachsen, in deren Verlauf die Minister am 24. Februar 1849 zurücktraten, ließ die neuernannte Regierung diese Grundrechte im königlich-sächsischen „Gesetz- und Verordnungsblatt“ publizieren, wodurch diese Gesetzeskraft erlangten. Doch brach zwei Monate später erneut die Regierungskrise aus, als die Nationalversammlung die Reichsverfassung fertigstellte, die die Schaffung eines Österreich ausschließenden Nationalstaates mit monarchischer Spitze und einem demokratischen Männerwahlrecht vorsah. Der als Monarch vorgesehene preußische König schlug 
diese Wahl brüsk ab und forderte die anderen deutschen Fürsten auf, seinem Beispiel zu folgen. Doch wurde in vielen Staaten die Reichsverfassung rasch anerkannt; so auch in Sachsen, wo der Landtag für die Annahme votierte. Der sächsische König aber weigerte sich; seine Regierung löste am 28. April 1849 den Landtag auf, wobei allerdings drei der fünf Minister die Bitte nach Annahme der Verfassung einbrachten (und dann zurücktraten).

Am 3. Mai 1849 ging die Demonstration der Dresdner Kommunalgarde für die Reichsverfassung in einen Barrikadenkampf über. Die beiden im Amt verbliebenen Minister flüchteten in der Nacht zum 4. Mai mit dem Monarchen auf die Festung Königstein. Als dies bekannt wurde, nutzten einige der in Dresden verbliebenen Mitglieder des aufgelösten Landtages die Situation, um per Akklamation eine „Provisorische Regierung“ einzusetzen, wodurch der Barrikadenkampf in einen republikanischen Aufstand übergegangen war. Bekannt ist, dass sich auch der königliche Hofkapellmeister Richard Wagner in diese Aktionen einband; strittig ist allerdings, worin seine Unterstützungshandlungen im Einzelnen bestanden. ${ }^{9}$ Als die königlichen Minis-

9 Dazu vgl. Hans-Joachim Bauer. Richard Wagner. Sein Leben und Wirken oder Die Gefühlswerdung der Vernunft. Berlin. Propyläen 1995, S. 152-190; Udo Bermbach. Persona non grata. Der Revolutionär Richard Wagner im Spiegel zweier Biographen. In: Getauft auf Musik. Festschrift für Dieter Borchmeyer. Hg. Ders./Hans Rudolf Vaget. Würzburg. Königshausen \& Neumann 2006, S. 325340; Hugo Dinger, Richard Wagners geistige Entwickelung. Versuch einer Darstellung der Weltanschauung Richard Wagners. I. Leipzig. E. W. Fritzsch 1892, S. 152ff.; William Ashton Ellis. 1849. Der Aufstand in Dresden. Ein geschichtlicher Rückblick zur Rechtfertigung Richard Wagner's. Leipzig. Feodor Reinboth 1894; Michael Bakunin, Gottfried Semper, Richard Wagner und der Dresdner Mai-Aufstand 1849. Hg. Forschungsinstitut der Friedrich-Ebert-Stiftung. Bonn 1995; Bernd Kramer. Michael Bakunin, Richard Wagner und andere während der Dresdner Mai-Revolution 1849. Berlin. Kramer 1999; Rüdiger Krohn. Richard Wagner und die Revolution von 1848/49. In: Richard-Wagner-Handbuch. Hg. Ulrich Müller/Peter Wapnewski. Stuttgart. Alfred Kröner 1986, S. 86-99; Jürgen Lotz. Richard Wagner auf den Barrikaden. In: Damals. Das Magazin für Geschichte 10 (1978), S. 415-438, 495-518; Hermann Müller. Richard Wagner in der Mai-Revolution 1849. Dresden. Oscar Laube 1919; Dieter David Scholz. Ein deutsches Mißverständnis. Richard Wagner zwischen Barrikade und Walhalla. Berlin. Parthas 1997, S. 27-41; Kerstin Stüssel. Punkt, Punkt, Komma, Strich ... - Revolution(en) und die Geschichte von „Gegenwartsliteratur“. In: 1848 und das Versprechen der Moderne. Hg. Jürgen Fohrmann/Helmut J. Schneider. Würzburg. Königshausen \& Neumann 2003, S. 33-48, $36 \mathrm{ff}$. 
ter am Abend des 4. Mai vom Königstein zurückkehrten, leisteten sie mit dem in Dresden verbliebenen Militär - wegen des Dänemarkkrieges nur 1800 Mann - hartnäckige Gegenwehr. Der König hatte schon vor seiner Flucht seinen preußischen Vetter um Truppenhilfe gebeten. Die provisorische Regierung sandte ihrerseits durchaus erfolgreiche Aufrufe ins Land und rief Städte und Gemeinden zu bewaffneter Unterstützung auf. Je mehr der Kampf in Dresden eskalierte, wo auf Seiten der Aufständischen vor allem proletarisierte Handwerksgesellen und Arbeiter, darunter viele Jugendliche, kämpften, desto erschrockener distanzierten sich bürgerliche Liberale oder gemäßigte Demokraten von den Vorgängen. Zudem war bald klar, dass der Kampf verloren gehen musste. Schon am 5. Mai waren preußische Truppen in Sachsen eingetroffen, am 6. Mai griffen sie in die Dresdner Kämpfe ein, am 9. Mai war der Aufstand blutig niedergeschlagen. Dem später steckbrieflich gesuchten Richard Wagner gelang die Flucht, die ihn nach Weimar, weiter nach Zürich, von dort nach Paris und schließlich wieder nach Zürich führte, wo er im Exil als freischaffender Komponist und Dirigent für lange Zeit lebte (und in seinen sog. „Zürcher Reformschriften“ seine Revolutionsbegeisterung in der Konzeption des Kunstwerks der Zukunft bzw. einer Gesellschaft als eines solchen Kunstwerks weiterentwickelte (worauf noch unter III. einzugehen ist)). Für Dresden wurde der Belagerungszustand erklärt, der jedoch nicht durchgesetzt wurde. Opfer waren auf der Seite der Aufständischen 197 Tote und 114 Verletzte, auf der Seite der sächsischen und preußischen Truppen 31 Tote und 94 Verwundete.

Die Revolution war gescheitert, endgültig mit der Kapitulation der Festung Rastatt am 23. Juli 1849. Das Verfassungswerk der Paulskirche trat nicht in Kraft, die nationsweite Geltung der Grundrechte wurde aufgehoben. Auch die in den Einzelstaaten bereits durchgeführten Verfassungsänderungen wurden wieder rückgängig gemacht. Im Königreich Sachsen setzte die Reaktion heftig ein. Im Juli 1850 hob ein Staatsstreich das Wahlrecht von 1848 auf und berief die vormärzlichen Stände wieder ein. Ein rigides Presse- und Vereinsrecht sorgte für öffentliche Ruhe. Doch unterschwellig prägte die Erfahrung der vorangegangenen Revolution das Handeln der Reaktionsregierungen. Wie fast überall in Deutschland setzte auch die sächsische Regierung der 1850er Jahre Forderungen um, die vor und während der Revolution artikuliert worden waren: in einem Reformprozess der kleinen Schritte. 


\section{Die theoretischen Schriften Wagners}

In der von Dieter Borchmeyer 1983 herausgegebenen Jubiläumsausgabe sind fünf „Revolutionstraktate“ abgedruckt: der Text der Rede vom 14. Juni 1848 („Wie verhalten sich republikanische Bestrebungen dem Königtum gegenüber?"), der unbestritten von Wagner stammt, dann drei Beiträge in den Dresdner „Volksblättern“ 1848 und 1849 („Deutschland und seine Fürsten“, „Der Mensch und die bestehende Gesellschaft“, „Die Revolution“), die anonym erschienen sind (weshalb die Zuschreibung vor allem des als zweiten Beitrag genannten Artikels zu Wagner nicht unbestritten ist) und schließlich das 1849 unter Namensnennung veröffentlichte Buch „Die Kunst und die Revolution“ (das meistens bereits zu den sog. "Zürcher Reformschriften“ gestellt wird, wie auch die Arbeit „Das Kunstwerk der Zukunft“, aus dem das dritte Eingangszitat stammt). In jüngerer Zeit wird vereinzelt ein weiterer anonym erschienener Beitrag in den „Volksblättern“ (mit dem Titel „Was ist Communismus?“) Wagner zugeschrieben. Wagner selbst hat diese Arbeiten in den „Volksblättern“ in der von ihm verantworteten Gesamtausgabe - „Gesammelte Schriften und Dichtungen“ (1871) - nicht aufgenommen. Da das dritte Eingangszitat aus den „Reformschriften“ stammt, werden kurz auch diese vorgestellt.

Strittig ist, ob auch manche Kunstwerke Wagners in einem Zusammenhang mit revolutionären Bestrebungen stehen. Darauf ist zunächst unter 1. kurz einzugehen; als 3. werden die Schriften im Einzelnen vorgestellt. Unter 2. sind einige theoretische Einflüsse auf Wagner aufzuzeigen.

\subsection{Revolutionäres in den Kunstwerken dieser Zeit}

Hierbei kommen vor allem drei frühe Opernprojekte in Betracht: „Das Liebesverbot“, „Die hohe Braut" und „Rienzi“. ${ }^{10}$

10 Nicht eingegangen wird auf folgende Projekte Wagners: „Männerlist größer als Frauenlist oder Die glückliche Bärenfamilie“ (1837, abgedruckt in: Wagner. Dichtungen [wie Anm. 1], I, S. 103ff.); „Die Sarazenin“ (1843, abgedruckt: ebenda, S. 197ff.); „Die Bergwerke zu Falun“ (1841/42, abgedruckt: ebenda, S. 229ff.); „Wieland der Schmied als Drama entworfen“ (1849/50, abgedruckt in: Wagner. Dichtungen [wie Anm. 1], VI, S. 158ff.). 


\subsection{1. „Das Liebesverbot oder Die Novize von Palermo“}

Zunächst ist die große komische Oper in drei Akten mit dem Titel „Das Liebesverbot oder Die Novize von Palermo“ zu nennen, die als Text im August $1834^{11}$, als Partitur im Frühjahr 1836 fertiggestellt und am 29. März 1836 in Magdeburg uraufgeführt wurde. Mit diesem Werk kehrte Wagner sich von der deutsch-romantischen Oper - die er noch in seiner Oper „Die Feen" (fertiggestellt Januar 1834) verherrlicht hatte - als Flucht vor der Realität in eine mystische Scheinwelt ab und wandte sich unter dem Einfluss des „Jungen Deutschland“, wie es vor allem in den Schriften von Heinrich Laube (1806-1884) zum Ausdruck kam, der historisch-gesellschaftlichen Realität zu. Wagner übernahm die „Polemik gegen Obskurantismus, reaktionäre kirchliche Orthodoxie, verstockt sinnenfeindliche Moral und rückständig-partikularistische Politik, die Begeisterung für die Rebellionen der letzten Jahre [den griechischen Freiheitskampf, die Pariser Juli-Revolution und den polnischen Aufstand] [...], den Lobpreis des von allen konventionellen Schranken befreiten sinnlich-schönen Lebens, die Utopie einer die Grenzen überschreitenden Universalpolitik“; und auch das in Wilhelm Heinses Roman „Ardinghello und die glücklichen Inseln“ (1787) gepriesene „Ideal sinnlichen Lebensgenusses und freier Liebe [...] in einem Staat ohne Eigentum"12. Wagner behandelte in diesem, sehr frei nach Shakespeares „Maß für Maß“ gedichteten Stück zwar eine Revolte, die darin gipfelt, dass

11 Abgedruckt in: Wagner. Dichtungen (wie Anm. 1), I, S. 53ff. - Vgl. dazu Sebastian Werr. „Das Liebesverbot oder Die Novize von Palermo (WWW 38)“. In: Wagner-Lexikon. Hg. Daniel Brandenburg. Laaber 2012, S. 398-402); Inge Mai Groote, „Das Liebesverbot odere Die Novize von Palermo“. In: Wagner Handbuch. Hg. Laurenz Lütteken. Kassel. Bärenreiter 2012, S. 291-196.

12 So Dieter Borchmeyer. Revolution der Lust. Richard Wagners Liebesverbot. In: ders. Die Götter tanzen Cancan. Richard Wagners Liebesrevoluten. Heidelberg. Manutius 1992, S. 28ff.; ders. Richard Wagner. Ahasvers Wandlungen. Frankfurt a. M. Insel 2002, S. 46ff.; Werner Wolf, Richard Wagners geistige und künstlerische Entwicklung bis zum Jahre 1848. Dissertation Leipzig 1965, S. $41 \mathrm{ff}$ - Zum „Jungen Deutschland“ vgl. Udo Bermbach. Der Wahn des Gesamtkunstwerks. Richard Wagners politisch-ästhetische Utopie. Stuttgart. Metzler ${ }^{2} 2004$, S. 8ff.; Udo Köster. Literarischer Radikalismus. Zeitbewußtsein und Geschichtsphilosophie in der Entwicklung vom jungen Deutschland zur Hegelschen Linken. Frankfurt a. M. Athenäum 1972; Helmut Koopmann. Das Junge Deutschland. Analyse seines Selbstverständnisses. Darmstadt. Wbg 
das Volk verkündet: „Das Gesetz ist aufgehoben“; aber dieses Gesetz ist nur das Verbot freier Liebe (und eines orgiastisch zelebrierten Karnevals), der Aufruhr nur eine Liebesrevolte und sein Ende die Errichtung einer „Karnevalsrepublik“. „Allgemeine Heiratslust ersetzt den Willen zur politischen Veränderung“; „die Liebesrevolution [begibt] sich in die Bahn einer saturnalistisch aufgelockerten Monarchie zurück“"13.

Von einer „Revolutionsoper" kann man wohl nur schwerlich sprechen ${ }^{14}$, sondern das Werk ist eher ein frivoles Stück im Geiste des sinnenfreudigen "Jungen Deutschland“ (auch wenn diese Bewegung 1835 von der Bundesversammlung als staatsgefährdend eingestuft wurde ${ }^{15}$ ).

\subsection{2. „Die hohe Braut oder Bianca und Guiseppe“}

Das zweite für einen revolutionären Hintergrund herangezogene Werk ist ein Libretto für eine Oper mit dem Titel „Die hohe Braut oder Bianca und Guiseppe“16, zunächst 1836 nach dem im „Jungen Deutschland“ hoch geschätzten gleichnamigen Roman von Heinrich Koenig (1833) entworfen, in der Absicht, es in französischer Übersetzung dem berühmtem Textdichter der französischen Grand Opéra, Eugène Scribe (1791-1861), zuzusenden, in

Academic 1993;Eckart Kröplin. Musik aus Licht. II. Würzburg. Königshausen \& Neumann 2011, S. 497ff.; Wolf, Entwicklung (wie oben), S. 29ff.

13 So Borchmeyer. Götter (wie Anm. 12), S. 40; ders. Ahasvers Wandlungen (wie Anm. 12), S. 55.

14 So aber Udo Bermbach. „Blühendes Leid“. Politik und Gesellschaft in Richard Wagners Musikdramen. Stuttgart. Metzler 2003, S. 36ff. (der von „frühen Motiven politisch-ästhetischer Kritik“ [auch in den „Feen“ und in der „Hohen Braut"] spricht). Vgl. auch Bermbach. Wahn (wie Anm. 12), S. 12 f.

15 So Borchmeyer. Ahasvers Wandlungen (wie Anm. 12), S. 56.

16 Vgl. dazu Frank Piontek. „Die hohe Braut (WWW 40)“. In: Wagner-Lexikon (wie Anm. 11), S. 314-318. Hinzuweisen ist auch auf: Dieter Borchmeyer. Die Franzosen vor Nizza oder Revolution aus Liebe. In: ders. Götter (wie Anm. 12), S. 45-90; ders. Ahasvers Wandlungen (wie Anm. 12), S. 56ff.; Isolde Vetter. Wagnerforschung - literarisch. Richard Wagner als Librettist von Johann Friedrich Kittls Oper Bianca und Guiseppe, oder die Franzosen vor Nizza (1848). In: Wagnerliteratur - Wagnerforschung. Bericht über das Wagner-Symposium München 1983. Hg. Carl Dahlhaus/Egon Voss. Mainz. Schott 1983, S. 163ff.; Wolf. Entwicklung (wie Anm. 12), S. $46 f f$. 
der Hoffnung, dass dieser bzw. das von ihm geleitete „Team“ den Entwurf zu einem Libretto für Wagner ausarbeiten und ihm dafür dann auch den Kompositionsauftrag vermitteln werde; da er damit die Auftragsgepflogenheiten der Opéra völlig verkannte, blieb dies ohne Erfolg. Am 4. Februar 1837 verständigte Wagner Giacomo Meyerbeer, der aber ebenfalls den hochfliegenden Plan des Provinzmusikers - Wagner lebte damals als Musikdirektor in Magdeburg - ignorierte. Im November 1838 erhoffte Wagner sich die Unterstützung August Lewalds, des Herausgebers der Zeitschrift „Europa“, doch auch dieser Versuch schlug fehl. 1840 - Wagner war nach Paris gezogen - versuchte er wiederum vergeblich, das Projekt in Paris zu realisieren; aus diesem Grunde schrieb er selbst einen französischen Prosaentwurf. Doch sah er offensichtlich ein, dass das Projekt nicht zu verwirklichen sei, weshalb er sich dem „Rienzi“ zuwandte. Doch kam er nach dessen Fertigstellung wieder auf sein altes Projekt zurück: er schrieb ein deutsches Libretto, das er im Juli 1842 dem Dresdner Dirigenten der Uraufführung des „Rienzi“, Carl Gottlieb Reißiger (1789-1859), schenkte. Nach dessen Ablehnung bot er den Text dem ihm befreundeten Komponisten Ferdinand Hiller (1811-1885), schließlich gegen 200 Gulden seinem Jugendfreund Johann Friedrich Kittl (1806-1868) an, der den Stoff - allerdings in einer „entschärften“ Umarbeitung - dann auch vertonte und die Oper in Prag unter dem Titel „Bianca und Giuseppe oder Die Franzosen vor Nizza“ zur erfolgreichen Uraufführung brachte (wobei Wagner gebeten hatte, seinen Namen nicht zu veröffentlichten). Interessant ist, dass Wagner Hiller wie auch Kittl vorgeschlagen hatte, die Geschichte in die Zeit des deutschen Bauernkrieges zu verlegen. Erhalten haben sich die Erstschrift und die Reinschrift des Prosaentwurfs Wagners aus dem Jahr $1838^{17}$, der Prosaentwurf in französischer Übersetzung (1840) und das Textbuch des von Kittl vertonten Textes (1842).

Geschildert wird ein Geschehen in dem Jahr 1793 unmittelbar vor der drohenden Einnahme von Nizza (damals noch Königreich Piemont) durch die französische Revolutionsarmee. Guiseppe, der Sohn des Schulzen auf dem Gut des Marchese Malvi, der als Repräsentant der Herrschaft gezeichnet wird, liebt dessen Tochter Bianka, die beide von derselben Amme genährt worden waren. Doch will ihr Vater sie standesgemäß mit einem Grafen verheiraten; zudem verdächtigt er Guiseppe der Komplizenschaft mit den „Neuerern“, die im Gebirge gemeinsame Sache mit den Franzosen

17 Abgedruckt in: Wagner. Zeitschrift der englischen Wagner-Society 1989, Vol. 10, Number 2, S. $50 \mathrm{ff}$. 
machen würden. Trotz dieses gestörten Verhältnisses warnt Guiseppe Malvi vor einem Anschlag; zum Dank - so verspricht es der Marchese - dürfe er beim bevorstehenden Fest den Ehrentanz mi Bianka durchführen. Da er aber dieses Recht provozierend einklagt, nimmt Malvi sein Wort zurück. Wutentbrannt schließt Guiseppe sich den Neuerern an: da diese die Gleichheit einführen wollen, glaubt er an die dadurch eröffnete Möglichkeit einer Verbindung mit der Geliebten. Die Verschwörer feiern den Aufgang der Sonne, die sie mit einem Gebet begrüßen; von Ferne ist die französische Feldmusik mit den Freiheitsliedern zu hören. Doch der Angriff der Neuerer scheitert; die Verschwörer werden besiegt und gefangen genommen. Bianka erklärt sich zur Hochzeit mit dem Grafen bereit, wenn Guiseppe freigelassen wird, was schließlich nach einigen Umwegen auch gelingt. Als der Brautzug aus der Kirche kommt, stürzt Guiseppe sich auf den Grafen und ersticht ihn. Bianka liegt leblos in Guiseppes Armen. „In demselben Moment hört man von der Zitadelle einen Kanonschuß es verbreitet sich schnell der Ruf: „Die Franzosen! Die Franzosen!" - Die französische Armee zieht unter dem Gesang der Marsellaise und mit geschwenkten Fahnen ein, in der Ferne sieht man auf [dem Schloß des Marchese] die dreifarbige Fahne wehen“"

Ein großartiges Finale mit einer eindeutig positiven Darstellung des Sieges der Revolution(sarmee) über die Adelsherrschaft in Nizza! Interessant ist, dass bereits Wagner selbst in der Erstschrift vorsah, dass Bianka überlebt und Guiseppe sie als die Seine preist, dass also - wie im "Liebesverbot“ eine erfolgreiche Liebesrevolte gezeigt wird. In der Reinschrift änderte Wagner den Schluss: Bianka stirbt, weil sie geschworen und dann den Schwur verwirklicht hat, sich unmittelbar nach der Hochzeit zu vergiften. Auch Guiseppe bricht tot zusammen. D.h. der revolutionäre Schluss wurde mit dem Tod der beiden Protagonisten verbunden. Wagner verschränkte nun das Schicksal einer privaten Liebesbeziehung mit der politischen Situation und machte jene von dieser abhängig. Dabei vermengte Wagner die Französische Revolution von 1789, die er wegen der schrecklichen Ereignisse in der späteren Entwicklung abgelehnt hatte, mit der ihn stark berührenden Juli-Revolution von 1830, der er positiv gegenüberstand. Jedenfalls ist anzunehmen, dass Wagner hier an die Tradition der Revolutionsopern ${ }^{18}$, vor allem an das

18 Dazu vgl. Stephan Aufenangel. Die Oper während der Französischen Revolution. Tutzing. Hans Schneider 2006; Bermbach. Leid (wie Anm. 14), S. 43; ders. Wahn (wie Anm. 12), S. 14ff.; Maria Birbili. Die Politisierung der Oper im 19. Jahrhundert. Frankfurt a. M. Peter Lang 2014, S. 7ff.; Stefan Bodo Würffel. 
maßgebende Vorbild der französischen Grande Opéra anschließen wollte, die 1828 mit der von Eugene Scribe geschriebenen und von Daniel-FrancoisEsprit Auber vertonten „La Muette de Portici“ („Die Stumme von Portici“) ihren Siegeszug begann ${ }^{19}$ (welche Oper im Übrigen trotz des keineswegs revolutionsfreundlichen Endes $^{20}$ bei der Brüsseler Erstaufführung 1830 durch die mitreißenden, von der leidenschaftlichen Musik untermalten Massenszenen den belgischen Volksaufstand auslöste ${ }^{21}$ ). Doch war der Zeitgeist seit der Etablierung der Juli-Monarchie in Frankreich einem Revolutionspessimismus gewichen, weshalb Wagners Entwurf bei Scribe, aber auch sonst in Paris keine Chance (mehr) hatte. Dies sah Wagner offenbar selbst nach seiner Ankunft in Paris ein, da er in dem französischen Entwurf die politischen Aspekte (wie eine aufrührerische Rede einer Person und auch den Schluss) strich; Guiseppe handelt nun nur aus privat-emotionalen Gründen (also als „Revolutionär aus Eifersucht“). Von daher ist verständlich, warum Wagner die „entschärfte“ Fassung in der Oper Kittls letztlich akzeptierte (was auch sein Vorschlag, die Handlung im Bauernkrieg spielen zu lassen, zeigt)(auch wenn er seinen Namen damit nicht verbunden sehen wollte). Insgesamt wird deutlich, wie schwierig es ist, die politische Einstellung Wagners in dieser frühen (Magdeburger und Pariser) Zeit herauszubringen, die immer auch im Zusammenhang mit der Planung seiner künstlerischen Karriere zu sehen ist.

Französische Revolution im Spiegel der Oper. In: Der schöne Abglanz. Stationen der Operngeschichte. Hg. Udo Bermbach/Wulf Konold. Berlin/Hamburg. Reimer 1992, S. 83ff.

19 Vgl. dazu Birbili. Politisierung (wie Anm. 18) (die auch die Oper „La Siège de Corinthe“ [„Die Belagerung von Korinth“,1826] von Gioachino Rossini nennt und als weitere prominente Vertreter "Guillaume Tell“ [ebenfalls von Rossini, 1829] und „La Prophéte“ [Eugene Scribe, Giacomo Meyerbeer, 1849] bespricht). Dazu vgl. auch Anselm Gerhard. Die Verstädterung der Oper. Paris und das Musiktheater des 19. Jahrhunderts. Stuttgart/Weimar. Metzler 1992. Zur Oper von Scribe/Auber vgl. Dietmar Rieger. La Muette de Portici von Auber/Scribe. Eine Revolutionsoper mit antirevolutionärem Libretto. In: Romanistische Zeitschr .f. Literaturgesch. 10 (1986), S. 349-359.

20 In der Schlussszene stürzt das Gewölbe mit den dort versammelten Korinthern und Osmanen ein, wodurch der Blick auf das brennende Korinth im Hintergrund ermöglicht wird: im Sinne einer „Katastrophenoper“.

21 Dazu vgl. Borchmeyer. Ahasvers Wandlungen (wie Anm. 12), S. 58ff.; Gerhart von Graevenitz. Mythos. Zur Geschichte einer Denkgewohnheit. Stuttgart. Metzler 1987, S. 261ff. (wobei als zweites Vorbild die Oper "Guillaume Tell“ von Rossini genannt wird). 
Interessant ist der Brief an Kittl vom 4. Januar 1848, der sich auf den von diesem stark veränderten, nämlich völlig entpolitisierten Schluss bezieht:

Weißt Du, was der Schluß einer Oper ist? Alles! ... Ich hatte auf das heftig Ergreifende, Sturmschnelle des Schlusses sehr gerechnet: die schreckliche Katastrophe beim Gange aus der Kirche darf mir nicht mehr versüßt werden, - das einzige furchtbar Erhebende ist das Daherschreiten eines großen Weltgeschickes, hier personifizirt in der französischen Revolutions-Armee, welches in fürchterlicher Glorie über die zertrümmerten alten Verhältnisse (der Familien) dahinzieht. Diese Beziehung darf meiner Ansicht in nichts geschwächt werden [...]; wird er so festgehalten, wie ich ihn mir dachte, so liegt die große Versöhnung im Erscheinen der Franzosen darin, daß wir hier mit offenen Augen ersichtlich eine neue Weltordnung eintreten sehen, deren Geburtswehen jene Schmerzen waren, die bis dahin die Bewegung des Dramas bildeten.

Diese Briefstelle passt zu dem Teilnehmer am Revolutionsgeschehen der Jahre 1848/49, gehört also eindeutig zu unserem Thema. Hinzuweisen ist auf die hier verwendeten Worte für die Revolution: es gehe um ein in der Revolutionsarmee personifiziertes „Weltgeschick“, um die „Geburt[swehen]“ einer „neuen Weltordnung“, so als würde die Französische Revolution ein Naturereignis (gewesen) sein. Auch ist bemerkenswert, dass die Bande der Natur zwischen Guiseppe und Bianka, begründet durch die Milchbrüderschaft, für stärker gehalten werden als die durch die Gesetze gestiftete Ständeordnung; in den Worten von Guiseppe: „Trennt uns die Natur? Tranken wir nicht in der Muttermilch an ein und derselben Brust Brüderschaft für diese Welt? Sollen uns die Mißstände eurer erbärmlichen Einrichtungen trennen, die der Natur frech zuwider laufen? - Ich will sie zertrümmern, und euch mir gleichmachen" ${ }^{\text {22 }}$.

\subsection{3. „Rienzi, der letzte der Tribunen“}

Schließlich verstehen manche auch die große tragische Oper in fünf Akten mit dem Titel „Rienzi der letzte der Tribunen“ als von revolutionärer Stimmung getragenes Werk, das als Prosaentwurf, dann als Textbuch nach dem

22 Vgl. Borchmeyer. Ahasvers Wandlungen (wie Anm. 12), S. 66 (mit den Veränderungen bei Kittl). 
Roman von Edward Bulwer-Lytton (London 1835) (vielleicht auch beeinflusst durch die 1828 in London aufgeführte Tragödie „Rienzi“ von Mary Russell Mitford) im August 1838 in Riga (wo er Musikdirektor war) niedergeschrieben wurde. ${ }^{23}$ Bis Frühjahr 1839 hatte Wagner die Partitur des ersten Aktes geschrieben, musste dann aber aus Riga die Flucht nach Paris antreten, wo er das Libretto mit Hilfe eines Sprachlehrers in das Französische übersetzte: offensichtlich wollte er versuchen, mit diesem Projekt einer Grande opéra erfolgreich zu sein. Von September 1839 bis Februar 1840 vollendete er die Komposition. Doch dürfte er bereits im Frühjahr 1840 seinen Versuch, diese Oper in Paris aufzuführen, aufgegeben haben, da er sich dem „Fliegenden Holländer“ zuwandte. Durch Vermittlung von Meyerbeer und den berühmten Dresdner SängerInnen Wilhelmine Schröder-Devrient und Joseph Tichatschek nahm das Dresdner Hoftheater die Oper an; sie wurde am 20. Oktober 1842 in Dresden uraufgeführt, trotz ihrer Länge von über sechs Stunden mit riesigem Erfolg, der schließlich Wagner den Posten des Hofkapellmeisters (Ernennung 2. Februar 1843) einbrachte.

Das Stück zeigt in einer Verdichtung auf fünf Tage das Schicksal des historischen römischen Staatsmannes und Volkstribuns Cola di Rienzo (13131354). Deutlich ist die Kritik an den adeligen Familien (den Nobili), hier der Orsini und der Colonna, die als Rauf- und Raubadel geschildert werden, unter deren Plünderungen und Fehden die Bevölkerung in dem vom Papst verlassenen Rom leidet. Es herrscht Chaos und Anarchie in der Stadt; der Papst ist nach Avignon geflohen. Die Colonna haben den kleinen Bruder des Bürgers Rienzi getötet, ohne dafür die gerechte Strafe zu erhalten. Nun versuchen die Orsini die Schwester des Rienzi - Irene - zu vergewaltigen, was durch das mutige Eingreifen des Adriano Colonna noch gerade verhindert wird. Ein Kampf zwischen den beiden Adelsfamilien beginnt, das Volk strömt herbei; Vermittlungsversuche des als Papstvertreter residierenden Kardinals werden spöttisch zurückgewiesen. Durch das Auftreten des angesehenen Rienzi tritt allmähliche Ruhe ein. Als ihm der durch seine vorherige Behandlung, aber auch wegen der anarchischen Zustände besorgte Kardinal die Hilfe der Kirche zusagt, verspricht Rienzi dem Volk, die Adelsherrschaft zu beseitigen. Die Nobili verlassen die Stadt; der Aufstand beginnt. Adriano

23 Abgedruckt in: Wagner. Dichtungen (wie Anm 1), I, S. 145ff. - Dazu vgl. Robert Braunmüller. „Rienzi, der letzte der Tribunen (WWW 49)“. In: WagnerLexikon (wie Anm. 11), S. 581-588; Gundula Kreuzer. „Rienzi, der letzte der Tribunen“. In: Wagner Handbuch (wie Anm. 11), S. 297-305. 
- der erkennt, dass durch die anstehenden Kämpfe die (von ihr erwiderte) Liebe zu Irene gefährdet ist - erklärt sich trotzdem zum Verbündeten Rienzis, der auf die Erfüllung seines Racheschwurs wegen der Ermordung des Bruders verzichtet. Der Aufstand gelingt; Rienzi verkündet die neue Verfassung $^{24}$, die er als Wiedergeburt des antiken Roms betrachtet: „Die Freiheit Roms sei das Gesetz, / ihm untertan sei jeder Römer; / bestraft sei streng Gewalt und Raub, / und jeder Räuber Romas Feind!“ Das Volk will Rienzi zum König ausrufen, was dieser abwehrt: „Nicht also! Frei wollt' ich euch haben! / Der ganzen Welt gehöre Rom, / Gesetze gebe ein Senat. / Doch wählet ihr zum Schützer mich / der Rechte, die dem Volk erkannt, / so blickt auf eure Ahnen hin, / und nennt mich euren Volkstribun!" Doch die Adeligen planen den Umsturz, um die alte Ordnung wiederherzustellen; beim kommenden Friedensfest soll Rienzi ermordet werden. Zu diesem Fest strömen Abgeordnete aus ganz Italien, auch aus Deutschland, Böhmen und Ungarn, was Rienzi zu dem Ausruf bringt: „Ja, Gott, der Wunder schuf durch mich, / verlangt, nicht jetzt schon stillzustehn. / So wißt, - nicht Rom allein sei frei: / nein! Ganz Italien sei frei! / Heil dem ital'schen Bunde!“ „Und weiter noch treibt Gott mich an: / Im Namen dieses Volks von Rom / und kraft der mir verliehnen Macht / lad' ich die Fürsten Deutschlands vor, / bevor ein Kaiser sei gewählt, / sein Recht den Römern darzutun, / mit dem er König Roms sich nennt“. Das Attentat misslingt. Das Volk will den Tod der Nobili; Rienzi verkündet das Urteil: Tod durch das Beil. Doch sieht er dann auf die Bitte von Adriano und Irene von der Bestrafung ab, gewährt also Gnade statt Recht und verkündetem Gesetz, was das Volk empört (obwohl es schließlich seine Entscheidung noch hinnimmt). Trotz ihres geleisteten Treueschwurs rüsten sich die Adelsfamilien zum Kampf, den Rienzi dann auch annimmt: „Der Gott, der Roma neu erschaffen, / führt euch durch seinen Streiter an! / Lasst eure neuen Fahnen wallen, / und kämpfet froh für ihre Ehre“. In der Schlacht um Rom gewinnen die Volkskämpfer, Orsini und Colonna finden den Tod. Adriano fällt daraufhin von Rienzi ab und schwört ihm Rache für den Tod des Vaters. Er unternimmt eine Intrige gegen Rienzi: er sei ein Verräter, habe wegen der gewünschten Heirat von Irene und Adriano die Adelsfamilien begnadigt. Das Volk gibt der Begnadigung der Adeligen die Schuld an dem Tod der gefallenen Römer. Rienzi versucht,

24 Wolf spricht von Rienzis „Idee des ,buono stato“" und meint damit die Herrschaft des Volkes, also die Demokratie; vgl. Wolf, Entwicklung (wie Anm. 12), S. $48 \mathrm{ff}$. 
die Aufgebrachten zu besänftigen; „Traut fest auf mich, den Tribunen, / haltet getreu an meiner Seite! / Gott, der bisher mich führte, / Gott steht mir bei, / verläßt mich nie“. Doch haben die deutschen Gesandten - durch die Ansprache Rienzis am Fest verärgert - Rom verlassen; der neu gewählte Kaiser hat sich mit dem Papst in Avignon verbündet, dieser hat Rienzi mit dem Bannfluch belegt, weshalb nun auch die Kirche in Person des Kardinals sich von ihm distanziert. Rienzi betet zu Gott: „Allmächt'ger Vater, blick herab, / hör mich im Staube zu dir flehn! / Die Macht, die mir dein Wunder gab, / laß jetzt noch nicht zugrunde gehn!“ Doch es ist zu spät. Das Volk wendet sich - aufgeheizt durch den Bannfluch der Kirche - gegen Rienzi: „Er ist verflucht, er ist gebannt! / Verderben treffe ihn und Tod! / Auf, ehrt der Kirche Hochgebot!“ Die Römer wollen ihn steinigen; schließlich setzen sie das Kapitol, in dem sich Rienzi und Irene - die beide auf ihre Liebe (er zu Rom, sie zu Adriano) verzichtet haben - aufhalten, in Brand. Rienzi wendet sich zum letzten Mal an das Volk: „Furchtbarer Hohn! Wie, ist dies Rom? / Elende! unwert eures Namen, / der letzte Römer fluchet euch! / Verflucht, vertilgt sei diese Stadt! / Vermodre und verdorre, Rom! / So will es dein entartet Volk!" 25 . Bei diesem Brand finden Rienzi und Irene den Tod; wie auch Adriano, der - offensichtlich wahnsinnig geworden - durch die Flammen zu Irene eilen will: krachend stürzt der Turm zusammen und begräbt sie unter seinen Trümmern. Und - so beschließt Wagner seine Oper: - „Die [zurück-

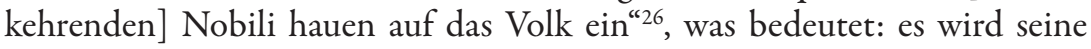
Freiheit wieder verlieren!

Es ist offensichtlich, dass Wagner in Paris - wo er diese Oper nach dem Vorbild der grande opèra schuf - von dem Revolutionspessimismus, wie er sich z. B. auch in der Oper „Les Huguenots“ von Scribe und Meyerbeer (1836) niederschlug ${ }^{27}$, erfasst war. Das Volk, das zunächst unter dem charismatischen Führer kämpfend seine Freiheit von der Adelstyrannei gewonnen

25 Für die Aufführung in Berlin 1847 strich Wagner diesen Fluch zugunsten einer Prophezeiung, indem er Rienzi singen ließ: „So lang die sieben Hügel Romas stehn, solang die ew'ge Stadt nicht soll vergehn. Sollt ihr Rienzi wiederkehren sehn!"

26 So das Libretto; bei der Vertonung änderte Wagner den Schluss, indem er von den Nobili spricht, ,welche teils zu Pferde, teils zu Fuß einen heftigen Angriff auf das Volk ausführen"; so Wolf, Entwicklung (wie Anm. 12), S. 50.

27 Vgl. v.Graevenitz. Mythos (wie Anm. 21), S. 263ff. - Anders Wolf, Entwicklung (wie Anm. 12), S. 51, der in Rienzi das „Bild des bürgerlichen Freiheitskampfes“ sieht. 
hat, erweist sich als dieser Freiheit nicht würdig; es lässt sich sehr leicht manipulieren, folgt auch der willkürlichen Verfluchung durch die Kirche, geht am Ende daher zu Recht zugrunde in einer neuen, eigentlich restituierten alten Herrschaft der Nobili. Wie in anderen „Schreckensopern“ (wie etwa in Rossinis „La Siège de Corinthe“ [„Die Belagerung von Korinth“, 1826] ${ }^{28}$ ) steht am Schluss ein Gebäude in Flammen, die einstürzenden Teile töten die Protagonisten. Revolutionär (und zugleich noch vom „Jungen Deutschland" beeinflusst) sind der deutliche Anti-Aristokratismus und die Kirchenfeindschaft, wobei Rienzi sich selbst von dem christlichen Gott zum Führer auserkoren und unterstützt sieht (was zeigt, dass zwischen Christentum und Kirche streng unterschieden wird). Doch insgesamt steht in Wagners „großer Oper" das bedeutende Individuum im Vorder- und Mittelpunkt, der charismatische Führer, überzeugt von seiner Gottgesandtheit, überheblich im Zeitpunkt seines politischen Triumphes; aber auch ein Revolutionär, der aus persönlichen Gründen Gnade vor Recht und dem selbst gegebenen Gesetz walten lässt, dadurch sich selbst verrät und dadurch scheitert. Ob Wagner in seiner Oper wirklich revolutionär gedacht hat ${ }^{29}$ Oder hat Dieter Borchmeyer Recht, wenn er in diesem Rienzi „ohne Zweifel eine ideale Selbstprojektion Wagners, des absoluten Künstlers in einsamer Auseinandersetzung mit der kunstfeindlichen Gegenwart“ sieht, einen „Fremdling, ein[en] Unverstandenen wie [den] Holländer, Tannhäuser oder Lohengrin, [den] anderen Symbolgestalten des modernen absoluten Künstlers" ${ }^{\text {“30? }}$

\subsubsection{Die Bedeutung der Musik für die revolutionäre Bewegung}

Zusammenfassend lässt sich sagen, dass Wagner sicherlich keine „Revolutionsoper" im eigentlichen Sinne ${ }^{31}$ geschrieben hat. Doch schließt dies nicht

28 Anzumerken ist, dass auch in der Oper „La prophète“ von Scribe und Meyerbeer (1849) am Ende das Schloss von Münster brennt und einstürzend alle Versammelten tötet.

29 Dazu vgl. Bermbach. Leid (wie Anm. 14), S. 47ff.; ders. Wahn (wie Anm. 12), S. $16 \mathrm{ff}$.

30 So Dieter Borchmeyer. Nachwort. In: Wagner, Dichtungen (wie Anm. 1), X, S. 221. Vgl. auch ders., Ahasvers Wandlungen (wie Anm. 12), S. $98 \mathrm{ff}$.

31 Oder im Sinne der "Arbeiteroper“, die Albert Lortzing 1848 mit seiner Oper "Regina" in Text und Musik schuf (die aber nicht aufgeführt werden konnte); vgl. dazu Garratt. Music (wie Anm. 7); Miriam Noa. Volkstümlichkeit und 
aus, dass - wie bei der schon erwähnten Aufführung der „Stummen von Portici“ 1830 in Brüssel - die von leidenschaftlicher Musik getragenen Massenszenen das Publikum (zumindest in Teilen) für revolutionäre Bestrebungen empfänglich machten. Es wäre interessant, einen solchen Einsatz der Musik bei Festveranstaltungen oder Versammlungen oder in Musikvereinen zu untersuchen. ${ }^{32}$ Auch in diesem Zusammenhang ist Wagner zu nennen, da er für das große Allgemeine Männergesangsfest am 6. Juli 1843 das Chorstück „Das Liebesmahl der Apostel“ komponierte und durchführte. ${ }^{33}$ Hier kamen zahlreiche sächsische Männerchöre in der Dresdner Frauenkirche zusammen, in denen durchaus national, aber auch revolutionär Gesinnte versammelt waren. Es sangen 1200 Sänger, es spielten 100 Orchestermusiker.

\subsubsection{Anmerkung zu den drei Dresdner romantischen Opern}

Nur angemerkt sei, dass die im Anschluss an „Rienzi“ geschriebenen Opern - die alle als „romantische Oper“ bezeichnet wurden - wohl nicht von einem revolutionären Pathos erfüllt waren ${ }^{34}$, was hier nur behauptet, nicht nachgewiesen werden kann.

„Der fliegende Holländer“ (1841 bis 1842, uraufgeführt in Dresden am 2. Januar 1843) enthält in diese Richtung nichts. „Tannhäuser“ (1842 bis 1845, uraufgeführt in Dresden am 19. Oktober 1845) handelt von einem Künstler, der sich gegen die Gesellschaft und das in ihr herrschende

Nationbuilding. Zum Einfluss der Musik auf den Einigungsprozess der deutschen Nation im 19. Jahrhundert. Münster. Waxmann 2013.

32 Vgl. Garratt, Music (wie Anm. 7), S. 84ff.; Karl-Dieter Völger. Über Musik und Musiker in der Revolution. In: Burschenschaftliche Blätter 1999, H. 1, S. 24-31.

33 Dazu vgl. Frank Piontek. „Das Liebesmahl der Apostel (WWW 69)“. In: Wagner-Lexikon (wie Anm. 11), S. 394-396.

34 Anders z. B. Udo Bermbach. Wo Macht ganz auf Verbrechen beruht. Politik und Gesellschaft in der Oper. Hamburg. Europäische Verlagsanstalt 1997, S. 183ff., 202ff., 218ff. - Vgl. aber auch Martin Geck. Wagner. Biographie. München. Siedler 2012, S. 139: „Mit den Titelgestalten seiner drei romantischen Opern ist Wagner nun [1849, WS] nicht länger zufrieden. Sie allesamt ichbezogen, an ihrer eigenen Erlösung interessiert, jedoch keine ,reinmenschlichen' Helden [...] Wagner sucht [den Menschen,der ...] sich in seiner ganzen Lebens- und Liebesfülle verströmt und auch den Tod nicht fürchten muss", den Menschen der Zukunft. Dazu auch Wolf, Entwicklung (wie Anm. 12), S. 97ff. 
Kunst- und Liebesideal stellt (insofern kulturell (aber nicht politisch) „revolutionär“ ist) und darin scheitert, wobei die Zeitgenossen im Zusammenhang mit dem Verhalten des Papstes die Frage diskutierten, ob Wagner hier Stellung im damaligen sächsischen Religionskrieg für die deutschkatholische oder protestantische Richtung beziehen oder ob er wegen des Stabwunders und der Heiligsprechung der Elisabeth, deren Gebet an die Gottesmutter die überirdische Errettung des Helden ermöglicht, überhaupt dem katholischen König gefällig sein wollte. ${ }^{35}$ Doch wird man auch festhalten müssen, dass diese Oper grundsätzlich von einer Kritik am Christentum getragen ist, was sich in der Ausgestaltung der antik-heidnischen Göttin Venus als ursprünglich germanische Gottheit Holda, die durch die Christen in den Berg vertrieben und verteufelt wurde, niederschlägt.

Überhaupt als religionskritisch erweist sich „Lohengrin“ (1845 bis 1848, uraufgeführt in Weimar am 28. August 1850), zumindest in der Interpretation durch Wagner selbst, der das Vorspiel mit der musikalischen Schilderung des Grals als Projektion der Sehnsucht der Menschen umschrieb und in einem Brief an Hermann Franck vom 30. Mai 1846 das Scheitern des vom Gral gesandten Helden damit begründete, dass „die Berührung einer übersinnlichen Erscheinung mit der menschlichen Natur" auf Dauer nicht möglich sei; „die Lehre würde sein: der liebe Gott thäte klüger, uns mit Offenbarungen zu verschonen, da er doch die Gesetze der Natur nicht lösen darf“. Diese religionskritische Sicht fand sich dann in der Schrift „Die Wibelungen" (1848), auf die noch eingegangen wird, weiter entwickelt. Darüber hinaus ist darauf hinzuweisen, dass Wagner Heinrich I. - historisch König der östlichen Franken - zum „deutschen König“ macht und vom „deutschen Reich“ spricht, was eindeutig im Sinne des Vaterlandsvereins war, dem Wagner beigetreten war.

\subsection{Theoretische Einflüsse auf Wagner}

Es ist unbestritten, dass Wagner in der gesamten, hier betrachteten Zeit keine politischen Schriften las, auch keine derartigen Bücher in seiner Bibliothek hatte. Er führte aber zahlreiche Gespräche mit entsprechend belesenen Freunden, bereits in seiner Zeit in Paris (1839-1842), das damals voll von

35 Vgl. dazu Kirchmeyer, Situationsgeschichte (wie Anm. 7), S. $333 \mathrm{ff}$. 
revolutionären Ideen war (auch wegen der zahlreichen Flüchtlinge) ${ }^{36}$, und dann in Dresden.

\subsection{1. (Karl) August Röckel}

In Dresden war sein hauptsächlicher Gesprächspartner der 1814 in Graz geborene (Karl) August Röckel. ${ }^{37}$ Nach Aufenthalten in Paris (wo Röckel die Juli-Revolution 1830 erlebt hatte und mit den Schriften der Frühsozialisten (Henri Saint-Simon, Charles Fourier, Pierre-Joseph Proudhon, Etienne Cabet) vertraut geworden war) und London und mehreren Engagements in deutschen Staaten war er 1843 zeitgleich mit Wagner als Musikdirektor in Dresden gelandet. Er war Komponist und Dirigent, hatte aber in Anerkennung und Verehrung Wagners auf eine diesbezügliche Karriere verzichtet und sich dem Hofkapellmeister Wagner als Korrepetitor und Hilfsdirigent untergeordnet; und besprach mit ihm auf zahlreichen ausgedehnten Spaziergängen die politischen Probleme.

Röckel war ein fanatischer Republikaner, Leiter des Dresdners Vaterlandsvereins - wobei er Wagner auch dazu brachte, selbst Mitglied zu werden -, trat in einer „Denkschrift an die deutsche Nationalversammlung zu Frankfurt und an alle deutsche Regierungen “ für die Volksbewaffnung ein ${ }^{38}$ und wurde später ab dem 26. August 1848 Herausgeber der „Volksblätter“, die ausdrücklich „unter Mitwirkung des Vaterlands-Vereins herausgegeben“

36 Dazu Bermbach. Wahn (wie Anm. 12), S. 23f. Ausführlich vgl. Manfred Kreckel. Richard Wagner und die französischen Frühsozialisten. Frankfurt a.M. Peter Lang 1986.

37 Dazu vgl. Udo Bermbach. „Röckel, (Karl) August“. In: Wagner-Lexikon (wie Anm. 11), S. 624-625; Jörg Heyne. Richard-Wagner-Museum Graupa bei Dresden. Dresden. Eigenverlag ${ }^{2}$ 1986. Vgl. auch Jörg Heyne. Richard Wagner und Karl August Röckel in weltanschaulicher und künstlerischer Auseinandersetzung unter den Bedingungen des kleinbürgerlichen Demokratismus der nachrevolutionären Periode (1849 bis 1876). Dissertation Halle-Wittenberg 1985.

38 Die Schrift trug den Titel „Die Organisation der Volksbewaffnung in Deutschland, mit besonderem Bezuge auf Sachsen“, im Untertitel „Auf Grund der Berathungen einer vom deutschen Vaterlandsvereine zu Dresden berufenen Commission“; sie erschien 1848. Röckel schrieb 1865 eine historische, mit biographischem Material gesättigte Arbeit „Sachsens Erhebung und das Zuchthaus zu Waldheim" (erschienen in Frankfurt a.M.). 
wurden. Sie gingen von dem Hereinbrechen einer neuen Zeit aus, die entweder zum Glück führen oder zum Fluche werden könne; deshalb seien die Deutschen aufgerufen, „,mit allen Kräften für das Wohl des theuren Vaterlandes zu wirken“, damit Deutschland „werde, was es werden kann, was es von Gott bestimmt ist zu sein: das schönste Land der Erde, bewohnt von dem Ersten, dem Glücklichsten aller Völker!"Röckel war sehr belesen, kannte die wichtigsten politisch-linken Schriftsteller (nicht nur aus Paris, sondern auch die deutschen Junghegelianer (wie Arnold Ruge, aber auch Ludwig Feuerbach $\left.^{39}\right)$ ) und trat gegenüber Wagner für deren Ideen ein. Für kurze Zeit war Röckel auch Abgeordneter im sächsischen Landtag.

\subsubsection{Michael Alexandrovic Bakunin}

Röckel kannte sicherlich auch die Schriften des 1814 in Russland geborenen, seit 1840 in Deutschland (und auch in Frankreich und der Schweiz) lebenden Philosophen Michael Alexandrovic Bakunin. Denn dieser war durch seinen vielgerühmten, unter dem Pseudonym Jules Elysard verfassten, deutschsprachigen Aufsatz „Die Reaction in Deutschland“ in den in Leipzig von Arnold Ruge herausgegebenen Deutschen Jahrbüchern für Wissenschaft und Kunst 1842 sehr bekannt geworden. Bakunin ${ }^{40}$ hatte noch in Russland

39 Von daher lernte Wagner offensichtlich Feuerbach durch Vermittlung der Gespräche mit Röckel kennen; vgl. dazu Heyne, Wagner (wie Anm. 37).

$40 \mathrm{Zu}$ ihm vgl. Rainer Beer. Einleitung. In: Michail Bakunin. Philosophie der Tat. Auswahl aus seinem Werk. Hg. Rainer Beer. Köln. Jakob Hegner 1968, S. 9-58; Udo Bermbach, „Bakunin, Michael Alexandrovic“ In: Wagner-Lexikon (wie Anm. 11), S. 53-54; Helmut Dahmer. Michael Bakunin, der Don Quijote der Revolution. In: Friedrich-Ebert-Stiftung, Bakunin (wie Anm. 9), S. 25-37; Madeleine Grawitz. Bakunin. Ein Leben für die Freiheit. Hamburg. Lutz Schulenburg 1999; Burkhardt Joachim Huck. „Der Traum von der absoluten Freiheit". Eine Studie zur Theorie und Praxis von Anarchismus und Terrorismus im Leben und Werk Michail Bakunins. Hausarbeit Univ. München 1980; Philippe Kellermann. Max Stirner und Michael Bakunin. Über Gemeinsamkeiten und Differenzen zweier anarchistischer Gründerväter. In: Anarchismus in Vor- und Nachmärz. Hg. Detlev Kopp/Sandra Markewitz. Jahrbuch Forum Vormärz Forschung 22 (2016), S. 41-70; Irene Lawen. Konzeptionen der Freiheit. Zum Stellenwert der Freiheitsidee in der Sozialethik John Stuart Mills und Michail A. Bakunins. Saarbrücken. Verlag für Entwicklungspolitik 1996, S. 151ff.; Max 
die Arbeiten von Fichte und Hegel kennengelernt, einige ihrer Arbeiten übersetzt (und z. B. die Hegelschen Gymnasialreden umfangreich eingeleitet), selbst 1839 einen stark an der „Vernünftigkeit der Wirklichkeit“-These Hegels orientierten Aufsatz in den Vaterländischen Annalen (Titel: „Über die Philosophie“) geschrieben. In Berlin hatte Bakunin 1840 die hegelkritischen Ansichten der Junghegelianer (Strauß, Feuerbach, Bruno Bauer) kennengelernt, übernommen und das Ende der theoretischen Reflexion - als deren Vollendung er Hegel pries, wobei die Vollendung zugleich die „Selbstaufösung in eine ursprüngliche und neue praktische Welt", in die „wirkliche Gegenwart der Freiheit" sei - verkündet. An die Stelle des absoluten Wissens (und damit der in der Geschichte des Geistes sich herausgebildet habenden Identität von Gott und Mensch) müsse nun die praktische autonome Tat treten ${ }^{41}$, die Realisierung der unbedingten Freiheit in einer politischen Aktion, die er als "Religion“ (und „Kirche der Freiheit") auffasste und und deren „einzig wahren Ausdruck“ er in "Gerechtigkeit und Liebe“ sah, in der Liebe, die das höchste Gebot Christi sei, weshalb er seine Lehre als Aufnahme des „einzigen Wesens des wahren Christentums“ ansah.

In dieser 1842 veröffentlichten Arbeit ${ }^{42}$ verwendete Bakunin die Hegelsche Dialektik (von Position - Negation - Negation der Negation in einer neuen Position) freilich zunehmend bloß als Form einer Hochpreisung der Negation. Er sprach von dem „rastlosen Sichselbstverbrennen des Positiven in dem reinen Feuer des Negativen“, das er als „die gänzliche Vernichtung der bestehenden politischen und sozialen Welt" durch die revolutionäre Tat verstand. Dieser revolutionäre praktisch-autonome Geist sei durch die teilweise erfolgreiche Reaktion in Europa nicht überwunden: „er ist nur, nachdem er

Nettlau. Michael Bakunin in den Jahren 1848-1849. In: Sozialistische Monatshefte 2 (1898), S. 187-195; Peter Scheibert. Von Bakunin zu Lenin. I. Leiden. E.J. Brill 1956; Petra Weber. Sozialismus als Kulturbewegung. Düsseldorf. Droste 1989; Justus Franz Wittkop. Michail A. Bakunin in Selbstzeugnissen und Bilddokumenten. Reinbek bei Hamburg. Rowohlt 1974.

$41 \mathrm{Zu}$ diesem wesentlichen Inhalt des Junghegelianismus vgl. Antonia Bertschinger, Vom Himmel auf die Erde. Die Erneuerung der Philosophie durch die Junghegelianer. Dissertation Zürich 2003; Köster. Radikalismus (wie Anm. 12); Elmar Treptow. Theorie und Praxis bei Hegel und den Junghegelianern. Habilitationsschrift München 1971 (Bakunin wird nicht behandelt, wohl aber u.a. Feuerbach).

42 Veröffentlicht u. a. in: Bakunin, Philosophie (wie Anm. 40), S. 61-96. Dazu vgl. Scheibert. Bakunin (wie Anm. 40), S. $158 \mathrm{ff}$. 
durch seine erste Erscheinung die ganze Welt in ihren Fugen erschüttert hat, wieder in sich zurückgegangen; er hat sich nur in sich vertieft, um bald wieder sich als affirmatives, schaffendes Prinzip zu offenbaren, und gräbt jetzt [nach einem Bild bei Hegel, WS] wie ein Maulwurf unter der Erde“; noch mehr: es

regen sich Erscheinungen um uns her, welche uns verkünden, daß der Geist, dieser alte Maulwurf, sein unterirdisches Werk bereits vollbracht hat, und daß er bald wieder erscheinen wird, um sein Gericht zu halten; - es bilden sich überall [...] sozialistisch-religiöse Vereine, welche, der gegenwärtigen politischen Welt ganz fremd, aus ganz neuen Quellen ihr Leben schöpfen und sich im stillen entwickeln und verbreiten [...] Oh, die Luft ist schwül, sie ist schwanger von Stürmen! - Und darum rufen wir unseren verblendeten Brüdern zu: Tut Buße! Tut Buße! .- Das Reich des Herrn ist nah!

\section{Der Beitrag von 1842 endete in dem vielzitierten Ausruf:}

Laßt uns also dem ewigen Geiste vertrauen, der nur deshalb zerstört und vernichtet, weil er der unergründliche und ewig schaffende Quell alles Lebens ist. - Die Lust der Zerstörung ist zugleich eine schaffende Lust!

Wahrscheinlich kannte Röckel auch eine Artikelserie, die Bakunin (vielleicht unter Mitarbeit von Moses Hess) anonym zu der Konzeption von Wilhelm Weitling in der Zeitschrift „Schweizer Republikaner“" (1843, Nr. 44-47) veröffentlicht hatte. ${ }^{43}$ Thema war "Der Communismus“ (wie er in einem Aufsatz in der schweizerischen Zeitschrift „Beobachter aus der östlichen Schweiz" dargestellt wurde, auf den Bakunin nun Bezug nahm). Bakunin lehnt den eigentlichen Kommunismus (im Sinne von Weitling) ab:

wir könnten [...] nicht in einer nach dem Weitling'schen Plane organisirten Gesellschaft leben; denn es wäre keine freie Gesellschaft, keine wirkliche, lebendige Gemeinschaft von freien Menschen, sondern ein unerträglicher Zwang, eine durch Gewalt zusammengebrachte Heerde von Thieren, die nur das Materielle im Auge hätten, und vom Geistigen und von allen hohen Genüssen des Geistigen nichts wüßten. - Wir glauben nicht einmal, daß so eine Gemeinschaft jemals zu Stande kommen könne; denn wir haben ein

43 Dazu vgl. Scheibert. Bakunin (wie Anm. 40), S. 166. Vgl. allgemein: Johann Langhard. Die anarchistische Bewegung in der Schweiz. Lindau. Unikum 2014. 
zu großes Vertrauen auf die heilige, allen Menschen mit mehr oder weniger Bewußtsein inwohnende Macht der Wahrheit.

Von dieser Wahrheit seien einige Elemente im Kommunismus enthalten, müssten aber freigelegt werden: „die heiligsten Rechte, die menschlichsten Forderungen liegen ihm zu Grunde, - und diese sind es, welche seine große, wunderbare, ja auf die Gemüther überraschend wirkende Macht ausüben“. Diese Macht hätten die Kommunisten aber nicht erkannt. Deshalb müsse man auf die Wahrheit der Philosophie - die nach den Worten des Evangeliums die Menschen frei macht - zurückgreifen. Bakunin verwies auf diese Philosophie und

ihren hartnäckigen Kampf, - ihren Kampf auf Tod und Leben [...], - mit allen Vorurtheilen, mit allem dem, was die Menschen verhindert, ihr hohes, ihr heiliges Ziel, - die Verwirklichung der freien und brüderlichen Gemeinschaft, - die Verwirklichung des Himmels auf der Erde, zu erreichen. - Sie hat noch vieles zu thun, noch vieles zu bekämpfen, um den Schleier der Lüge, den die konservativen Freunde des Volkes eigennützig über ihn ausbreiten, zu zerreißen. Sie hat aber den Muth der Wahrheit und sie wird und muß auch siegen, da die Wahrheit, die Erkenntniß der Wahrheit ihre einzige Waffe ist. Sie kämpft im Lichte und ihre Feinde in der Nacht; die Feinde rufen die groben, die dunkeln Leidenschaften, das Dämonische im Volk hervor, sie aber stützt sich im Gegentheil nur auf der gottähnlichen, nur auf der lichten Seite der menschlichen Natur, sie appellirt an die hohe Leidenschaft der Freiheit, der Liebe und der Erkenntniß, und Gott, die Wahrheit, wird doch am Ende über das Dunkel den Sieg erhalten.

In diesem Kampf würden sich die Philosophie und der Kommunismus treffen, aber zugleich im Gegensatz von theoretischer Erkenntnis und praktischer Tat. Indes:

Wohl sind das Denken und die That, die Wahrheit und die Sittlichkeit, die Theorie und die Praxis in höchster Instanz ein und dasselbe, ein einziges untrennbares Wesen; wohl besteht das größte Verdienst der modernen Philosophie darin, daß sie diese Einheit erkannt und begriffen hat; mit dieser Erkenntniß ist sie aber zu ihrer Grenze angelangt, bis zu einer Grenze, die sie, als Philosophie, nicht überschreiten kann, denn jenseits dieser Grenze fängt ein höheres Wesen als sie - die wirkliche, durch die Liebe beseelte und aus dem göttlichen Wesen der ursprünglichen Gleichheit entsprossene Gemeinschaft von freien 
Menschen - an, die diesseitige Verwirklichung dessen, was das eigentliche Wesen des Christenthums ausmacht, der wahre Kommunismus.

Bakunin stellte damit auch die Dimension dieses „wahren christlichen Kommunismus" heraus:

Alle Menschen, alle ohne Ausnahme, sind Brüder, lehrt das Evangelium, und wenn sie sich gegenseitig lieben, nur dann ist der unsichtbare Gott, die erlösende und beseelende Wahrheit in ihnen gegenwärtig, singt dazu Johannes; folglich kann der einzelne Mensch, sei er noch so schön und sittlich gesinnt, nicht der Wahrheit theilhaftig werden, wenn er nicht in der Gemeinschaft lebt; nicht in dem Einzelnen, sondern nur in der Gemeinschaft ist Gott gegenwärtig, und so ist die Tugend eines Einzelnen, die lebendige, die fruchtbringende Tugend nur durch das heilige und wunderthätige Band der Liebe, nur in der Gemeinschaft möglich. Außer der Gemeinschaft ist der Mensch nichts, in der Gemeinschaft alles; und wenn die Bibel von der Gemeinschaft spricht, so ist sie sehr weit entfernt, darunter einzelne, engherzige, sich von den andern abschließende Gemeinden oder Nationen zu verstehen; von nationalen Unterschieden weiß das ursprüngliche Christenthum nichts, und die von ihm gepredigte Gemeinschaft ist die Gemeinschaft aller Menschen, die Menschheit.

Freilich sei - so Bakunin weiter - dieses wahre Christentum im heutigen sozial-staatlichen Leben Europas verschwunden, genauer: es sei abgelöst worden durch den Geist der französischen Revolution:

Der heilige Geist der Freiheit und der Gleichheit, der Geist der reinen Menschlichkeit, der durch die französische Revolution unter Blitz und Donner der Menschheit geoffenbart und durch die stürmischen Revolutionskriege als Same eines neuen Lebens überall verbreitet wurde. Die französische Revolution ist der Anfang eines neuen Lebens; viele sind so blind, daß sie meinen, ihren mächtigen Geist überwunden und gebändigt zu haben; armselige Menschen, wie schrecklich wird ihr Erwachsen sein! Nein, das revolutionäre Drama ist noch nicht geschlossen. Wir sind unter dem Gestirne der Revolution geboren, wir leben und bewegen uns unter seinem Einflusse und wir werden alle, alle die wir jetzt leben, ohne Ausnahme, unter seinem Einflusse sterben. Wir sind am Vorabend einer großen, welthistorischen Umwandlung, am Vorabend eines neuen und desto gefährlicheren Kampfes, als er nicht mehr einen bloß politischen, sondern einen prinzipiellen, religiösen Charakter haben wird. Ja man muß sich nicht täuschen: es wird sich um nichts Geringeres handeln, als 
um eine neue Religion, um die Religion der Demokratie, welche unter der alten Fahne mit der Inschrift: ,Liberté, Egalité et Fraternité ihren neuen Kampf, einen Kampf auf Leben und Tod, eröffnen wird. - Dieser Geist ist es, aus dem der Kommunismus entstanden; dieser Geist verbindet jetzt auf eine unsichtbare Weise alle Völker ohne Unterschied der Nationen.

Die sog. christlichen Staaten, die ein Scheinchristentum vertreten, könnten diesem neuen Geist nicht widerstehen, seinen „flammenden Blick“ nicht ertragen, weshalb sie das nationale Gefühl im Volke, auf Kosten der Menschlichkeit und der Liebe entwickeln; „sie, die christlichen Regierungen predigen den Haß und den Mord im Namen der Nationalität". Bakunin schloss seinen Beitrag: „Gegen sie (die christlichen Regierungen) haben Weitling und der Kommunismus ein unbedingtes Recht, denn nach den Prinzipien des Christenthums selbst muß alles vernichtet werden, was dem Geist der Liebe entgegensteht".

Bemerkenswert ist, dass in dieser Artikelserie die revolutionäre Vernichtung eindeutig im Vordergrund und Mittelpunkt steht. Bakunin begann sich hier offensichtlich zu radikalisieren, die schaffende Lust aus dem Jahr 1842 durch die Lust der Zerstörung zu verdrängen; vielleicht auch deshalb, weil nun das Erschaffen des Neuen in die absolute Freiheit der durch die revolutionäre Vernichtungstat Befreiten gelegt wurde (wie seine Ablehnung der kommunistischen im Sinne einer von oben, also staatlich durch Gesetze organisierten Gesellschaft zeigt). Wie Bakunin im Sommer 1848 an Georg Herwegh schrieb: „Ich glaube nicht an Konstitutionen und Gesetze [...] Wir brauchen etwas Anderes: Sturm und Leben und eine neue gesetzlose und darum freie Welt “ ${ }^{\text {‘4 }}$. Es lässt sich zeigen, dass Bakunin zunehmend (und schließlich durch die Niederschlagung des Wiener Aufstandes (wie er in seiner „Beichte“ den russischen Behörden gegenüber bekannte)) zu einem „Fanatiker" wurde, gepackt von einer furchtbaren revolutionären Wut und einem hemmungslosen Vernichtungswillen. ${ }^{45}$

Bedeutend war schließlich der „Aufruf an die Slaven. Von einem russischen Patrioten“, den Bakunin in deutscher Sprache unter Namensnennung im Selbstverlag (angegeben: Koethen) im Dezember 1848 veröffentlichte. ${ }^{46}$

44 Zitiert in: Michael Bakunin/Wolfgang Eckhardt. „Barrikadenwetter“ und „Revolutionshimmel“ (1849). Berlin. Karin Kramer 1995, S. 9 Fn. 2.

45 So Bakunin/Eckhardt. Barrikadenwetter (wie Anm. 44), S. 47, 102, 109, 111.

46 Abgedruckt in: Michael Bakunin. Zwei Schriften aus den 40er Jahren des XIX. Jahrhunderts. Prag 1936, S. 23ff. Die Seitenzahlen im Text beziehen sich auf 
Darin trat er für einen Freiheitskampf aller europäischen Völker ein: für Freiheit, Gleichheit und Brüderlichkeit aller Nationen. „Unser Aller Heil ist in der Revolution“ (35), in ihrer „dämonischen Kraft, welche die Welt verjüngt" (26). In dem Bauernaufstand in Galizien sah er - adressiert an den Zaren -

den Keim einer neuen, ungeahnten Kraft, ein vulkanisches Feuer, dessen Ausbruch die wohlangelegten Kunstgeräte deiner Diplomatie und Herrschaft unter berghohen Lavamassen begraben und deine Macht, verblendeter Zar, verschütten und in einem Augenblicke spurlos vernichten wird. Ein Bauernaufstand in Galizien ist ein Nichts, aber sein Feuer frißt auf dem unterirdischen Herde weiter und schon wirft es unter den Bauernmassen des ungeheueren russischen Reiches riesige Krater auf. Das ist die Demokratie Rußlands, deren aufschlagende Flammen das Reich verzehren und mit ihrem blutigen Schein über ganz Europa leuchten werden. Wunder der Revolution werden aus der Tiefe dieses Flammen-Ozeans emporsteigen [...] In Moskau wird aus einem Meer von Blut und Feuer hoch und herrlich das Gestirn der Revolution emporsteigen und zum Leitstern werden für das Heil der ganzen befreiten Menschheit. (37f.)

Dann fand Bakunin Worte, die wir vergleichbar in Wagners Artikel vom 8. April 1849, auf den noch eingegangen wird, lesen können:

Werfet Euch mutig in die Arme der Revolution! - Sie ist Alles, Euer Wiedererwachen, Euer Auferstehen, Euere Hoffnung, Euere Errettung, Euere Zukunft. Sie und nur sie! [...] Die Revolution ist überall. Sie allein herrscht, sie allein ist gewaltig. Der neue Geist mit seiner auflösenden, zersetzenden Kraft ist unwiderruflich eingedrungen in die Menschheit und durchwühlt die Gesellschaft bis in ihre tiefsten dunkelsten Schichten. Und nicht ruhen wird die Revolution, bis sie die alte vermorschte Welt völlig zerstört und eine neue herrliche Welt daraus geschaffen hat. In ihr also und nur in ihr ist alle Kraft und Stärke, alle Siegesgewißheit. Nur in ihr ist das Leben, außer ihr der Tod [...] Sie ist die Macht, sie ist das Recht, sie ist die Wahrheit, sie ist das Heil dieser Zeit [...] Sie allein kann Lebensfülle schaffen. [...] Gebet Euch voll und ganz ihr hin! (38f.)

diese Schrift. - Dazu vgl. Jean-Christophe Angaut. Revolution, socialism, and the Slavic question: 1848 and Michael Bakunin. In: The 1848 revolution and European political thought. Hg. Douglas Moggach/u. a. Cambridge University Press 2018, S. 405-428. 


\subsubsection{Offenheit Wagners für revolutionäre Gedanken}

Die vielen Gespräche über die aktuellen politischen Fragen und die dafür entwickelten philosophischen Theorien fielen bei Wagner auf fruchtbaren Boden. Er war in seiner Tätigkeit als Hofkapellmeister sehr unzufrieden ${ }^{47}$, hatte auch drückende Geldsorgen, bekam nicht die Aufmerksamkeit und die künstlerische Wertschätzung (vor allem außerhalb Dresdens), die er sich eigentlich zusprach; allmählich merkte er, dass das Dresdner Publikum (noch) nicht reif war für die musikdramatischen, die Konzeption der traditionellen Oper verlassenden Kunstwerke, die er mit dem „Fliegenden Holländer“ (1843) und „Tannhäuser“ (1845) schuf; kurz: Wagner war offen für kritische Blicke auf das künstlerische, gesellschaftliche, politische Leben seiner Zeit.

Interessant ist in diesem Zusammenhang die Schilderung einer persönlichen Begegnung 1846 mit Wagner, an die sich der deutsch-böhmische Schriftsteller (und promovierte Mediziner) Alfred Meißner (1822-1885), mehrere Jahre in Paris (geschildert in den "Revolutionären Studien aus Paris“ in zwei Bänden 1849), auch in Leipzig und Dresden lebend, erinnerte. Er schrieb darüber:

Frühere Kämpfe hatten ihm [Wagner, WS] schon eine ungewöhnliche Reizbarkeit gegeben, er hatte bereits etwas Aufgeregtes, Gereiztes, Giftkochendes in sich. - Auf diesem ersten Spaziergange hatten wir viel miteinander gesprochen, doch ausschließlich über Politik. Richard Wagner hielt die politischen Zustände für reif zur gesellschaftlichen Änderung und sah einer in nächster Zeit stattzuhabenden Umwälzung als etwas Unausbleiblichem entgegen. Die

$47 \mathrm{Zu}$ Wagners Zeit in Dresden vgl. Bauer. Wagner (wie Anm. 9), S. 112-144; Udo Bermbach. Richard Wagner. Stationen eines unruhigen Lebens. Hamburg. Ellert \& Richter 2006, S. 58-95; Richard Wagner. Ein Lebens- und Charakterbild in Dokumenten und zeitgenössischen Darstellungen. Hg. Werner Otto. Berlin. Der Morgen 1900, S. 48ff.; Dinger. Entwickelung (wie Anm. 9), S. 91ff.; Karl Richard Ganzer. Richard Wagner der Revolutionär gegen das 19. Jahrhundert. München. F. Bruckmann 1934; Peter Gülke. Die Dresdner Jahre - Wagners „Achsenzeit“. In: wagnerspectrum 8 (2012), H. 2, S. 135-144; Robert W. Gutman. Richard Wagner. Der Mensch, sein Werk, seine Zeit. München. Piper 1970, S. 110-150; Kirchmeyer, Situationsgeschichte (wie Anm. 7), Bd. I, Bd. IV; Robert Prölss. Geschichte des Hoftheaters zu Dresden. Von seinen Anfängen bis zum Jahre 1862. Dresden. Wilhelm Baensch 1878, S. 531-559. 
Umwandlung werde leicht und mit wenigen Schlägen vor sich gehen, denn die staatlichen und gesellschaftlichen Formen hielten nur noch ganz äußerlich fest. Ich erinnere mich noch genau der Worte: „eine Revolution sei bereits in allen Köpfen vollzogen, das neue Deutschland sei fertig wie ein Erzguß, es bedürfe nur eines Hammerschlages auf die thönere Hülle, daß es hervortritt”“. 48

Auch andere Bekannte und Freunde (wie der 1801 geborene, als Schauspieler, Sänger, seit 1844 am Dresdner Hoftheater tätige Eduard Devrient, der mit seinen Schriften „Das Nationaltheater des neuen Deutschlands“ (1848) und "Geschichte der deutschen Schauspielkunst“ (1848ff. in fünf Bänden) als Theaterreformen bekannt und mit Wagner auch wegen der diesbezüglichen Zusammenarbeit befreundet war, was sich in seinen 1964 veröffentlichten Tagebüchern ${ }^{49}$ zeigt) berichten mehrmals über die politisch-revolutionäre Begeisterung Wagners. Der Wiener Musikkritiker Eduard Hanslick berichtete in seiner Autobiographie von einem Zusammentreffen mit Wagner in Wien 1848: „Wagner war ganz Politik; er erwartete von dem Sieg der Revolution eine vollständige Wiedergeburt der Kunst, der Gesellschaft, der Religion, ein neues Theater, eine neue Musik"50.

\subsubsection{Brief an Professor Wigard (19. Mai 1848)}

Zu den Arbeiten Wagners im Zusammenhang mit der Revolution gehört jedenfalls der am 19. Mai 1848 verfasste Brief an Professor Franz Jacob Wigard, damals Mitglied der deutschen Nationalversammlung in Frankfurt

48 Zitiert nach: Dinger, Entwickelung (wie Anm. 9), S. 94. - Interessant ist in diesem Zusammenhang der Brief vom 23. November 1847 (nach dem Scheitern der Rienzi-Aufführung in Berlin) an den Berliner Musikkritiker (und Schöpfer des Feuilletons) Ernst Kossak (1814-1880): „Was ist all unser Hineinpredigen in das Publikum? [...] Hier ist ein Damm zu durchbrechen und das Mittel heißt: Revolution! Die positive Basis muss gewonnen werden; was wir für gut und recht halten, das muß das Gegebene, Feste und Unabänderliche werden, dann löst sich das jetzt herrschende Schlechte von selbst zur albernen, leicht besiegbaren Opposition auf. Ein einziger vernünftiger Entschluß des Königs von Preußen für sein Operntheater und alles ist mit einmal in Ordnung".

49 Vgl. Eduard Devrient aus seinen Tagebüchern. Berlin - Dresden 1836-1852. Hg. Rolf Kabel. Weimar. Hermann Böhlaus Nachfolger 1964.

50 Zitiert in: Kröplin, Wagner und der Kommunismus (wie Anm. 4), S. 68. 
(die einen Tag zuvor eröffnet worden war). Darin ${ }^{51}$ forderte er den Abgeordneten, den er durch August Röckels Vermittlung kennengelernt hatte, auf, dafür einzutreten, dass das Parlament „die einzelnen Staaten erst noch vollkommen revolutionieren " müsse, nämlich dadurch, dass die Ungleichheit der deutschen Bundesstaaten beseitigt wird (was bedeutet, dass Staaten unter drei und über sechs Millionen Einwohner nicht mehr zugelassen werden sollten). „Nun hängt es von dem Benehmen der Fürsten ab, welches Los sie sich bereiten wollen. Beginnen sie feindselig, protestieren sie, so sind sie samt und sonders in Anklagezustand zu versetzen; und die Anklage gegen sie ist auf völlig historischer Basis zu begründen" (262f.). Daneben trat Wagner für die Aufhebung des alten deutschen Bundestages, die sofortige Einführung der Volksbewaffnung und ein Schutz- und Trutzbündnis mit Frankreich ein.

Eine Revolutionsschrift im eigentlichen Sinne kann man diesen Brief allerdings nicht nennen

\subsection{5. „Gruß aus Sachsen an die Wiener“ (1. Juni 1848)}

Wie auch nicht das Gedicht „Gruß aus Sachsen an die Wiener", das am 1. Juni 1848 in der Allgemeinen Österreichischen Zeitung mit Namensnennung erschien. ${ }^{52}$ Doch findet sich - dem Anlass entsprechend (die Wiener Revolution im Mai 1848) - manch Revolutionär-Aggressives darin. „Aus Frankreich scholl der Freiheitsruf: / wir haben ihn nachgesprochen; / die Bande, die uns Knechtschaft schuf, / sie werd' von uns zerbrochen“. Doch bleibt die Frage, ob es wirklich zur befreienden Tat (,in unsrer Hand das Freiheitsschwert“) kommen wird. Aber: „nun jauchz' ich auf aus voller Brust, / mein Zagen ist gehoben: / Drum muß ich nun mit heißer Lust / euch Wiener Helden loben! / Ihr habt die Frage recht erwogen, / euch macht sie kein Graun: / Das gute Schwert habt ihr gezogen, / den Knoten zu durchhau'n“. Deshalb grüßt der Sachse nun die Wiener: „laßt nun von uns euch melden: / stellt wer uns je das Schmachgebot: / ,Nun werdet wieder Diener!' / dem sei dann mit dem Schwert gedroht: /,Wir machen's wie die Wiener!““ Auf weitere „Revolutionsgedichte“ Wagners wird noch im Folgenden eingegangen.

51 Abgedruckt auch in: Wagner, Dichtungen (wie Anm. 1), V, S. 262f. (als "Anhang" zu den Revolutionstraktaten).

52 Abgedruckt in: Wagner, Dichtungen (wie Anm. 1), V, S. $263 f f$. 


\subsection{Die Rede vom 14. Juni 1848}

Mit revolutionären Tönen begann Wagner seinen Vortrag vom 14. Juni 1848 abends in der Hauptversammlung des Vaterlandsvereins, aus dem das erste in der Einleitung gebrachte Zitat stammt. Im Folgenden werden die Seitenangaben der gedruckten Fassung ${ }^{53}$ angegeben.

\subsubsection{Inhalt der Rede}

Das fest ins Auge zu fassende Ziel - so sprach Wagner - ist zunächst der „Untergang auch des letzten Schimmers von Aristokratismus“; „unsre Herren vom Adel“, die „Feudalherren, die uns knechten und schinden konnten, wenn sie Lust hatten“ müssen ihre Ahnen vergessen und jeden Titel, jede Auszeichnung von sich werfen, vor allem: jedes Vorrecht aufgeben und damit ihre Nähe zum königlichen Hof. „Tretet frei zurück von diesem [...] Hofe der müßigen Altersversorgung, damit er ein Hof des ganzen, frohen, glücklichen Volkes werde“. Daher verlangt Wagner ein Einkammersystem und das Stimm- und Wahlrecht für jeden volljährigen, im Lande geborenen Menschen (212). Es darf nur mehr den „einen großen Stand des freien Volkes“ geben (213), in dem jeder einzelne „der Erste eines freien, gesegneten Volkes“ ist (212). Zu diesem Stand gehört alles, „was auf dem lieben deutschen Boden von Gott menschlichen Atem empfing“ (212). Denn wir alle sind „Kinder eines Vaters, Brüder einer Familie“ (212). Doch gelten als Konsequenz auch - wie Wagner als „Mahnung“ (nicht als Drohung) an die Adeligen anfügt - die Christus-Worte: „Ärgert dich ein Glied, so reiß es aus: es ist besser, daß es verderbe, als daß der ganze Leib zur Hölle fahre!“ (212).

Der religiös-christliche Hintergrund scheint in der zweiten revolutionären Forderung auf. Der Mensch, als Krone der Schöpfung und Ebenbild Gottes, als König der Natur, bzw. seine hohen geistigen sowie seine so künstlerisch regsamen leiblichen Fähigkeiten und Kräfte sollen von Gott bestimmt sein; und nicht von dem „bleichen Metall“, dem Geld, dem die Kraft gegeben wird, „den schönen freien Willen des Menschen zur widerlichsten Leidenschaft, zu Geiz, Wucher und Gaunergelüste zu verkrüppeln“ (213). „Gott wird uns erleuchten, das richtige Gesetz zu finden“; und „wie ein böser nächtlicher Alp wird dieser dämonische Begriff des Geldes von uns

53 Abgedruckt in: Wagner, Dichtungen (wie Anm. 1), V, S. $211 \mathrm{ff}$. 
weichen mit all seinem scheußlichen Gefolge von öffentlichem und heimlichem Wucher, Papiergaunereien, Zinsen und Bankiersspekulationen. Das wird die volle Emanzipation des Menschengeschlechtes, das wird die Erfüllung der reinen Christuslehre sein“ (214). Nämlich: dieses von Gott gegebene Gesetz beruht auf der Erkenntnis, „daß die menschliche Gesellschaft durch die Tätigkeit ihrer Glieder, nicht aber durch die vermeinte Tätigkeit des Geldes erhalten wird“ (214). Wagner spricht vom "großen Befreiungskampf der tief entwürdigten leidenden Menschheit", der aber nicht einen Tropfen Blutes, nicht eine Träne, nicht eine Entbehrung kosten wird, sondern nur der Überzeugung bedarf,

daß es das höchste Glück, das vollendetste Woblergeben aller herbeifübren muß, wenn so viele tätige Menschen, als nur irgend der Erdboden ernähren kann, auf ihm sich vereinigen, um in wohlgegliederten Vereinen durch ibre verschiedenen mannigfaltigsten Fähigkeiten, im Austausch ibrer Tätigkeit sich gegenseitig zu bereichern und zu beglücken. (213)

Diese Forderung ist revolutionär in ihrem Bezug auf die erforderliche Erkenntnis und Überzeugung der reinen Christuslehre; sie muss im Kopf einsetzen und die Einstellung verändern. Es bedarf keiner gewaltsamen Revolte, keines - wie Wagner sagt - Tropfen Blutes. Und doch würde dann Revolutionäres geschehen: nämlich die „,vollkommene Wiedergeburt der menschlichen Gesellschaft“ „durch die gesetzkräftige Lösung der letzten Emanzipationsfrage“, durch die Erkenntnis von dem - wie in dem Eingangszitat angegeben - „von Gott verliehene[n] Menschenrecht“, von den „Rechte[n] freier Menschenwürde“ (215). Aus dieser neuen Gesellschaft - so beginnt Wagner visionär zu schwärmen - wird ein „freies, allseitig zu voller Tätigkeit erzogenes neues Geschlecht" hervorgehen, das die Kraft haben wird, an die höchsten Aufgaben der Zivilisation zu schreiten, nämlich: Betätigung und Verbreitung. Dieses neue Geschlecht wird mit Schiffen übers Meer fahren und da und dort „ein junges Deutschland“ gründen,

es mit den Ergebnissen unsres Ringens und Strebens befruchten, die edelsten, gottähnlichsten Kinder zeugen und erziehen: wir wollen es besser machen als die Spanier, denen die neue Welt ein pfäffisches Schlächterhaus, anders als die Engländer, denen sie ein Krämerkasten wurde. Wir wollen es deutsch und herrlich machen: vom Aufgang bis zum Niedergang soll die Sonne ein schönes, freies Deutschland sehen und an den Grenzen der Tochterlande soll, wie an denen des Mutterlandes, kein zertretenes, unfreies Volk wohnen, die 
Strahlen deutscher Freiheit und deutscher Milde sollen den Kosaken und Franzosen, den Buschmann und Chinesen erwärmen und verklären. (215f.)

So kommt für Wagner das eigentliche Ziel der republikanischen Bestrebungen des Vaterlandsvereines, für deren Mitglieder er diesen Vortrag hält, in Sicht: die „Beglückung des ganzen großen Menschengeschlechts“ (216). Dieses Ziel ist nur dann ein Traum und eine Utopie, wenn wir kleingläubig und selbstsüchtig hin- und hersprechen; es ist dies nicht, wenn „wir froh und mutig handeln“ (216). Ob Wagner damit wirklich die tiefsten Interessen des nicht zufällig so genannten „Vaterland“svereins angesprochen hat? Jedenfalls kehrt er in seiner Rede nach Sachsen (und Deutschland) zurück.

$\mathrm{Zu}$ diesem Mut gehört nun für Wagner auch eine neue Konzeption des Königtums, die den republikanischen Bestrebungen in dem aufgezeigten Sinne entspricht. Es ist eine ganz einfache Lösung: der König muss der „erste und allerechteste Republikaner" sein (216). Es ist der König, der das Entscheidende selbst ausspricht: „Ich erkläre Sachsen zu einem Freistaate“ (219). Dieser König ist „der erste des Volkes, der Freieste der Freien“ (220), „der echte, freie Vater seines Volkes“, getragen von der reinen Liebe des Volkes zu seinem Fürsten (218). Erneut deckt Wagner einen religiös-christlichen Hintergrund auf: „Das ist der Mann der Vorsehung!“ (218); und diese Konzeption stellt zugleich die schönste deutsche Auslegung des Ausspruches von Christus dar: „Der höchste unter euch soll der Knecht aller sein“. „Denn indem er der Freiheit aller dient, erhöht er in sich den Begriff der Freiheit selbst zum höchsten, gotterfüllten Bewußtsein“ (220). Darüber hinaus meinte Wagner, dass diese Konzeption von Königtum dessen Bedeutung in den germanischen Nationen entspreche, weshalb von einer Wiederherstellung auszugehen sei: „der Kreislauf der geschichtlichen Entwicklung des Königtums wird an seinem Ziele, bei sich selbst wieder angelangt sein" $(220)^{54}$.

Nur angemerkt soll werden, dass Wagner in diesem Vortrag auch auf eine alte Forderung der Vaterlandsvereine, für die August Röckel eine „Denkschrift an die deutsche Nationalversammlung zu Frankfurt und an alle deutsche Regierungen " für die Volksbewaffnung verfasst hatte, wiederholte: statt „ein[es] stehenden Heer[es] und eine[r] liegenden Kommunalgarde“ sollte eine allgemeine große Volkswehr geschaffen werden (212f.). ${ }^{55}$

54 Diese These findet sich dann auch in der noch zu besprechenden Wagner-Schrift „Die Wibelungen“.

55 Dieser Hinweis auf die „liegende“ Kommunalgarde hat Wagner nicht viele Freunde eingebracht. 
Moderne Interpreten drücken meist ihr Unbehagen über diese Konzeption einer „republikanischen Monarchie "56 aus. Doch hat Wagner damit eigentlich nur eines der "Grundgesetze des Deutschen Vaterlandsvereins" vom 24. April 1848 angesprochen. Neben den Zielen (Freiheit, Gleichheit, Wohlstand), den dazu erforderlichen Mitteln (Bildung, Liebe und Begeisterung für das deutsche Vaterland) und dem obersten Grundsatz („der verfassungsmäßig ausgesprochene Wille des deutschen Volkes ist das höchste Gesetz“) wurde für Sachsen ausdrücklich bestimmt: „Beibehaltung und zeitgemäße Fortbildung der constitutionellen Monarchie als Vertreterin und Vollzieherin des Volkswillens“. Hugo Dinger hat in seiner ausführlichen Besprechung der Rede auf die zahlreichen übereinstimmenden Belegstellen in zeitgenössischen Schriften hingewiesen. ${ }^{57}$ Deshalb ist auch verständlich, warum der Vortrag mit „,rauschendem Beifall“ aufgenommen wurde, wie der Diaconus Pfeilschmidt - der nach Wagner sprach - berichtete. ${ }^{58}$ Wagner wollte mit seiner Rede - wie er brieflich am 14. Juni 1848 (also am nächsten Tag) seinem Freund Eduard Devrient (Mitglied des Deutschen Vereins) und dem Buchhändler Eduard Avenarius (der ebenfalls für eine „monarchische Republik “ eingetreten war) mitteilte - zu einer Versöhnung der Vaterlandsvereine und der Deutschen Vereine beitragen. Erst in der Hauptversammlung der Abgeordneten aller sächsischen Vaterlandsvereine am 3. und 4. September 1848 wurde die Streichung dieses letzten Satzes beschlossen. Dazu findet sich ein Bericht in Röckels „Volksblättern“ vom 23. September 1848 , der von dem „Glaubensbekenntnis“ der Vaterlandsvereine spricht. Als Grund für die beschlossene Streichung dieses Satzes wurde in diesem anonymen (wohl von Röckel selbst stammenden) Artikel der hauptsächliche Grundsatz dieses Glaubensbekenntnisses angegeben: „der verfassungsmäßig ausgesprochene Wille des Volks ist das höchste Gesetz"; und deshalb könne nicht der Vaterlandsverein, sondern nur das Volk selbst entscheiden, ob es für Republik oder Monarchie sei. ${ }^{59}$

56 So Dinger. Entwickelung (wie Anm. 9), S. 143.

57 Vgl. Dinger, Entwickelung (wie Anm. 9), S. 104ff.

58 So Dinger. Entwickelung (wie Anm. 9), S. 148.

59 Vgl. Anonym. Die Vaterlandsvereine und ihr Glaubensbekenntnis. In: Volksblätter 23. September 1848, Nr. 5. 


\subsection{2. „Die Wibelungen. Weltgeschichte aus der Sage“(1848/49)}

Freilich ist anzumerken, dass Wagner in diesem emphatischen Konzept des republikanischen Königs auf die romantische Staatstheorie des Volkskönigs zurückgriff. Man denke an die Schrift „Glauben und Liebe oder Der König und die Königin“ (1798) des Novalis, der schrieb: „Der ächte König wird Republik, die ächte Republik König sein“, oder an Achim von Arnim, der den "ganz revolutionär" gesinnten Herrscher daran erkennen wollte, dass „die Stimme des Volkes" in seiner „eigenen Brust" erklinge. ${ }^{60}$

Kurz nach dieser Rede vom 14. Juni 1848, nämlich im Spätsommer dieses Jahres, führte Wagner in seiner seltsamen, meist nicht berücksichtigten ${ }^{61}$ Schrift „Die Wibelungen. Weltgeschichte aus der Sage“ ${ }^{\text {"62 }}$ diese Konzeption des „Urkönigthums" weiter aus, bewusst nicht methodisch als Wissenschaft (für die „historisch-juristische Kritik“), sondern geschrieben (nur) für seine „Freunde" ${ }^{{ }^{63}}$; und zwar im Zusammenhang mit einem Drama über „Fried-

60 Vgl. Borchmeyer. Götter (wie Anm. 12), S. 43 Fn. 8; v. Graevenitz. Mythos (wie Anm. 21), S. 269; Kröplin. Musik aus Licht (wie Anm. 12), I, S. 174f. Vgl. auch Herfried Münkler. Politische Romantik. Der Fall Richard Wagner. In: Zukunftsbilder (wie Anm. 4), S. 47-60, 52ff.

61 In die Jubiläumsausgabe nahm Borchmeyer diese als „zähe ideologisch-spekulativ“ bezeichnete Schrift aus Gründen des „intellektuellen Niveaus“ nicht auf, stellte sie aber im Nachwort ausführlich dar (vgl. Borchmeyer. Nachwort. In: Wagner, Dichtungen (wie Anm. 1), X, S. 185, 244ff.). 1995 bedauerte Borchmeyer diese Lücke (vgl. Borchmeyer. Wagners Mythos vom Anfang und Ende der Welt. In: Richard Wagners „Der Ring des Nibelungen“. Ansichten eines Mythos. Hg. Udo Bermbach/Borchmeyer. Stuttgart. Metzler 1995, S. 1-25, 10), 2002 stand für ihn die Schrift im Mittelpunkt der Mythentheorie Wagners (vgl. Borchmeyer, Ahasvers Wandlungen (wie Anm. 12), S. 279ff., 290ff.). Dazu vgl. auch Dieter Borchmeyer. Was ist Deutsch? Die Suche einer Nation nach sich selbst. Berlin. Rowohlt 2017, S. 298ff. - Es fehlt auch ein diesbezüglicher Artikel im umfangreichen „Wagner Lexikon“ (wie Anm. 11)). Zur Ehrenrettung dieser Schrift vgl. Petra-Hildegard Wilberg. Richard Wagners mythische Welt. Freiburg. Rombach 1996.

62 Das Manuskript wurde von Wagner in Zürich Anfang September 1849 noch überarbeitet. Die dann veröffentlichte Fassung ist abgedruckt in Richard Wagner. Gesammelte Schriften und Dichtungen. Bd.II. Leipzig. E.W. Fritzsch ${ }^{2} 1887$, S. $115 \mathrm{ff}$.

63 So Wagner in seiner Schrift „Eine Mittheilung an meine Freunde“, Abgedruckt in: Wagner, Dichtungen (wie Anm. 1), VI, S. 292. 
rich Rothbart" (also den Stauferherrscher Friedrich I. Barbarossa), das er als Skizze am 31. Oktober 1846 fertiggestellt, dann liegen gelassen hatte und nun 1848, dann noch im Frühjahr $1849^{64}$ in Konkurrenz mit dem Nibelungensagehelden Siegfried neu zu bearbeiten überlegte.

Im Einzelnen ist weder auf diese Skizze ${ }^{65}$ noch auf die „Wibelungen“ einzugehen $^{66}$, nur anzumerken, dass Wagner in dieser „Weltgeschichte aus der Sage“ von einem "Urkönigthum“ bei den europäischen Völkern ausging, dessen Idee in deren asiatischer Urheimat entstanden sei: als Ausdruck des „Von den Göttern entsprossenen“ Stammvaters. Wagner zog dann eine aus der Religion und Sage gespeiste Reihe von königlichen Nachfolgern, die in Friedrich I. endete. Seine Zusammenfassung: „Im deutschen Volke hat sich das älteste urberechtigte Königsgeschlecht der Welt erhalten: es stammt von einem Sohne Gottes her, der seinem nächsten Geschlechte selbst Siegfried, den übrigen Völkern der Erde aber Christus heißt; dieser hat für das Heil und Glück seines Geschlechtes, und der aus ihm entsprossenen Völker der Erde, die herrlichste That vollbracht [Drachenkampf, WS], und um dieser That willen auch den Tod erlitten. Die nächsten Erben seiner That und der durch sie gewonnenen Macht (den Hort, WS] sind die ,Nibelungen', denen im Namen und zum Glücke aller Völker die Welt gehört. Die Deutschen sind das älteste Volk, ihr blutsverwandter König ist ein ,Nibelung', und an ihrer Spitze hat dieser die Weltherrschaft zu behaupten“. Doch habe Friedrich I. - der Nachfolger des Siegfrieds, mythisch mit ihm identisch - erkannt, dass der Hort seinen geistigen Gehalt als Gral erhalten habe, in seiner realen Existenz aber zu bloßem Besitz und Eigentum geworden sei. Er sei zur Rettung des Grales in den Orient aufgebrochen und niemals wiedergekehrt;

64 So eine Notiz im Tagebuch des Theaterdirektors Eduard Devrient vom 22. Februar 1849: „Zu Haus las Kapellmeister Wagner eine geschichtsphilosophische Arbeit vor, in der mit außerordentlich geistreicher und poetischer Kombination die erhabene Begeisterung für die Weltherrschaft aus den frühesten Sagenquellen entwickelte. Friedrich I. stieg als der gewaltigste Träger des ganzen Inhalts dieser Idee, von riesengroßer, wundervoller Schönheit auf. Er will ihn dramatisch behandeln“. Wagner erwähnt den Friedrich-Stoff noch in einem Brief an Theodor Uhlig vom 9. August 1849. - Bemerkenswert ist die positive Einschätzung der "Wibelungen“ durch den erfahrenen Devrient.

65 Abgedruckt in: Wagner, Dichtungen (wie Anm. 1), II, S. 211ff. - Dazu vgl. Borchmeyer, Deutsch (wie Anm. 61), S. 289, 303.

66 Dazu vgl. Wolfgang Schild. Staatsdämmerung. Berlin. Wissenschaftsverlag 2007, S. $11 \mathrm{ff}$. 
doch in der Volkssage sei er in einen alten Götterberg eingegangen, wo er nun sitze, zur Seite das scharfe Schwert, das einst den grimmigen Drachen erschlagen habe. In der Veröffentlichung im Jahr 1850 fügte Wagner hinzu: „Wann kommst du wieder, Friedrich, du herrlicher Siegfried! und schlägst den bösen, nagenden Wurm der Menschheit?" Also der mythische König als ersehnter Revolutionär!

Anzumerken ist noch, dass Wagner in den „Wibelungen“ eine junghegelianische Religionskritik vertrat. Die Götter - so seine These - seien die Personifikationen von beeindruckenden und für wesentlich gehaltenen Natureindrücken (so Siegfried wie Apollon, wie auch Christus der Lichtund Sonnengott; so Wuotan wie Zeus, wie auch der christliche Gottvater der Inbegriff der ewigen Bewegung des Lebens). Deutlich wurde dies auch in einem Brief an Ferdinand Heine vom 4. Dezember 1849: „Zu allen Zeiten ist den Menschen Gott das gewesen, was sie gemeinsam als das Höchste erkannten, das stärkste gemeinsame Gefühl, die mächtigste gemeinsame Anschauung, die wir Menschen - weil wir doch immer alles nur wieder nach menschlichem Wesen uns denken können - personifiziert als Gott uns darstellen“; Gott sei der „Begriff der menschlichen Gemeinsamkeit von ihrem echten, wirklichen Wesen, in Wahrheit aus dem Leben heraus gewonnen“, „ein dem allgemeinen rein menschlichen Wesen Entsprechendes, aus der wahren menschlichen Natur Hervorgegangenes“.

\subsection{3. „Siegfried's Tod“(Oktober 1848)}

Diese „Wibelungen“-Schrift zeigte die mythische Identität von Friedrich I. und Siegfried auf, weshalb Wagner sich nun für die zweite Gestalt und damit für den „Nibelungen-Mythus“ - den er am 4. Oktober 1848 als Entwurf für ein Drama niederschrieb - entschied. Am 20. Oktober 1848 war die Dichtung „Siegfried's Tod“ abgeschlossen. Auch hier fand sich diese Hochwertung des König(tum)s, nun in der Gestalt des Allvaters Wotan. Das Ende ist nicht - wie in der "Götterdämmerung “ - dessen Vernichtung in dem Weltenbrand, sondern die Stärkung und Sicherung der Götterherrschaft: Brünnhilde geleitet den toten Siegfried hinauf nach Walhall: „Nur einer herrsche, Allvater, herrlicher, du! Daß ewig deine Macht sei, führ' ich dir diesen [Siegfried, WS] zu: empfange ihn wohl, er ist des wert!“

Die Zurückstufung der Götter oder des/eines Gottes (in den „Wibelungen“) findet sich auch im Nibelungen-Mythus, wo Wagner schrieb: 
In dem Menschen ersehen die Götter die Fähigkeit zu [einem unabhängigen, freien Willen, WS]. In den Menschen suchen sie also ihre Göttlichkeit überzutragen [...] Ihre Absicht würde erreicht sein, wenn sie in dieser Menschenschöpfung sich selbst vernichteten, nämlich in der Freiheit des menschlichen Bewußtseins ihres unmittelbaren Einflusses sich selbst begeben müßten. ${ }^{67}$

\subsection{4. "Jesus von Nazareth“(1849)}

Es ist bemerkenswert, wie stark Wagner in dieser revolutionsschwangeren Zeit mit unterschiedlichen Projekten beschäftigt war; wie etwa im Frühjahr 1849, als er den Entwurf zu einer fünfaktigen Oper niederschrieb, die das Leben des "Jesus von Nazareth“ - so der Titel ${ }^{68}$ - behandeln sollte. In Abgrenzung zu der Christus-Gestalt in der religiös-theologischen christlichen Überlieferung (also zu dem „symbolischen Christus“) wird der historische Jesus in einigen Szenen bis zur Verurteilung und Abführung zur Kreuzigung dargestellt, sicherlich beeinflusst von dem „Leben Jesu“ des Junghegelianers David Friedrich Strauß (1835) und dem „Evangelium eines armen Sünders"von Wilhelm Weitling (1845).

Manche interpretieren diesen Jesus als „Sozialrevolutionär“" ${ }^{\text {69 }}$. Doch zeigt Martin Geck zu Recht ${ }^{70}$, dass dies an der Sache vorbeigeht. Zwar zeichnet Wagner einen Jesus, der sich gegen den Zwang des Gesetzes und für das absolute Liebesgebot starkmacht und sich mit den Machtlosen gegen die Besitzenden verbündet; auch gilt für ihn ebenso wie für die Göttersprosse

67 Vgl. die Darstellung bei Schild. Staatsdämmerung (wie Anm. 66), S. 22ff. - In der Skizze eines Dramas „Achilleus“, die Wagner während des Mai-Aufstandes 1849 erdachte (abgedruckt in: Wagner, Dichtungen [wie Anm. 1], II, S. 273), heißt es: „Der Mensch ist die Vervollkommnung Gottes [...] Achilleus ist höher und vollendeter als die elementare Thetis."

68 Abgedruckt in: Wagner, Dichtungen (wie Anm. 1), II, S. 214ff. Dazu vgl. Ulrich Frey. „Jesus von Nazareth (WWV 80)“. In: Wagner-Lexikon (wie Anm. 11), S. 342-345; Peter Hofmann. Richard Wagners politische Theologie. Kunst wider Revolution und Religion. Paderborn. Ferdinand Schöningh 2003, S. 132ff.; Schild. Staatsdämmerung (wie Anm. 66), S. 39ff.

69 Vgl. Alan David Aberbach. The Ideas of Richard Wagner. Lanham. University Press of America 2003, S. 209; Martin Gregor-Dellin. Richard Wagner. Sein Leben, sein Werk, sein Jahrhundert. München/Zürich. Piper 1980, S. 254.

70 Vgl. Geck. Wagner (wie Anm. 34), S. 142 f. 
Siegfried und Achilleus, dass der Mensch "die vervollkommnung Gottes“ ist. Doch Wagners Jesus ist - wiederum Geck - eine spirituelle Erscheinung und (gemeinsam mit Apollon) einer der beiden „erhabensten Lehrer der Menschheit", auch bzw. nur deshalb, weil er sich für die Menschheit opferte, litt und starb: denn der Tod ist das „letzte Aufgehen in das Gesammtleben“ und damit „die letzte und bestimmteste Aufhebung des Egoismus“. Wagner versteht - so Geck abschließend - sowohl „Siegfried's Tod“ als auch „Jesus von Nazareth“ als „Heldenfeier“, als Ankündigung des gewünschten und gewollten Menschen der Zukunft im Drama - einem Drama, das sich nach seinen Vorstellungen maßgeblich am kultischen Charakter der attischen Tragödie orientiert. Es sei daher nicht verwunderlich, dass Bakunin für diesen Dramaentwurf nur Spott übrig hatte.

Interessant ist der zweite Teil dieses Fragmentes, in dem Wagner in einzelnen Bruchstücken zu den Themenbereichen Gesetz, Liebe, Eigentum, Ehe, Tod und „das Weib“ Stellung bezog. In unserem Zusammenhang ist die Gegenüberstellung des äußerlich gegebenen Gesetzes, das die menschliche Natur abtötet, die Lieblosigkeit verkörpert und das von Wagner als das Gesetz des Eigentums/der Herrschaft/der Macht umschrieben wird, und des Gesetzes des lebendig machenden heiligen Geistes wichtig: „Dies Gesetz aber ist die Liebe [...] Gott aber ist die Liebe, und durch die Liebe sandte er euch seinen Sohn; dessen Brüder sind alle Menschen und ihm gleich durch die Liebe“. "Jede Kreatur liebt, und die Liebe ist das Gesetz des Lebens für alles Erschaffene“ (230). Dabei gibt es eine Stufenleiter der Liebe: beginnend von der noch stark egoistischen Geschlechtsliebe über die Freundesund Vaterlandsliebe bis hin zur allgemeinen Menschenliebe $(245 \mathrm{ff} \text {. })^{71}$, in der der Egoismus aufgehoben ist in das Allgemeine, in der höchsten Form im Sterben für die Menschheit, durch die die Individualität vollendet und das Individuum Gott selbst wird. „Egoismus ist Nehmen oder Empfangen - die Entäußerung desselben in der Liebe ist Geben und Mitteilen“ (248).

Durch diese Überlegungen war es Wagner möglich, die Kritik an den bestehenden sozialen Verhältnissen mit dem Gesetz des Eigentums in Verbindung zu bringen und als mögliche Lösung auf das kommende Gesetz der Liebe abzustellen, durch das der Egoismus aufgehoben werde in der Hingabe und Mitteilung an das Allgemeine. Jedenfalls veränderte Wagner sein Nibelungendrama: hatte er zunächst auf das „Unrecht“ abgestellt, das in der

71 Wiederholt in der Schrift „Kunst und Klima“ (1850), abgedruckt in: Wagner. Schriften (wie Anm. 62), III, S. 218. 
Herrschaft des Ringes über das Volk der Nibelungen (erst durch Alberich durch die Schaffung des Ringes, dann durch die Götter und auch Siegfried durch die Nichtrückgabe des Ringes) besteht und erst durch die Rückgabe des Rings durch Brünnhilde aufgehoben wird, trat der Gegensatz zwischen Herrschaft und Liebe in den Vordergrund (worauf hier nicht näher eingegangen werden kann).

\subsubsection{Zum Problem des „Kommunismus“}

Zurück zur Rede vom 14. Juni 1848! In einem Absatz bezog Wagner kurz Stellung zu dem damals vieldiskutierten Problem, ob nämlich seine Konzeption als Lehre des „Kommunismus“ aufzufassen sei, was er heftig zurückwies. ${ }^{72}$ Denn er verstand darunter die "Lehre der mathematisch gleichen Verteilung des Gutes und [des] Erwerbes“, die er als „abgeschmackteste und sinnloseste Lehre“ erklärte (214). Ihm gehe es stattdessen um die „notwendige Erlösung des Menschengeschlechts von der plumpesten und entsittlichendsten Knechtschaft gemeinster Materie“ (214).

Doch in späteren Schriften verwendete Wagner auch unter dem Einfluss Feuerbachs, dessen Werke er in Zürich im Exil zu lesen begann, dessen Thesen er aber sicher auch schon früher aus den Gesprächen mit Röckel kannte $^{73}$, den Begriff „Kommunismus“ als Gegenbegriff zum „Egoismus“74, weshalb er sich konsequent dann als Kommunist bezeichnete (allerdings im 1872 geschriebenen Vorwort zum 3. und 4. Band seiner „Sämtlichen Schriften und Dichtungen“ diese Terminologie klarstellte, um Missverständnisse zu vermeiden). ${ }^{75}$ Konsequent wurde das Gesetz der Liebe (als die Aufhebung des Egoismus durch dessen Vollendung) als „kommunistisch“ aufgefasst.

72 Oben wurde der Beitrag zu diesem Thema von Bakunin - gleichfalls mit negativem Ergebnis, aber mit einer anderen Argumentation - skizziert.

73 So Heyne. Wagner (wie Anm. 37), S. 271.

74 So in: Wagner. Dichtungen (wie Anm. 1), V, S. 244, 259; VI, S. 18, 25, 35, 37, 39, 109, 109 Anm. Auch in der „Mittheilung an meine Freunde“ (1852), abgedruckt in: Wagner. Dichtungen (wie Anm. 1), VI, S. $219 f$.

75 Abgedruckt in: Wagner. Dichtungen (wie Anm. 1), VI, S. 192-199, 196. Zum Problem vgl. Kröplin. Wagner und der Kommunismus (wie Anm. 4), S. $176 f f$. 


\subsection{Die Beiträge in den "Volksblättern“}

Die Beiträge in den von Röckel seit dem 26. August 1848 herausgegebenen „Volksblättern“ („unter Mitwirkung des Vaterlands-Vereines“) waren im Regelfall anonym, weshalb es nicht leicht ist, die von Wagner verfassten Aufsätze auszulesen. Wagner selbst hat keinen Beitrag aus dieser Zeitschrift in seine Gesamtausgabe aufgenommen.

So war es Hugo Dinger, der in seiner 1892 erschienenen Arbeit erstmals zwei Zuordnungen behauptete. Völlig eindeutig war für ihn Wagners Autorenschaft für den Beitrag „Die Revolution“ (8. April 1849), wobei er sich auf eine Mitteilung eines Zeitgenossen und auf die Eigentümlichkeit von Form und Inhalt des Aufsatzes selbst berief. ${ }^{76}$ Da dieser Zeitgenosse von „Aufsätzen“ Wagners im Plural sprach, ordnete Dinger auch den Beitrag „Der Mensch und die bestehende Gesellschaft“ (10. Februar 1849) mit "Wahrscheinlichkeit" Wagner zu. ${ }^{77}$ Schließlich wies Dinger auf einige Passagen in dem Artikel „Deutschland und seine Fürsten“ (15. Oktober 1848) hin mit den Worten „Klingt das nicht ganz wie - Wagner?" ${ }^{\text {"78 }}$ Richard Sternfeld griff im ergänzenden 12. Band der 1911 erscheinenden Volksausgabe der Wagnerschen „Sämtliche Schriften und Dichtungen“ auf Dinger (und auf den diesem zustimmenden Glasenapp) zurück, nahm deshalb auch diesen zuletzt genannten Artikel (allerdings nur) als Anhang auf. Die WagnerLiteratur folgte diesen Zuordnungen. Doch behauptete 1983 Jörg Heyne aufgrund intensiver Untersuchungen des Röckel-Nachlasses, dass der Autor dieses Beitrags vom 15. Oktober 1849 nicht Wagner, sondern Röckel sei. ${ }^{79}$ Darüber hinaus schrieb Eckart Kröplin Wagner einen weiteren Beitrag zu, nämlich den am 9. September 1848 veröffentlichten Artikel „Was ist Communismus?" ${ }^{30}$ - Im Folgenden soll auf alle (nun) vier Beiträge eingegangen werden, deshalb mit dem zuletzt angesprochenen, weil zeitlich frühesten begonnen werden.

76 So Dinger. Entwickelung (wie Anm. 9), S. 233ff.

77 So Dinger. Entwickelung (wie Anm. 9), S. 248ff.

78 So Dinger Entwickelung (wie Anm. 9), S. 128 Fn. 1.

79 Vgl. Jörg Heyne. Zur Autorschaft eines Wagner zuerkannten Aufsatzes. In: Musik und Gesellschaft 1983, S. 96-98.

80 Nämlich von: Kröplin. Wagner und der Kommunismus (wie Anm. 4), S. 61ff. In seiner "Wagner-Chronik“ (wie Anm. 8) meint Kröplin, dass die Autorschaft Wagners „mit ziemlicher Sicherheit“ feststehe. Ähnlich Kröplin. Musik aus Licht (wie Anm. 12), II, S. 576. 


\subsection{1. „Was ist Communismus?"(9. September 1848)}

In den „Volksblättern“ vom 9. September 1848 wurde in einem anonymen Artikel unter der Überschrift „Was ist Communismus?“ zu dieser Frage Stellung bezogen und deutlich gemacht, dass dessen Grundsatz laute, dass „alle Menschen, eben weil sie Menschen sind, gleich [sind] und gleiches Recht an Allem, was den Menschen beglücken kann, [haben]"; doch würden sie dabei übersehen, dass die Menschen „nur in der allgemeinsten Körperform sich ähnlich, keineswegs aber sich gleich sind“. Freilich wären die Menschen dann tatsächlich gleich und hätten ein gleiches Recht auf Alles, wenn sie zu ihrem Glück nur allein das, was frei, ohne ihr Zutun in der Natur vorhanden ist, bedürften; das sei aber nicht der Fall: „Der Menschen Bedürfnisse können vielmehr nur allein durch der Menschen Thätigkeit befriedigt werden“, durch seine Arbeit.

Des Menschen Arbeit aber ist ein Theil von ihm selbst, ist sein heiligstes Eigenthum, und Niemand außer ihm selbst, hat ein Recht daran. Es kann daher auch Jeder nur auf so viel Genuß Anspruch machen, als er sich durch seine eigne Arbeit verschafft, wollte er mehr genießen, so würde nothwendiger Weise dadurch ein Anderer der Früchte seines Fleißes beraubt werden müssen.

Daraus zog der anonyme Autor die Konsequenz:

daß der Communismus ungerecht ist, indem er den Thätigen beraubt zu Gunsten des Trägen [...], daß folglich der Communismus nicht der Menschen Glück, sondern der Menschen Unglück nach sich ziehen muß. Wir haben uns aber auch überzeugt, daß der Communismus unmöglich ist. ${ }^{81}$

Hinzuweisen ist auf das Bemühen des Verfassers, auch Kommunisten als ehrliche Menschen zu charakterisieren, die der „reinen Christuslehre“ folgen und entgegen dem „Pfaffen“-Christentum die Überzeugung vertreten würden, dass

wir eigentlich auf der Welt [sind], nicht um unglücklich, sondern um glücklich zu sein, daß nur deßhalb Gott die Welt so schön, so reich, und uns Menschen so

81 So Anonym. Was ist Communismus? In: Volksblätter 9. September 1848, Nr. 3, S. 1 ff. Abgedruckt in: Kröplin. Wagner und der Kommunismus (wie Anm. 4), S. $243 \mathrm{ff}$. 
empfänglich, so genußsüchtig gemacht [hat]; daß er uns den Verstand gegeben [hat], nicht um ihn zu ertödten, wie die Pfaffen sagten, sondern ihn zu entwickeln und zu vervollkommnen, auf daß wir durch den Geist wieder neue, höhere Genüsse erlangen sollten. Und als sich endlich diese Ueberzeugung weiter und weiter verbreitete, als man allgemeiner und klarer einsah, daß es unsre Aufgabe sei, immer besser und edler, immer reicher an Genüssen und Freuden, kurz, immer glücklicher zu werden, da erkannte man denn auch zugleich, daß unser Zustand ein durchaus falscher, verkehrter und sündhafter sei, weil, statt alle Menschen glücklich zu machen, wie sie das Recht haben, es zu sein, er nur sehr Wenigen das Glück bietet, die Meisten aber im tiefsten geistigen und körperlichen Elende verschmachten läßt [...] So kamen denn endlich alle ehrlichen Männer, die denken können, zu der Ueberzeugung, daß unser jetziger Zustand mit seinem tiefen Elende und den daraus entspringenden vielen Lastern unmöglich länger so fortdauern dürfe, und daß er durchaus umgestaltet werden müsse.

Doch - wie gezeigt - sei der Kommunismus nicht der richtige Weg dieser erforderlichen Umgestaltung.

In diesen Zeilen ist viel „Revolutionswagner“ enthalten: die Unterscheidung der „reinen Christuslehre“ vom Pfaffenchristentum (also dem kirchlich institutionalisierten Christentum, das das Elend der Welt als gottgewollte Prüfung betrachtet), der Bezug des Rechts des Menschen - hier hätten wir sogar ein viertes Zitat! - auf das größtmögliche Glück, das durchaus sinnlich-genussreich konzipiert ist; und daraus folgend die sozialkritische Diagnose des gegenwärtigen sozialen Zustandes des Elend der Mehrheit der Menschen. Manches wird uns noch in späteren Schriften begegnen. Aber zugleich ist dies die Lehre der französischen Sozialisten und der linken Junghegelianer, die August Röckel - den Herausgeber der „Volksblätter“ - begeisterte, die dieser übernahm und sie in vielen Gesprächen an Wagner weitergab. Es ist daher durchaus möglich, den Verfasser dieses Beitrags auch in Röckel zu sehen (so wie es die bisher herrschende Meinung getan hat). Derzeit steht die Zuschreibung der Autorschaft an Wagner durch Kröplin ${ }^{82}$ allein. Auf das spätere „Kommunismus“-Verständnis Wagners (nämlich darin den Gegensatz zum „Egoismus“ zu sehen) wurde unter 2.3.5. schon hingewiesen.

82 In: Kröplin. Wagner und der Kommunismus (wie Anm. 4), S. $61 \mathrm{ff}$. 


\subsection{2. „Deutschland und seine Fürsten“(15. Oktober 1848)}

Schon der Titel zeigt, dass es um die Stellung der Adeligen geht; nach dem bisher (schon in der Rede vom 14. Juni 1848) Ausgeführten in gleichfalls aggressiv-revolutionärer Weise. Im Folgenden werden die Seitenzahlen des gedruckten Textes ${ }^{83}$ angegeben.

Gefragt wird: „wenn die Natur Überfluß bietet, warum muß der Mensch Mangel leiden?" (223), wobei unter „Mensch“ offensichtlich die Nicht-Adeligen verstanden werden, nämlich die Bauern, die Fabrikarbeiter, die Stadtbürger, also die „Schaffenden aller Arten“, aber auch die „unglücklichen, verachteten Mädchen“, die ihre Tugend der Not opfern müssen. Die Lösung liegt für den Autor auf der Hand: „Es ist keine von Gott gebotene Notwendigkeit, es ist eine von Menschen verschuldete Ungerechtigkeit“ (224), nämlich von den Fürsten, die eigentlich von Gott zu Leitern des Geschicks der Völker bestimmt sind. Sie geben der Arbeit der Schaffenden nicht den Lohn, der ihnen entspricht (224). Es wäre aber ihre von Gott gegebene Pflicht, die Not und das Leiden zu beseitigen. „Vergebens schützt ihr Unwissenheit vor, ihr waret gewarnt und ermahnt!“ (224) Denn „euch [ward] längst gesagt: das Land gehört dem Volke und das Volk gehört sich selbst; der Mensch hat nur Gott über sich". Doch der Adel beruft sich auf die Verdienste seiner Ahnen vor soundso viel hundert Jahren und gründet darauf seine Vorrechte. Doch: „das Vorrecht ist ein Unrecht; das Vorrecht ist ein Betrug am Rechte; soll das Recht gelten, so darf kein Vorrecht sein [...] Eure [d.h.: des Adels, WS] Vorrechte sind eine Verletzung des Rechtes" (225).

Der Autor warnt:

Erwacht! Die elfte Stunde hat geschlagen, und wahrlich, wir brauchen keinen Daniel, um uns die Zeichen zu erklären, die an euren Palästen prangen! [...] Vergeßt, was ihr gewesen, die Zeit kehrt nimmer wieder. Sühnt, was ihr gefehlt, noch ist Gelegenheit dazu geboten, noch liegt es in eurer Macht, das Gute zu tun, das Schlechte zu meiden; ergebt euch willig dem Geschick, das über euch, über uns allen waltet. - Blickt um euch, seht, was ist, erkennt, was ihr seid. [...] Nicht vermochtet ihr zu befolgen, zu erfüllen die Mahnungen der Menschen, und ihr wähnt Kraft zu besitzen, an die Stelle Gottes, des Schicksals zu treten, das Rad der Zeit, welches über eure Sitze dahinrollt, aufzuhalten? O laßt das ohnmächtige, fruchtlose Widerstreben! (227)

83 Abgedruckt in: Wagner. Dichtungen (wie Anm. 1), V, S. 222ff. 
Der Autor richtet sich also an die Mitglieder des Adels selbst und unmittelbar. Sie müssen ihr Unrecht erkennen und daher von diesem als von ihrem Vorrecht lassen, gleichberechtigt zu allen anderen werden. Eigentlich haben sie keine Wahl: denn Gottes Wille, gleichgesetzt mit dem Schicksal (und dem „Rad der Zeit“) wird das gleiche Recht aller Menschen verwirklichen, wobei diese religiöse Sprache nach der grundlegenden Kritik in den „Wibelungen“ auf die oben hingewiesen ist - nicht zu ernst genommen werden darf. Es geht nicht mehr um Religion, sondern: was bleibt, ist nur die willentliche Annahme dieses Geschicks; und damit: die „Selbstvernichtung“ (als Adel).

Der Autor greift auf ein „kleines Bild“ zurück, das „uns Gott offenbart“ hat über das Leben der Völker und der Fürsten (227): nämlich die Raupe. Sie kriecht auf der Erde, nur ausgerichtet nach Nahrung; ihr wässriger Körper wird durch die Haut zusammengehalten; ebenso wie „der Völker erste[s] Alter" durch das Fürstentum. Dann (im Winter) wird die Haut fest und hart, der Körper scheinbar leblos. Doch bereitet sich in seinem Inneren ein neues, höheres Leben vor. Dann kommt der Frühling, der den Zusammenhang zwischen der zur trocknen, marklosen Schale gewordenen Haut und dem inneren Körper auföst. Die Haut springt auf, bricht in Staub zusammen, hat ihre Aufgabe gelöst, ist „gewesen “; und „der Schmetterling schwebt empor in die blauen Lüfte, ein Zeugnis der Allmacht Gottes, ein Gleichnis unsrer Zeit" (227f.).

Das Schicksal (als Gottes Wille und als Rad der Zeit) gleicht also einem Naturvorgang, der Entstehung des Schmetterlings durch Zerfall der Raupe, die vergeht („gewesen“ ist), um der neuen wunderbaren Schöpfung Existenz zu geben. Das Geschick der Haut - also des Adels, der in früheren Zeiten die gottgewollte Aufgabe hatte, den Körper des Volkes zu schützen und zu formen - ist es, in diesem natürlichen Prozess des Werdens und Vergehens den letzteren Weg zu gehen. Die „Aufgabe [der Haut ist] die allmähliche Selbstvernichtung“ (227), was meint: der Adel muss - wenn er dieses Geschick erkannt hat - selbst auf seine Vorrechte verzichten und sich in die Gesellschaft der Gleichen einordnen. Die Adeligen müssen also Menschen werden wie alle anderen auch: in Freiheit, Gleichheit und Brüderlichkeit. „Vernichtung" meint also die Vernichtung der Vorrechte zugunsten der gleichberechtigten Stellung aller, nicht die leibliche Vernichtung als Menschen (im Sinne des Getötetwerdens durch revolutionäre Gewalt). ${ }^{84}$

84 In ebendiesem Sinne verwendete Wagner den Begriff der "Selbstvernichtung“ für die Juden, bereits in seiner zunächst anonym, dann unter dem Pseudonym 


\subsection{3. „Der Mensch und die bestehende Gesellschaft“ (10. Februar 1849)}

Der Autor dieses Beitrages - wobei im Folgenden wieder die Seitenzahlen der Druckfassung angegeben sind ${ }^{85}$ - beginnt mit einem Hinweis auf das „,vorige Blatt“ der „Volksblätter“, in dem nachgewiesen sei, dass der Kampf des Menschen gegen die bestehende Gesellschaft im Jahre 1848 bereits begonnen hat. Gemeint ist der Artikel „Unsere Gesellschaft“ vom 3. Februar 1849, in dem ein anonymer Autor auf das Problem der Volksbildung (Volksschulen) eingegangen und zum Ergebnis gekommen war, dass trotz aller gegenteiligen Bemühungen der Kirche und des Staates, Bildung zu verhindern, das Volk „zum Bewußtsein seiner Menschenwürde, zur Erkenntnis seiner Aufgabe“, zur „Erkenntnis dessen, was Recht ist“, zum „Bewußtsein unseres Werthes“ gekommen sei und damit das „Menschwerden der in thierischer Stumpfheit herumwandelnden Brüder“ begonnen habe. „Das Schlechte muß verderben, und wer sich seinem Dienste weiht, theilt sein Loos; das ist das ewige Gesetz der Welt“. Dem Verfasser war klar geworden, dass nicht mehr einzelne Gruppen (Christ, Jude, Türke, Fürst, Bauer, Deutscher, Reicher, Armer) kämpfen würden, sondern die Menschen als solche gegen die Gesellschaft. Es gehe um die Auflösung der bisherigen gesellschaftlichen Bande, darum, „eine neue Grundlage zu finden, welche Allen das Glück zu bieten vermag, auf welches sie Anspruch zu machen berechtigt sind, weil sie Menschen sind“. Ein gewaltiger Ruf widerhalle überall: ,ich bin ein Mensch, und der Menschheit gebührt die Herrschaft!" Denn der Mensch sei das Höchste auf Erden, erkenne keinen höheren Zweck „als sich selbst und sein Glück, durch immer höhere Vervollkommnung seiner geistigen und körperlichen Fähigkeiten“. Zum Abschluss hatte der Verfasser angekündigt, in den nächsten „Volksblättern“

K. Freidank 1850 veröffentlichten Schrift „Das Judenthum in der Musik“. Es ist daher verfehlt, einen unmittelbaren Bezug zur den Vernichtungsaktionen des NS-Staates zu ziehen. Zu diesem Problem vgl. Dieter Borchmeyer. Richard Wagner und der Antisemitismus. In: Richard-Wagner-Handbuch (wie Anm. 9), S. 137-161; ders. Deutsch (wie Anm. 61) , S. 553ff.; Jens Malte Fischer. Richard Wagners „Das Judentum in der Musik“. Eine kritische Dokumentation als Beitrag zur Geschichte des Antisemitismus. Frankfurt a. M./Leipzig. Insel 2000; Manuela Jahrmärker. „Das Judenthum in der Musik“. In: Wagner-Lexikon (wie Anm. 11), S. 345-348; Rudolf Wellingsbach. Wagner und der Antisemitismus. In: Wagner Handbuch (wie Anm. 11), S. 96-101.

85 Abgedruckt in: Wagner. Dichtungen (wie Anm. 1), V, S. $229 f f$. 
ein möglichst deutliches Bild der gesellschaftlichen Zustände und ihrer Entwicklung bis zur heutigen Zeit vorzulegen, damit klar erkannt wird, was ist!

Dieser versprochene Artikel trägt nun diesen Titel: „Der Mensch und die bestehende Gesellschaft"; und stammt offensichtlich von demselben Verfasser des vorigen Beitrags. Daher ist der Kritik von Heyne zuzustimmen und August Röckel selbst als Autor beider Beiträge anzunehmen. Dagegen spricht nicht, dass sich zahlreiche ähnliche Formulierungen in späteren Schriften Wagners finden, auf die noch hinzuweisen ist. Es zeigt nur die enge geistige Verbundenheit von Wagner und Röckel, die in zahlreichen Gesprächen entwickelt und ausgebaut wurde. Die Konsequenz ist, dass das zweite Zitat - mit dem dieser Beitrag eröffnet wurde - nicht als von Wagner stammend anzuerkennen ist. Doch soll trotzdem kurz der Zusammenhang, in dem diese Umschreibung von „des Menschen Recht“ steht, gezeigt werden, da Wagner diesen Ausführungen sicher zugestimmt hätte (und wohl auch hat).

Die Argumentation verläuft einfach. Wenn die Aufgabe besteht, das mit Bewusstsein zu vollbringen, was die Zeit fordert, dann muss man die „wahre Bedeutung der Bewegung, in welcher wir leben" erkennen (230). Der Satz, dass der Mensch gegen die bestehende Gesellschaft kämpft, kann nun nur dann wahr sein, „wenn es erwiesen ist, daß unsre bestehende Gesellschaft gegen den Menschen ankämpft, daß die Ordnung der bestehenden Gesellschaft der Bestimmung, dem Rechte des Menschen feindlich gegenüber tritt" (230). Und daher finden sich die beiden inhaltlich fast identischen Sätze, die sowohl "des Menschen Bestimmung“ als auch "des Menschen Recht“ dahingehend beschreiben: „durch die immer höhere Vervollkommnung seiner geistigen, sittlichen und körperlichen Fähigkeiten zu immer höherem, reinerem Glücke [bzw.] zum Genusse eines stets wachsenden, reineren Glückes zu gelangen“. Bestimmung und Recht sind damit gleich; „das Recht des Menschen ist einfach: seine Bestimmung zu erreichen“" (230f.).

Der Verfasser stellt die Frage nach der für diese Vervollkommnung erforderlichen Kraft und sieht den Einzelnen dazu nicht in der Lage. Sie findet sich aber in der "Gesamtheit der Menschen“ (231), in deren Vereinigung, in der Gesellschaft. Der einzelne Mensch ist für sich nichts; nur als Teil des Ganzen kann er seine Bestimmung / sein Recht finden (232). Daher ist die Gesellschaft die notwendige Bedingung unseres Menschentums, was für den Autor bedeutet: die Menschen sind nicht nur berechtigt, sondern auch verpflichtet, an die Gesellschaft die Anforderung zu Ermöglichung ihrer Vervollkommnung zu stellen (232). Nun erkennen wir aber die Verworfenheit 
der bestehenden Gesellschaft, die „gewaltsam und oft vorsätzlich uns abhält, unsere Bestimmung, unser Recht, unser Glück zu erlangen“; und mit diesem Bewusstsein gewinnen wir auch die „Kraft, sie zu bekämpfen, sie zu besiegen“ (233). Der Beitrag endet optimistisch: „ist [das Wesen und das Wirken unserer bestehenden Gesellschaft, WS] einmal erkannt, dann ist sie auch gerichtet!" (233)

Die Ähnlichkeit zu der in dem Beitrag vom 15. Oktober 1848 behaupteten Selbstvernichtung des Adels in dem Bild der Raupe ist offensichtlich, erinnert auch an das in dem Artikel vom 3. Februar 1849 genannte „ewige Gesetz der Welt“, nämlich: „Das Schlechte muß verderben“. Bedarf es daher überhaupt eines revolutionären Kampfes? Und weiter: wie soll es eine (neue) Gesellschaft schaffen, diese Vervollkommnung aller zu ermöglichen? Darüber hinaus stellt sich die entscheidende Frage nach der argumentativen Begründung dieser „Bestimmung“ des Menschen zum Glücklichsein. Die Berufung auf den christlichen Gott (oder sonst eine Gottheit) ist dafür nicht (mehr) geeignet, wenn man die oben skizzierte Religionskritik in den „Wibelungen“ bedenkt. Später wird Wagner auf die „Natur“ des Menschen (als der Gattung) abstellen: aber auch dies - wie noch kurz angedeutet werden wird - ist keine zureichende Begründung. Schließlich ist die Gleichrichtung von „Bestimmung“ und „Recht“ zu hinterfragen. Müsste nicht die „Bestimmung“ eigentlich zu einer „Pflicht“ des Menschen werden, nämlich seine Bestimmung auch anzustreben, zu verwirklichen und zu vervollkommnen; und ebenso die Vervollkommnung der anderen in den gesellschaftlichen Zuständen zu fördern und herbeizuführen? Offen muss bleiben, wie diese Pflicht überhaupt erfüllt werden kann, wenn die Vervollkommnung doch in der Ausbildung der allgemeinen Menschenliebe liegt (wie Wagner es in "Jesus von Nazareth" vertreten hat), deren höchster Ausdruck das Sterben für die Allgemeinheit ist (nach dem Vorbild Jesu, aber auch des Siegfrieds bzw. der Brünnhilde in dem neuen Drama der Nibelungen).

\subsection{4. „Die Revolution“(8. April 1849)}

In der letzten der eigentlichen „Revolutionsschriften“- einem Artikel in den „Volksblättern“ vom 8. April 1849 - ging Wagner all diesen Fragen im Grunde aus dem Weg (wobei im Folgenden die Seitenangaben aus der Druckfassung $^{86}$ entnommen werden) Er hatte im März durch Vermittlung

86 Abgedruckt in: Wagner. Dichtungen (wie Anm. 1), V, S. $234 \mathrm{ff}$. 
von Röckel Michael Alexandrovic Bakunin kennengelernt, der nach Dresden kam $^{87}$, als „Dr. Schwarz“ in der Nachbarschaft der Wagners wohnte und dadurch in einen auch durchaus engen Kontakt mit dem Hofkapellmeister kam. Wagner war offensichtlich von diesem Mann, dessen oben vorgestellte Schriften er sicherlich durch die Gespräche mit Röckel kennengelernt hatte, fasziniert. Dessen revolutionäres Feuer griff auf ihn über.

\subsubsection{Exkurs: „Die Not“(1849)}

In dem Gedicht „Die Not“88 aus diesem Frühjahr 1849 wurde dies deutlich. "Jetzt kenn' ich nur noch einen Gott, / der Gott, er heißt - die Not“. Doch so viele würden diese nicht kennen, nur im Reichtum schwelgen oder Wissenschaft betreiben oder in philosophischen „Geistespfiffen“ (nach Kant und Hegel) träumen:

Nun sollen sie dein Antlitz sehen, / erhaben, nackt und bloß: / daß sie nicht mehr in Zweifel stehen, / zeig' ihnen jetzt ihr Los! [...] Ein langes, langes Menschenleiden / brennt heiß in unsrer Brust, / es sengt uns seit der Väter Zeiten, / verzehrt uns jede Lust: / daran lass' deine Fackel zünden / und ihren Schein den Schächern künden: / wir halten dein Gebot, / du strenge Gottheit, Not! / Die Fackel, ha! sie brenne helle, / sie brenne tief und breit, / zu Asche brenn' sie Statt und Stelle, / dem Mammonsdienst geweiht [...] Dann weiter brenne, immer weiter, / du heil'ger Feuerbrand! / Du furchtbar hehrer Gottesstreiter, / vernichte, was uns band!

Verbrannt sollten werden die Schuld- und Geldscheine, die Schriften der Denker, die Staatsmaschinerie - der Wagner am 22. März 1849 ein eigenes Gedicht widmete („An einen Staatsanwalt ${ }^{\text {“89 }}$ ), in dem der Staat („der absolute große Egoist“, „der steht und stemmt sich in die Steife“) als lebensvernichtend gebrandmarkt wurde -, denn:

87 Dazu vgl. Heinrich Butte. Über Michael Bakunins Dresdner Zeit. Dresden 1947; Hans-Karl Tannewitz. M. A. Bakunins publizistische Persönlichkeit, dargestellt an seiner politisch-journalistischen Arbeit 1849 in Dresden. Dissertation Freie Universität Berlin 1962.

88 Abgedruckt in: Wagner. Dichtungen (wie Anm. 1), V, S. $266 f f$.

89 Abgedruckt in: Wagner. Dichtungen (wie Anm. 1), V, S. $270 f f$. 
Der Menschheit wahre Gottgeschichte / erlebt nun Tag für Tag; / daß er ihr lebend Werk verrichte, / zeig' jeder, was er mag: / aus Büchern nicht und Dokumenten / empfangt ihr mehr des Todes Spenden; / das Leben sei eu'r Maß, / nicht was der Moder fraß! / Denn über allen Trümmerstätten / blüht auf des Lebens Glück: / es blieb die Menschheit, frei von Ketten, / und die Natur zurück / Natur und Mensch - ein Elemente! / vernichtet ist, was je sie trennte! / Der Freiheit Morgenrot - / entzündet hat's - die Not!

\subsubsection{Der Grußder Göttin Revolution}

In diesem Beitrag vom 8. April 1849 feierte Wagner - dessen Autorschaft seit Dinger unbestritten ist - „Die Revolution “90, wie der Titel verkündet. Allen Problemen aus dem Weg gehend, lässt Wagner das Subjekt der Revolution selbst auftreten: nämlich als „die erhabene Göttin Revolution“, die

dahergebraust [kommt] auf den Flügeln der Stürme, das hehre Haupt von Blitzen umstrahlt, das Schwert in der Rechten, die Fackel in der Linken, das Auge so finster, so strafend, so kalt, und doch, welche Glut der reinsten Liebe, welche Fülle des Glückes strahlt dem daraus entgegen, der es wagt, mit festem Blicke hineinzuschauen in dies dunkle Auge! (234)

Sie kommt „das Haupt hoch in den Wolken“ herangeschritten (236). Nach der Religionskritik in den „Wibelungen“" ist diese Göttin nicht als solche ernst zu nehmen; eigentlich wird sie als Personifikation einer umfassenden Tugend eingeführt: das Schwert der Justititia (Gerechtigkeit), die Fackel der Veritas (Wahrheit), der finstere Blick der Dike (Gerechtigkeit); man denkt sofort an Bakunins Huldigung der Revolution im oben vorgestellten „Aufruf an die Slaven“ („Sie ist das Recht, sie ist die Wahrheit, sie ist das Heil der Zeit!"). Aber auch sonst finden sich erstaunliche Parallelen zu dieser Schrift. Kannte Wagner vielleicht auch das „Manifest der Kommunistischen Partei“, das Karl Marx und Friedrich Engels im Januar 1848 in London in mehreren Sprachen veröffentlicht und darin ebenfalls eine Personifikation eingeführt hatten: „Ein Gespenst geht um in Europa - das Gespenst des Kommunismus“, das nun von den reaktionären Mächten gehetzt werde. ${ }^{91}$

90 Abgedruckt in: Wagner. Dichtungen (wie Anm. 1), V, S. $234 \mathrm{ff}$.

91 Zum Verhältnis Wagner - Marx vgl. Kröplin. Wagner und der Kommunismus (wie Anm. 4), S. $205 \mathrm{ff}$. 
Jedenfalls ist die Gestalt über-menschlich (und deshalb wohl als „Göttin“ und geflügelt bezeichnet); Wagner sagt ausdrücklich: „eine übernatürliche Kraft“, die „unsren Weltteil erfassen, aus dem alten Geleise herausheben und in eine neue Bahn schleudern zu wollen [scheint]" (234). Er gebraucht auch das Bild eines „ungeheuren Vulkans“, aus dessen Inneren beängstigendes Gebrause ertönt, aus dessen Krater Rauchsäulen hoch zum Himmel emporsteigen und aus dem sich Lavaströme bereits als feurige Vorboten alles zerstörend in das Tal hinabwälzen (234), auch dies Bilder, die wir von Bakunin kennen. Wo sind aber die Menschen? Sind sie nicht diejenigen, die eigentlich Revolution machen sollten?

Wagner lässt uns einen Blick nach unten, wohl von diesem Vulkan weg in die tiefen Täler, tun. Er zeigt uns einen Fürsten, der mit ängstlich klopfendem Herzen eine ruhige Miene erheuchelt; einen ordensgekrönten Hofbeamten, der dem ängstlichen Dämchen und dem zähneklappernden Junkerchen Beruhigung einflößt und mitteilt, dass die Regierung alles im Griff habe; dann einen Börsenspekulanten, der immer weiter schachert und feilscht (und nicht merkt, dass sein ganzer Plunder in die Lüfte zerstäubt); einen Staatsbeamten, der hinter dem verstaubten Aktentische eines der eingetrockneten, verrosteten Räder unser jetzigen Staatsmaschine kauert und den alten Haufen der papierenen Weltordnung zu vermehren strebt; dann eine tapfere Heldenschar unter einem Feldherrn, der den Feind sucht (und die heranschreitende Revolution nicht bemerkt); und schließlich einen ehrlichen, fleißigen Bürger, der auf sein trotz lebenslanger Arbeit kummervolles Dasein zurückblickt. Dann schaut Wagner auf die Hügel, wo sich Tausende, Hunderttausende, Millionen versammeln: die Fabrikarbeiter, denen die Frucht ihrer Arbeit nicht gehört, sondern den Reichen und Mächtigen; auch die Arbeiter in den Dörfern und Gehöften, denen der Segen der von ihnen bearbeiteten Erde nicht gehört, sondern den Reichen und Mächtigen. Es sind die „Scharen jener Armen, jener Elenden, die bisher vom Leben nichts gekannt als das Leiden, die Fremdlinge waren auf dieser Erde“, die nun alle die Revolution erwarten als ihre Erlöserin aus dieser Welt des Jammers, als die Schöpferin einer neuen, für alle beglückenden Welt (237). Wagner erwähnt auch die Menschen, „denen nichts zu bedauern bleibt, denen man selbst die Söhne raubt, um sie zu tapfern Kerkermeistern ihrer Väter zu erziehen, deren Töchter mit Schande beladen die Straße der Städte durchwandeln, ein Opfer der niedrigen Lüste des Reichen und Mächtigen“ (237). Sie alle, diese Millionen, lagern nun auf den Höhen und schauen mit angestrengtem Blick und bebend vor wonnevoller Erwartung der nahenden Revolutionsgöttin entgegen. 
Diese spricht in dem anschwellenden Brausen der Winde „den Gruß der Revolution“ (238). Die Scharen auf den Hügeln hören in stummer Verzückung zu, ihr von heißem Jammer verdorrtes Herz saugt die Worte ein und neues Leben quillt durch ihre Adern. Weit öffnen sich ihre wieder erweckten Herzen, sie werden von den Worten der Revolution ganz und gar erfüllt.

In göttlicher Verzückung springen sie auf von der Erde [...], stolz erhebt sich ihre Gestalt, Begeisterung strahlt von ihrem veredelten Antlitz, ein leuchtender Glanz entströmt ihrem Auge, und mit dem himmelerschütternden Rufe: ,ich bin ein Mensch!'stürzen sich die Millionen [...] hinab in die Täler und Ebenen, und verkünden der ganzen Welt das Evangelium des Glückes!

Was hier durch den Gruß der Revolution erweckt und herbeigeführt wird, hat Wagner selbst erlebt: nämlich bei den Aufführungen der 9. Sinfonie von Beethoven, in deren viertem Satz nicht nur die Musik zur Sprache (nämlich zur Ode an die Freude von Friedrich Schiller) und damit zum Gesamtkunstwerk drängt, sondern auch - wie Wagner in einem Programm für die Aufführung 1846 in Dresden ausgeführt hat - ein Kampf geschildert wird, deren Siegesfrucht die Freude sein soll und auch wird: „Freude, schöner Götterfunken, Tochter aus Elysium“ und „alle Menschen werden Brüder, wo dein sanfter Flügel weilt“. Hier ist die Freude eine Göttin (daher als „Himmlische“ bezeichnet, in deren „Heiligtum“ die Menschen treten, daher auch geflügelt), die durch Zauber die menschlichen Bande wieder festigt („Deine Zauber binden wieder"). Wagner schreibt 1846 dazu $^{92}$ :

Nun dringt im Hochgefühl der Freude der Ausdruck allgemeiner Menschenliebe aus der hochgeschwellten Brust hervor, [... in der] Umarmung des ganzen Menschengeschlechts [...] es ist, als ob wir nun [...] zu dem beseligenden Glauben berechtigt worden wären: jeder Mensch sei zur Freude geschaffen [...] Denn im Bunde mit [...] allgemeiner Menschenliebe, dürfen wir die reinste Freude genießen [...] So schließen wir die Welt an unsere Brust, Jauchzen und Frohlocken erfüllt die Luft wie Donner des Gewölkes, wie Brausen des Meeres, die in ewiger Bewegung und wohltätiger Erschütterung die Erde beleben und erhalten zur Freude der Menschen, denen Gott sie gab, um glücklich darauf zu sein. (26f.)

92 Abgedruckt in: Wagner. Dichtungen (wie Anm. 1), IX, S. $18 f f$. 
Die Revolution steht also für die Freude, beide bringen die Menschen zur Liebe und zum Glück. In dem Programm von 1846 folgt Wagner dem Gedicht Schillers und führt diese Erlösung auf den Schöpfergott zurück, der über dem Sternenzelt wohnt; und offensichtlich auch der Schöpfer dieser göttlich-himmlischen (engelsgleichen) Tochter ist. In dem Artikel vom 8. April 1849 fehlen dieser Hinweis und diese Begründung. Nun ist die Revolution selbst die Gottheit und die göttliche Kraft. Die Abschlussworte ihres Rufes lauten denn auch: „Ich bin das ewig schaffende Leben, ich bin der einige Gott, den alle Wesen erkennen, der alles, was ist, umfaßt, belebt und beglückt“ (241). Sie wird auch als "die ewig verjüngende Mutter der Menschheit" eingeführt (234). Aber noch mehr: die Menschen, die sich mit dem Rufe „Ich bin ein Mensch!“ in die Täler und Ebenen hinabstürzen, werden von Wagner vergöttlicht: denn sie sind „die lebendige Revolution, der Mensch gewordene Gott“ (241). Offensichtlich erfüllt die göttliche Kraft die von ihren Worten begeisterten Menschen und vergöttlicht sie. Hier schrieb der Verfasser des Nibelungen-Mythos (in dem die Götter ihre Göttlichkeit auf den freien Menschen übertragen wollen) und von „Jesus von Nazareth“! - Anzumerken ist, dass Wagner am 1. April 1849, also wenige Tage vor dem Erscheinen dieses Artikels, die 9. Sinfonie Beethovens in Dresden aufgeführt hatte, wobei seine Interpretation nach zeitgenössischen Berichten als „,nach jeder Seite hin zu Extremen' ausgeufert ${ }^{\text {‘93 }}$ sei.

Trotz dieser Vergöttlichung der Menschen machen diese Millionen keine Revolution, sondern „verkünden der ganzen Welt das neue Evangelium des Glückes" (241). Die Revolutionsarbeit macht die Göttin selbst; die Menschen hören nur ihrer Schilderung zu; sie können diese göttliche Kraft nicht am Werk sehen. Doch bringt Wagner zu Beginn des Artikels eine etwas andere Schilderung des revolutionären Kampfes: die Revolution

fährt über die Erde [dahin], und vor ihr saust der Sturm und rüttelt so gewaltig an allem von Menschen Gefügten, daß mächtige Wolken des Staubes verfinsternd die Lüfte erfüllen, und wohin ihr mächtiger Fuß tritt, da stürzt in Trümmer das in eitlem Wahne für Jahrtausende Erbaute [...] Doch hinter ihr, da eröffnet sich uns, von lieblichen Sonnenstrahlen erhellt, ein nie geahntes Paradies des Glückes, und wo ihr Fuß vernichtend geweilt, da entsprossen

93 So Kröplin. Theatralisches Leben (wie Anm. 4), S. 116. Zeitgenossen berichten von einer leidenschaftlichen Erregtheit Wagners in diesen Tagen, von einer fieberhaften Spannung. 
duftende Blumen dem Boden, und frohlockende Jubelgesänge der befreiten Menschheit erfüllen die noch vom Kampfgetöse erregten Lüfte. (234)

Es eröffnet sich die griechisch-mythologische Insel der Seligen, das Elysium, wie es in der 9. Sinfonie (und von Schiller) angesprochen ist. Es ist wie im Theater, in dem diese Sinfonie aufgeführt wird.

Wagner dachte aber offensichtlich nicht daran, nun selbst diese Arbeit der Revolution zu machen. Es ist interessant, dass in seiner Autobiographie „Mein Leben“, die er seineer (späteren) Frau Cosima ab 1865 diktierte, seine Schilderung des Mai-Aufstandes und seine Teilnahme daran an eine musikalische Aufführung erinnert, genauer: nach Kröplin „entpuppt sich [seine Darstellung] als eine kunstvolle literarische Paraphrase auf Berlioz'

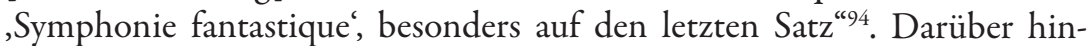
aus wird auf die Parallele zu Goethes Schilderung der Kanonade von Valmy hingewiesen..$^{95}$

Zurück zu diesem Artikel! Im Einzelnen grüßt die Revolution mit zahlreichen Aktionen, die einerseits Vernichtung und Zerstörung, andererseits Wiederbelebung und Erneuerung bedeuten. Daher:

Ich bin das ewig verjüngende, das ewig schaffende Leben! [...] Ich vernichte, was besteht, und wohin ich wandle, da entquillt neues Leben dem toten Gestein [...] Alles, was besteht, muß untergehen, das ist das ewige Gesetz der Natur, das ist die Bedingung des Lebens, und ich, die ewig Zerstörende, vollführe das Gesetz und schaffe das ewig junge Leben. (238)

Vernichtet wird also alles, was der allgemeinen Freude und dem allgemeinen Glück entgegensteht: die Gewalt der Mächtigen, der Staatsgesetze, des Eigentums, das Gesetz der Toten, die Ketten der Unfreiheit und Sklaverei, schließlich jede Spur der „wahnwitzigen Ordnung der Dinge, die zusammengefügt ist aus Gewalt, Lüge, Sorge, Heuchelei, Not, Jammer, Leiden, Tränen, Betrug und Verbrechen [...] Zerstört sei alles, was euch bedrückt und leiden macht“. Stattdessen soll neu entstehen: „der eigne Wille sei der

94 So Kröplin. Theatralisches Leben (wie Anm. 4), S. 47. Zum Problem vgl. Eckard Roch. Dresdner Reminiszenzen: Wagners Dresdner Zeit aus der Perspektive der Cosima-Tagebücher. In: Richard Wagner - Kgl. Kapellmeister in Dresden. Hg. Ortrun Landmann/u. a. Hildesheim. Georg Olms 2016, S. 375-394.

95 So Dieckmann. Komponist (wie Anm. 4), S. 21; Kröplin. Theatralisches Leben (wie Anm. 4), S. 46. 
Herr des Menschen, die eigne Lust sein einzig Gesetz, die eigne Kraft sein ganzes Eigentum“. „das Leben ist sich selbst sein Gesetz [...], ihr selbst [seid] das Gesetz, euer eigner freier Wille [ist] das einzig höchste Gesetz", der Genuss des höchsten Gutes des Menschen im „Erzeugen selbst, im Betätigen eurer Kraft“, allgemeine Freiheit im Wollen und Tun und Genießen, insgesamt eine „neue [Welt] voll nie geahnten Glückes“.

\subsection{Wagners "Reformschriften“}

Der Aufstand war am 9. Mai 1849 gescheitert, Wagner auf der Flucht und für lange Jahre gezwungen, im Exil zu leben ${ }^{96}$, August Röckel und Michael A. Bakunin gefangen und zunächst zum Tod verurteilt, dann zu lebenslanger Freiheitsstrafe begnadigt.

\subsubsection{Abschied von der revolutionären Aktion}

Wagner schrieb am 14. Mai 1849, also fünf Tage nach der Flucht, an seine Frau und versuchte, die Selbstzerstörung seiner Karriere in Dresden ihr gegenüber zu rechtfertigen. Er sei damals mit der Welt zerfallen gewesen, habe aufgehört gehabt, Künstler zu sein, und „wurde - wenn auch nicht mit der That, so doch in der Gesinnung - nur noch Revolutionär, d. h. ich suchte nur in einer gänzlich umgestalteten Welt den Boden für neue künstlerische Schöpfungen meines Geistes. Die Dresdener Revolution u. ihr ganzer Erfolg hat mich nun belehrt, daß ich keineswegs ein eigentlicher Revolutionär bin“; dieser müsse gänzlich ohne jede Rücksicht einzig nach Vernichtung streben; er (Wagner) aber sei Revolutionär nur, „um auf einem frischen Boden aufbauen zu können; nicht das Zerstören reizt uns, sondern das Neugestalten“. „So scheide ich mich von der Revolution“; „,u. mit einem Schlage bin ich wieder ganz Künstler geworden“, auch um sie (Minna) glücklich machen zu können. Am 17. Mai 1849, also drei Tage später, schrieb Wagner an Eduard Devrient in ähnlichem Sinne. Zunächst kam er auf das Geschehen in Dresden zurück und bekannte, dass er anfänglich mit voller Sympathie bei

$96 \mathrm{Zu}$ Wagners Bemühungen um eine Amnestie vgl. Woldemar Lippert. Richard Wagners Verbannung und Rückkehr 1849-1862. Dresden. Aretz 1927 (Nachdruck Hamburg. Severus 2012). 
der Erhebung gewesen sei, die zwei mittleren Tage mit Erbitterung und die beiden letzten Tage mit höchst aufgeregter Spannung und Neugierde; er sei aber nirgends tätig gewesen. Nun habe er eingesehen, dass er kein Revolutionär sei, denn dieser werde von „seiner einzigen kraft [, dem] Haß, nicht [der] Liebe" geleitet; er aber habe die Revolution gewollt, um schnell auf ihr etwas Gutes aufbauen zu können. Nun hoffe er, „daß ich wieder ganz künstler sein kann, nichts anderes als künstler und mensch“"

Dieser Abschied von der Revolution betraf die revolutionäre Aktion, die aber (wie gezeigt) eigentlich schon in Wagners Artikel für die „Volksblätter" - vor allem in dem Beitrag „Die Revolution“ - distanziert worden war. Nur in einigen Briefen begeisterte sich Wagner für eigene Tätigkeiten; so im Brief an Theodor Uhlig vom 22. Oktober 1850 („wie wird es uns aber erscheinen, wenn das ungeheure Paris in schutt gebrannt ist, wenn der brand von stadt zu stadt hinzieht, wir selbst endlich in wilder begeisterung diese unausmistbaren Augeasställe anzünden, um gesunde luft zu gewinnen?") oder im Brief an Ernst Benedekt Kietz vom 2. Juli 1851 („ich verlange mit leidenschaft nach der revolution, und nur die hoffnung, sie noch zu erleben und sie mitzumachen, giebt mir eigentlich lebenslust"). Aber überwiegend stellte sich Wagner die Revolution weiterhin, aber nur als Ergebnis fremder Aktionen vor, was bedeutet, dass er sich von dem Gedanken - dass die bestehende Gesellschaft revolutionär verändert werden müsste - in keiner Weise verabschiedete. So schrieb Wagner am 5. Juni 1849 aus Paris an Franz Liszt von der Niederträchtigkeit des dortigen Kunstgetriebes, „so verfault und todesreif, daß es nur eines muthigen schnitters bedarf, der den richtigen hieb zu führen versteht". Ferdinand Heine teilte er am 19. November 1849 brieflich mit, dass die Revolution „,in nicht gar zu ferner Zukunft“ unausbleiblich sei, und am 4. Dezember 1849, dass derjenige nicht „schwärmt, [der] Frankreich nicht ein Jahr ruhe mehr voraussagt, und im gegentheil die furchtbarsten socialen umwälzungen dort als sehr wahrscheinlich und zwar in großer Nähe erkennt“. Uhlig konnte im Brief vom 27. Dezember 1849 von der „socialen Republik“ lesen, „die früher oder später in Frankreich unvermeidlich und unausbleiblich ist"; ähnlich auch im Brief von 22. Oktober 1850 („mit völligster besonnenheit und ohne allen schwindel versichere ich Dir, daß ich an keine andere revolution mehr glaube, als an die, die mit dem Niederbrande von Paris beginnt"); ähnlich meinte Wagner am 12. November $1851 \mathrm{zu}$ Uhlig, dass die Revolution der gesamten "theaterwirtschaft“ das Ende bringen werde: „sie müssen und werden alle zusammenbrechen, dies ist unausbleiblich“. 
Dabei ist anzumerken ${ }^{97}$, dass Wagner im Frühjahr 1850 eine Wählerversammlung der Sozialdemokratischen Partei in St. Denis besuchte und von der Haltung der 6000 Teilnehmer so stark beeindruckt war, dass er von den im Jahre 1852 bevorstehenden Wahlen in Frankreich und der Neuwahl des Präsidenten der Republik eine radikale Veränderung der bestehenden Zustände erwartete. Deshalb maß er dem Staatsstreich von Louis Bonaparte vom 2. Dezember 1851 keine Bedeutung bei (Brief an Uhlig vom 13. Dezember 1851; Brief an Hans von Bülow vom 14. Dezember 1851 wegen der französischen Bauernaufstände), datierte sogar seinen Brief an Uhlig vom 22. Januar 1852 mit „53. Dezember 1851“, um das Jahr bis zu Beginn der erwarteten Revolution weiterzuführen („ich bleibe so lange im Staatsstreich=monate, bis das erhoffte 1852 wirklich kommt").

\subsubsection{Das Subjekt der revolutionären Aktion}

Freilich war das Subjekt dieser Aktionen noch zu klären. Einen Hinweis haben wir ja schon: „die Revolution“ als göttliche Kraft. Wer aber so religionskritisch gearbeitet hat, wie es Wagner in den "Wibelungen“ vorgelegt hatte, konnte damit nicht zufrieden sein. In einem Brief an Ferdinand Heine vom 4. Dezember 1849 vollendete Wagner seine Religionskritik, indem er schrieb: „Zu allen Zeiten ist dem Menschen Gott das gewesen, was sie gemeinsam als das Höchste erkannten, das stärkste gemeinsame Gefühl, die mächtigste gemeinsame Anschauung“; „Gott“ sei der „Begriff der menschlichen Gemeinsamkeit von ihrem echten, wirklichen Wesen, in Wahrheit aus dem Leben heraus gewonnen“, „ein dem allgemeinen rein menschlichen Wesen Entsprechendes, aus der wahren menschlichen Natur Hervorgegangenes“. Das war im Wesentlichen Feuerbach! Wagner folgerte weiter aus diesem Ansatz:

der wirkliche Gott muß eben nicht der einzelne, sondern alle müssen es sein: zugunsten aller empören wir uns daher gegen den Gott des einzelnen, gegen die Eigensucht; [...] gegen ihn empört sich, wer Kraft dazu hat, das heißt, wer in seiner inneren Natur einen so notwendigen Trieb empfindet, daß er ihn stillen muß; der innere Naturtrieb des einzelnen ist aber nur ein solcher, der allen

97 Dazu Gertrud Strobel/Werner Wolf, Einleitung. In: Richard Wagner. Sämtliche Briefe. Bd. 4. Leipzig. Deutscher Verlag für Musik 1979, S. $6 f$. 
Menschen gleich gemeinsam ist, denn er kommt - sobald er unüberwindlich stark ist - nicht aus der Natur des einzelnen, sondern aus der menschlichen Natur überhaupt.

Dann vollendete Wagner seine Religionskritik: „Diese Kraft habe ich nicht von mir, sondern von Gott, und dieser Gott ist nichts anderes als die gesunde - ursprünglich allgemeine - menschliche Natur“.

In der unter Namensnennung 1849 veröffentlichten Schrift „Die Kunst und die Revolution" (abgeschlossen Ende Juli 1849) ${ }^{98}$ - der ersten der drei, von Wagner als Einheit gesehenen Schriften ${ }^{99}$ - beantwortete Wagner die Frage nach der Kraft der Revolution mit dem Hinweis auf die „Natur“. „Die Natur, und nur die Natur, kann [...] die Entwirrung des großen Weltgeschickes allein vollbringen" (298). Diese Natur ist von der Kultur, vor allem vom

98 Abgedruckt in: Wagner. Dichtungen (wie Anm. 1), V, S. $273 \mathrm{ff}$. Die Seitenzahlen im Text beziehen sich auf diese Ausgabe.

99 Im Brief an Uhlig vom 16. September 1849 und in dem Brief an Heine vom September 1849 nannte Wagner die drei Schriften: „Die Kunst und die Revolution“, „Das Kunstwerk der Zukunft“ und „Die Künstlerschaft der Zukunft“. Im Brief an Uhlig vom 27. Juli 1850 kündigte Wagner eine Schrift, die alles umfassen sollte, mit dem Titel „Die Erlösung des Genies“ an (später als Skizze eines „Das Genie der Gemeinsamkeit“ erhalten, abgedruckt in: Wagner, Dichtungen (wie Anm. 1), V, S. 254ff.), dann auch einige kleinere Arbeiten („Das Monumentale“, „Die Unschönheit der Civilisation“), die nicht ausgearbeitet wurden. Zu den sog. „Reformschriften“ gehört jedenfalls die 1850 veröffentliche Arbeit „Kunst und Klima“" (die in der Jubiläumsausgabe von Borchmeyer nicht aufgenommen ist) und dann die umfangreichen Schriften „Oper und Drama“ (abgeschlossen am 10. Januar 1851) und „Eine Mittheilung an meine Freunde“(Sommer 1851). - Dazu vgl. Udo Bermbach. „Die Kunst und die Revolution“, „Das Kunstwerk der Zukunft". In: Wagner-Lexikon (wie Anm. 11), S. 373-376, 377-379; Stefanie Hein. Richard Wagners Kunstprogramm im nationalkulturellen Kontext. Würzburg. Königshausen \& Neumann 2006, S. 51ff.; Hans-Joachim Hinrichsen. Die Zürcher Kunstschriften. In: Wagner Handbuch (wie Anm. 11), S. 125136; Karin Koch. „Zürcher Kunstschriften“. In: Wagner Lexikon (wie Anm. 11),

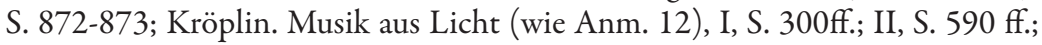
Kunstwerk der Zukunft. Richard Wagner und Zürich (1849-1858). Hg. Laurenz Lütteken. Zürich. Verlag Neue Zürcher Zeitung 2008; Simone Siwek. „Der Künstler und die Öffentlichkeit“. In: Wagner Lexikon (wie Anm. 11), S. 376377. Jürgen Kühnel, Wagners Schriften: Revolutionsschriften, in: Richard-Wagner-Handbuch (wie Anm. 9), S. 471-588, 498ff. 
Christentum - das nach Ansicht von Wagner (eigentlich entgegen seiner eigenen These, dass „uns denn Jesus gezeigt [hat], daß wir Menschen alle gleich und Brüder sind "100) die menschliche Natur als verwerflich bezeichnet hat $(298,304)$ - die Menschennatur verleugnet worden, wodurch diese zum Feind geworden ist: als die

ewig und einzig lebende Natur. Die Natur, die menschliche Natur, wird den beiden Schwestern, Kultur und Zivilisation, das Gesetz verkünden: ,soweit ich in euch enthalten bin, sollt ihr leben und blühen; soweit ich nicht in euch bin, sollt ihr aber sterben und verdorren!' (298f.)

An die Stelle des Schöpfergottes trat nun die menschliche Natur, die sich aus sich heraus entwickelt und gestaltet.

\subsubsection{Natur, Mensch und Kunst}

Die bei Borchmeyer als „Revolutionstraktat“ eingeordnete Schrift „Die Kunst und die Revolution“ bildet mit der ebenfalls in diesen Rahmen gestellten Schrift „Das Künstlertum der Zukunft“ eine Einheit mit dem von ihm als „Reformschrift“ eingeordneten Werk „Das Kunstwerk der Zukunft“, aus dem das dritte Eingangszitat stammt. Revolutions- und Reformschriften gehen ineinander über.

„Das Kunstwerk der Zukunft“ (abgeschlossen am 4. November 1849) ${ }^{101}$ begann Wagner mit dem Abschnitt „Natur, Mensch und Kunst“. Erstere „erzeugt und gestaltet absichtslos und unwillkürlich nach Bedürfnis, daher aus Notwendigkeit: dieselbe Notwendigkeit ist die zeugende und gestaltende Kraft des menschlichen Lebens; nur was absichtslos und unwillkürlich, entspringt dem wirklichen Bedürfnisse, nur im Bedürfnis liegt aber der

100 In: „Die Kunst und die Revolution“ (1849), abgedruckt in: Wagner. Dichtungen (wie Anm. 1), V, S. 309ff. Den Widerspruch kann man durch die Unterscheidung der „Ansicht jenes armen galiläischen Zimmermannssohnes“, der beim Anblicke des Elends seiner Mitbrüder ausgerufen habe, er sei nicht gekommen, Frieden zu bringen, und der die allgemeine Menschenliebe gepredigt habe, von der dogmatischen Lehre des kirchlich interpretierten Christus auflösen (vgl. ebenda S. 280).

101 Abgedruckt in: Wagner, Dichtungen (wie Anm. 1), VI, S. 9ff. Die Seitenzahlen im Text beziehen sich auf diese Ausgabe. 
Grund des Lebens“ (9) ${ }^{102}$. Deshalb wird auch der Mensch „nicht eher das sein, was er sein kann und sein soll, als bis sein Leben der treue Spiegel der Natur, die bewußtlose Befolgung der einzig wirklichen Notwendigkeit, der inneren Naturnotwendigkeit ist“ (10). „Der wirkliche Mensch wird daher nicht eher vorhanden sein, als bis die wahre menschliche Natur [...] sein Leben gestalte $[t]$ und ordne[t]" (11). In einem Brief an Uhlig vom 16. September 1849 verband Wagner diese Naturnotwendigkeit und der eigentlichen Freiheit:

Ich will glücklich sein, und das ist der Mensch nur wenn er frei ist: nur der mensch ist aber frei, der das ist, was er sein kann und deshalb sein muß. Wer daher der inneren nothwendigkeit seines wesens genügt, ist frei, weil er sich bei sich fühlt, weil alles was er thut seiner natur, seinen wirklichen Bedürfnissen entspricht. ${ }^{103}$

Maßgebend ist also das Bedürfnis, nämlich das „wahre Bedürfnis“, das bezüglich der Menschen nur ein allgemeines sein kann, das Bedürfnis der Gattung. Die „Kraft des wahren Bedürfnisses“ ist - wir kennen diese These aus dem Revolutionsgedicht „Die Not“ - die „wahre Not“. Das Subjekt, das also zur äußersten Aktion getrieben wird, ist der „Inbegriff aller derjenigen, welche eine gemeinschaftliche Not empfinden“: nämlich das „Volk“ $(15)^{104}$. Es sind diejenigen, die ihre eigene Not als gemeinschaftliche erkennen oder sie in einer gemeinschaftlichen begründet finden, also die die Stillung ihrer Not nur in der Stillung einer gemeinsamen Not verhoffen dürfen und demnach ihre gesamte Lebenskraft auf diese Stillung verwenden. Nun führt Wagner alles zusammen: „nur die Not, welche zum Äußersten treibt, ist die wahre Not; nur diese Not ist aber die Kraft des wahren Bedürfnisses; nur ein gemeinsames Bedürfnis ist aber das wahre Bedürfnis; nur wer ein wahres Bedürfnis empfindet, hat aber ein Recht auf Befriedigung desselben; nur die

102 Ähnlich auch in „Oper und Drama“ (fertiggestellt am 10. Januar 1851), abgedruckt in der von Klaus Kropfinger herausgegebenen Ausgabe (Stuttgart. Reclam 1986), S. 23.

103 Dabei sprach Wagner über sein Leben, auch über seine Tätigkeit in Dresden: er betonte sein „wirkliches freies künstlerthum“. In einem Brief an Heine vom 4. Dezember 1849 schrieb Wagner: „mein gott, der mich treibt und durch den ich handle, ist die innere nothwendigkeit“.

104 Wiederholt in: „Das Künstlertum der Zukunft“ (1849), abgedruckt in: Wagner. Dichtungen (wie Anm. 1), V, S. 242 ff., 247. 
Befriedigung eines wahren Bedürfnisses ist Notwendigkeit, und nur das Volk handelt nach Notwendigkeit, daher unwiderstehlich, siegreich und einzig wahr“ (15). Diese Notwendigkeit ist für Wagner „die treibende Kraft in der großen Menschheitsrevolution, dieselbe Befriedigung wird diese Revolution abschließen. - Jene treibende Kraft, die eigentliche Lebenskraft schlechthin, wie sie sich im Lebensbedürfnis geltend macht, ist [...] ihrer Natur nach eine unbewußte, unwillkürliche“: eben die wahre, entscheidende Kraft im Volk (19).

\subsubsection{Lebens- und Liebesbedürfnis zur kommunistischen Anarchie}

Neben diesem Lebensbedürfnis, dem Lebenstrieb, der sich im Nehmen von der Natur befriedigt, steht für Wagner das „Lebensbedürfnis des Lebensbedürfnisses“, nämlich das Liebesbedürfnis, das befriedigt wird durch das Geben, genauer das „Sichselbstgeben an andere Menschen, in höchster Steigerung an die Menschen überhaupt“ (37). „Das höchste menschliche Bedürfnis [...] ist die Liebe“ (38). Dabei kennt Wagner seit "Jesus von Nazareth" eine Stufenleiter der Liebe, die er in der Arbeit „Kunst und Klima“ (abgeschlossen am 23. Februar 1850) ${ }^{105}$ wiederholt: „aus der Kraft der unentstellten, wirklichen menschlichen Natur [...], die in ihrem Ursprung nichts anderes als die thätigste Lebensäußerung dieser Natur ist, die sich in reiner Freude am sinnlichen Dasein aussprich" gehe die Liebe hervor, „von der Geschlechtsliebe ausgehend, durch die Kindes-, Bruder- und Freundesliebe

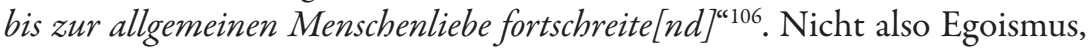

105 Veröffentlicht in der „Deutschen Monatsschrift für Politik, Wissenschaft, Kunst und Leben 1, April 1850, H. 4, S. 1ff. Dazu Wagner in einem Brief an Uhlig vom 13. März 1850: „Der Aufsatz ist wichtig“. Abgedruckt in: Wagner. Schriften (wie Anm. 62), III, S. 218ff.

106 In einem Brief an Uhlig vom 27. Juli 1850 schrieb Wagner: „nur der mensch ist fähig, zur überzeugten kräftigen menschenliebe zu gelangen, der die liebe zuerst in einem ganz individuellen, persönlichen verhältnisse nach ihrer vollsten kraft empfand: diese kraft zerstören, heißt dann aber nur, sie unendlich erweitern und ausdehnen". Wagner hat in einem Brieffragment an Schopenhauer dessen Metaphysik der Geschlechtsliebe kritisiert und die Geschlechtsliebe als „Heilsweg zur Selbsterkenntnis und Selbstverneinung des Willens“ charakterisiert. 
sondern Kommunismus entspricht der menschlichen Natur (worauf unter 2.3.5. bereits eingegangen worden ist).

Diese „Gesetze innerer Notwendigkeit" müssen auch die gemeinschaftliche Vereinigung der Menschen(-gattung) bestimmen, also an der Befriedigung des Liebesbedürfnisses (letztlich: der allgemeinen Menschenliebe) ausgerichtet sein. „Eine natürliche [...] Vereinigung einer größeren oder geringeren Anzahl von Menschen kann nur durch ein, diesen Menschen gemeinsames Bedürfnis hervorgerufen werden“. Solche „natürliche[n] Vereinigungen“ haben nur so lange einen „natürlichen Bestand“, als das ihnen $\mathrm{zu}$ Grunde liegende Bedürfnis ein gemeinsames und seine Befriedigung eine noch zu erstrebende ist; ist der Zweck erreicht, ist die Befriedigung geglückt, hört das Bedürfnis auf; und ebenso löst sich die entsprechende Vereinigung auf. Und es entsteht aus einem neuen Bedürfnis eine neue Vereinigung, usw. (146). Dabei ist noch das Bedürfnis zu berücksichtigen, das allen Menschen gemeinsam ist: „das Bedürfnis zu leben und glücklich zu sein“ (147). So entsteht eine Vereinigung aller Menschen als „Gemeinschaft aller Menschen“ - gegründet in dem „natürlichen Band“, eben diesem gemeinsamen Bedürfnis -, die sich dann weiter in die einzelnen besonderen Vereinigungen gliedert, die dann entweder auf eine gewisse Dauer gestellt sind (weil sie materieller Art sind, sich auf den gemeinschaftlichen Grund und Boden beziehen) oder sich in mannigfaltigem und regem Wechsel immer neu gestalten (147). ${ }^{107}$

\subsubsection{Die unmittelbar bevorstehende Revolution}

Wagner beantwortet daher zunächst die Frage nach dem, der „die Erlösung aus [dem] unseligsten Zustande vollbringen“ wird: „die Not, - welche der Welt das wahre Bedürfnis empfinden lassen wird, das Bedürfnis, welches

107 In der Skizze „Das Genie der Gemeinsamkeit“ kann man lesen: „Die Vernichtung der geschlechtlichen und nationalen Schranken und Kundmachung der Notwendigkeit der Erlösung des Individuums in die menschliche Allgemeinheit [...] Darstellung der Gemeinsamkeit der Zukunft. Genossenschaften. Gemeinde. Altersversorgung: - natürliche Mannigfaltigkeit. - Erziehung. Liebe. Alter. - Allgegenwärtigkeit aller Momente des Lebens zu gleicher Zeit durch den Kommunismus. Das gemeinsame Genie“; abgedruckt in: Wagner. Dichtungen (wie Anm. 1), V, S. 259. 
seiner Natur nach wirklich aber auch zu befriedigen ist. - Die Not wird die Hölle des Luxus endigen; sie wird die zermarterten, bedürfnislosen Geister, die diese Hölle in sich schließt, das einfache, schlichte Bedürfnis des rein menschlichen sinnlichen Hungers und Durstes lehren [...]; gemeinsam werden wir wirklich genießen, gemeinsam wahre Menschen sein. Gemeinsam werden wir aber auch den Bund der heiligen Notwendigkeit schließen“ $(17)^{108}$.

In einem Brief an Uhlig vom 22. Oktober 1850 nahm Wagner dessen Frage - „Du fragst mich nun: ,ja wo stecken denn diese menschen, die diesen nothwendigen umsturz vollführen werden? Ich sehe nichts als die erbärmlichsten menschen [...], selbst in den niederen regionen sehe ich nur stumpfheit und lastthiernaturen“" - an und räumte ein, dass es bisher bloße durch Politik irregeleitete Pöbelherrschaft sei: „Bis jetzt kennen wir die äußerung der geknechteten menschlichen natur nur im Verbrechen, das uns anwidert...] und erschreckt"; ein Raubmörder komme uns recht gemein und ekelhaft vor; aber: „wie wird es uns erscheinen, wenn das ungeheure Paris in schutt gebrannt ist, wenn der brand von stadt zu stadt hinzieht, wie selbst endlich in wilder begeisterung diese unausmistbaren Augeasställe anzünden, um gesunde luft zu gewinnen?" Wagner beruhigt seinen Briefpartner:

der mensch ist sich heilig geworden, nicht aber sind dieß mehr die mauerlöcher [eine Anspielung auf die Barrikadenkämpfe in Dresden, WS], in denen sie zu bestien werden. [...] Starker nerven wird es bedürfen, und nur wirkliche menschen werden es überleben, $\mathrm{d}$ h. solche, die durch die noth und das großartigste entsetzen erst zu menschen geworden sind. ${ }^{109}$

108 Vgl. den Hinweis in der „Mittheilung an meine Freunde“ (Sommer 1851): die Erkenntnis der Nichtswürdigkeit der politischen und sozialen (und Kunst-) Zustände hätten ihn das ,drängende Motiv [ersehen lassen, WS], was sich [...] aus der schlechten, sinnlichen Form der Gegenwart zum Gewinn einer neuen, dem wahren menschlichen Wesen entsprechenden, sinnlichen Gestaltung heraustrieb, - einer Gestaltung, die eben nur durch Vernichtung der sinnlichen Form der Gegenwart, also durch die Revolution zu gewinnen ist“, vermittelt (Wagner. Dichtungen [wie Anm. 1], VI, S. 286f.).

109 Wagner sprach von der „feuerkur" (ähnlich auch im Brief an Ernst Benedikt Kietz vom 2. Juli 1851. - Von diesem Ansatz aus war konsequent, dass Wagner den Theoretikern, Philosophen, auch den politischen (selbst sozialistischen) Führern keine bestimmende Bedeutung für die Revolution zusprach (so in einem Brief an Uhlig vom 22. Oktober 1850: der Inhalt des Sozialismus ist 


\section{Ausblick auf das Kunstwerk und die Künstler der Zukunft}

Darüber hinaus hatte Wagner die Antwort gefunden auch auf die Frage, was für die Zukunft - nach der erfolgreichen Revolution und durch sie und in ihr vorbereitet (und angelegt) - zu gelten hat: es wird ein von der inneren Notwendigkeit der menschlichen Natur erzeugtes anarchisches Leben in den geschilderten natürlichen Vereinigungen sein. ${ }^{110}$ Wagner hat das Vorbild von Bakunin erreicht! Auch darin, nun den Gegner zu fassen, der zu besiegen, d.h. zu vernichten ist. Zunächst die gesellschaftlichen Zustände, die die äußerste Not begründen, damit vor allem die Verhältnisse des Eigentums und der Unfreiheit (wobei Wagner an seine revolutionären Einsichten anschließen kann).

Nun rücken aber andere Zustände in den Vordergrund, die nämlich unnatürlich, willkürlich, von menschlichem Bewusstsein - das der Natur gegenüberstehend sich entwickelt, in ein Verhältnis zu dieser kommt, das Wissen, aber auch Irrtum sein kann - gesetzt. Dies betrifft einmal den Staat, der bereits in den Revolutionsschriften (etwa im Gedicht „An den Staatsanwalt") als leblos und starr / tot erfasst war und nun zu dem Feind wird (worüber die Schrift „Oper und Drama“ ausführlich handelt ${ }^{111}$ ); und sodann

nur der Wille zum Organisieren, nur Überfluss und Entbehrung überflüssig zu machen, daher nicht geeignet für eine Revolution“; ",ich sehe nichts als die erbärmlichsten menschen, philister und feige um mich"). Daher seien - so das Motto auf der Titelseite der Schrift „Die Kunst und die Revolution“ (abgedruckt in: Wagner. Dichtungen (wie Anm. 1), V, S. 311) - „der Staatsweise und Philosoph zu Ende“, nun fange der Künstler wieder an. Wagner sah 1872 im Vorwort zu Band 3 und 4 seiner "Gesammelten Schriften und Dichtungen“ darin eine Kühnheit (Wagner. Dichtungen (wie Anm. 1), VI, S. 193. - Von vornherein schied eine Reformierung der Gesellschaft aus (vgl. Brief an Uhlig vom 18. September 1859: „mein jetziger unglaube an alle reform und mein einziger glaube an die revolution").

110 Vgl. Bermbach. Wahn (wie Anm. 12); Olaf Briese. „ich will zerbrechen die Gewalt der Mächtigen, des Gesetzes und des Eigentums“. Richard Wagners frühe Anarchismen. In: Ne znam. Zeitschr. f. Anarchismusforschung 2 (2016), H. 3, S. 78-100; Carol van der Meer Hamilton. Wagner as Anarchist, Anarchists as Wagnerians. In: Oxford German Studies 22 (1993), S. 168-193; Wolfgang Schild. Staat und Recht im Denken Richard Wagners. Stuttgart, Richard Boorberg 1994.

111 Vgl. Wagner. Oper (wie Anm. 102), S. 175, 200ff. Kritisch aber schon „Das Künstlertum der Zukunft“, in: Wagner. Dichtungen (wie Anm. 1), V, S. $245 \mathrm{ff}$. 
(und für Wagner als Künstler vordringlich) die bestehenden Kunstzustände, die nur Luxus, Moden, Langeweile, Leblosigkeit usw. produzieren.

Den Staat wird die Anarchie ersetzen; die schlechte Kunst muss durch das wahre, echte Kunstwerk ersetzt werden, wobei Wagner den Unterschied zum unwillkürlich-natürlichen Erzeugen durch die Bedürfnisse und ihre Befriedigung im bewusstlosen Handeln des Volkes darin sieht, dass das Kunstwerk willkürliches, vom Bewusstsein getragenes, aber darin das wahre menschliche Wesen (die Natur des Menschen, das Reinmenschliche, die Notwendigkeit der Menschenliebe usw.) erfassende und zur Darstellung bringende Handeln ist. Dieser reinmenschliche „Held der Zukunft“ (nämlich als Darsteller im Kunstwerk der Zukunft) ist die Gestalt, die weder im Bereich von Politik, Historie oder Gesellschaft noch in Märchen oder Sagen gesucht werden kann, sondern auf den Grund des uralten „Mythos“ des Volkes zurückreicht, wie dieses die einst in seiner Religion (und Sage) vorgestellt hat. ${ }^{112}$ Will der Künstler der Zukunft diese Themen aufgreifen, ist dies nur denkbar, wenn er eine Kunstreligion schafft und sich zugleich als Bevollmächtigter des Volkes versteht, in dessen Schoß diese Mythen entstanden sind. ${ }^{113}$

Ein solches (wahres) Kunstwerk, wenn es in der Gegenwart bereits geschaffen wird (wofür Wagner in den „Reformschriften“ die Kriterien erarbeiten will), geht dann selbstverständlich der Revolution voraus, erzeugt und unterstützt das unwillkürliche Agieren des Volkes, ist also damit selbst revolutionär; was sich auch darin zeigt, dass nicht vereinzelte Künstler irgendetwas auf die Bühne bringen, sondern dass es der Genossenschaft (also der Vereinigung) der sich in Liebe verbindenden (wahren) Künstler bedarf, die sich in ihren jeweiligen Kunstarten (Musik, Dichtung, Tanz) ebenfalls

112 Für Wagner war die Gestalt des Siegfried, wie er sie in den „Wibelungen“ (als anfänglichen Sonnengott, über die Identifikation mit Christus bis zum Stammgott der Franken) und in seinem Nibelungen-Projekt entwickelte, das Beispiel eines solchen wesentlichen, natürlichen, liebenden, furchtlosen, wahren, daher anarchischen Menschen. Vgl. Geck. Wagner (wie Anm. 34), S. 139f.: Wagner sucht den „Menschen der Zukunft“, der „,ich in seiner ganzen Lebens- und Liebesfülle verströmt und auch den Tod nicht fürchten muss, da er der Welt zuvor alles gegeben hat, was er geben konnte"; ferner vgl. dazu Bermbach. Wahn (wie Anm. 12); Lothar Bornscheuer. Richard Wagner: Der Ring des Nibelungen. Ein Meisterwerk des Anarchismus. In: Goethezeitportal 22.12.2005 (Internet); Schild. Staatsdämmerung (wie Anm. 66).

113 So Geck. Wagner (wie Anm. 34), S. 140. - Auf das Mythos-Konzept Wagners kann hier nicht näher eingegangen werden. 
liebend zu einem Gesamtkunstwerk verbinden. Darüber hinaus zeigt ein solches Kunstwerk, wie Menschen überhaupt ihr Wesen verwirklichen, die Liebe leben können und sollen. Denn eigentlich werden die anarchischen Vereinigungen der Zukunft selbst solche lebenden Kunstwerke, die Menschen Künstler, das Leben Kunst sein.

Deshalb ist auch das Kunstwerk dem Wechsel unterworfen. Im Brief an Uhlig vom 12. November 1851 teilt Wagner deshalb seinen Plan in Bezug auf sein Nibelungen-Projekt mit:

An eine Auffübrung kann ich erst nach der Revolution denken [...] Aus den trümmern rufe ich mir dann zusammen, was ich brauche: ich werde, was ich bedarf, dann finden. Am Rheine schlage ich dann ein theater auf, und lade zu einem großen dramatischen feste ein: nach einem jahr vorbereitung führe ich dann im laufe von vier tagen mein ganzes werk auf: mit ihm gebe ich den menschen der revolution dann die bedeutung dieser Revolution, nach ihrem edelsten sinne, zu erkennen. Dieses publikum wird mich verstehen, das jetzige kann es nicht. ${ }^{114}$

Und nach dieser Aufführung, ,werfe ich mich mit der Partitur aufBrünnhilde’s Scheiterhaufen, so daß Alles verbrennt" (Brief an Clara Brockhaus vom 12. März 1854). Denn schon in einem Brief an Heine vom 19. November 1849 hatte Wagner geschrieben: „währen die Menschen wie sie sein sollten [also nach der Revolution, WS], so blühte heute ein Kunstwerk auf und stürbe morgen, während das neue schon wieder im vollen frischen Leben dasteht“. Erinnern wir uns an den Ruf der Revolution (den Wagner später der Erde in den Mund legen wird): „Alles, was besteht, muß untergehen, das ist das ewige Gesetz der Natur [...], und ich, die ewig Zerstörende, vollführe das Gesetz und schaffe das ewig junge Leben“.

Wagner widmete seine „Reformschriften“ diesem Ziel, über die Revolution - die aus der Not geboren werden wird und daher mit innerer Notwendigkeit kommen wird - hinaus das wahre Kunstwerk zu denken und zu

114 In einem Brief an Uhlig vom 22. Oktober 1850 schrieb Wagner noch von „einem begeisterten Mann“, der nach der Feuerkur der Revolution „die lebendigen überreste unsrer alten kunst zusammenruft, und ihnen sagt - wer hat lust, mir ein Drama aufführen zu helfen? nur die werden antworten, die wirklich lust dazu haben, denn jetzt setzt es kein geld mehr dafür, und die so sich einfinden, werden in einem schnell hergereichteten holzbauwerke plötzlich den leuten zeigen, was kunst ist“. 
schaffen. ${ }^{115}$ Das Recht des Menschen ist nicht mehr interessant; es wird - wie wir gehört haben - eingebunden in diese oben zitierte Zusammenschau der Entwicklung der Natur: „nur wer ein wahres Bedürfnis empfindet, hat [...] ein Recht auf Befriedigung desselben", was aber zugleich die innere Notwendigkeit ist.

115 Vgl. dazu Udo Bermbach. Dresden und die Folgen - Wagners Grundlegung seines politisch-ästhetischen Denkens. In: Friedrich-Ebert-Stiftung, Bakunin (wie Anm. 9), S. 71-86; Hans Erismann. Richard Wagner in Zürich. Zürich. Verlag Neue Zürcher Zeitung 1987; Rainer Franke. Richard Wagners Zürcher Kunstschriften. Hamburg. Verlag der Musikalienhandlung Wagner 1983; Garratt. Music (wie Anm. 7), S. 160ff.; Hans Gerhard Heymel. Die Entwicklung Richard Wagners bis1851 als politischer Künstler und sein Kunstwerkbegriff als gesellschaftliche Utopie. Dissertation Osnabrück 1981; Hans-Joachim Hinrichsen. Die Zürcher Kunstschriften. In: Wagner Handbuch (wie Anm. 11), S. 125-136; Rüdiger Jacobs. Revolutionsidee und Staatskritik in Richard Wagners Schriften. Perspektiven metapolitischen Denkens. Würzburg. Königshausen \& Neumann 2010; Andrea Mock. Richard Wagner als politischer Schriftsteller. Weltanschauung und Wirkungsgeschichte. Frankfurt a.M. Campus 1990; Franz-Peter Opelt. Richard Wagner - Revolutionär oder Staatsmusikant? Frankfurt a. M. Peter Lang 1987. 